CENTRO UNIVERSITÁRIO FEI

RODRIGO SOUSA FREITAS

EFEITO DO TEOR E DO TAMANHO DE PARTÍCULA DO POLIETILENO RETICULADO (XLPE) NAS PROPRIEDADES DE ENGENHARIA DE POLIETILENO DE ALTA DENSIDADE (HDPE)

São Bernardo do Campo 
RODRIGO SOUSA FREITAS

\section{EFEITO DO TEOR E DO TAMANHO DE PARTÍCULA DO POLIETILENO RETICULADO (XLPE) NAS PROPRIEDADES DE ENGENHARIA DE POLIETILENO DE ALTA DENSIDADE (HDPE)}

Dissertação de Mestrado apresentada ao Centro Universitário FEI, como parte dos requisitos necessários para obtenção do Título de Mestre em Engenharia Mecânica, orientada pelo Prof. Dr. Baltus Cornelius Bonse.

São Bernardo do Campo 
Freitas, Rodrigo Sousa .

Efeito do teor e do tamanho de partícula do polietileno reticulado (XLPE) nas propriedades de engenharia de polietileno de alta densidade (HDPE) / Rodrigo Sousa Freitas. São Bernardo do Campo, 2017.

89 f. : il.

Dissertação - Centro Universitário FEI.

Orientador: Prof. Dr. Baltus Cornelius Bonse.

1. Reaproveitamento. 2. Polietileno reticulado XLPE. 3. Tamanho de partícula. 4. Polietileno de alta densidade. I. Bonse, Baltus Cornelius, orient. II. Título. 
Título do Trabalho: Efeito do teor e do tamanho de partícula do polietileno reticulado (XLPE) nas propriedades de engenharia de polietileno de alta densidade (HDPE).

Área de Concentração: Materiais e Processos

Orientador: Prof. Dr. Baltus Cornelius Bonse

Data da realização da defesa: 29/08/2017

\section{ORIGINAL ASSINADA}

Avaliação da Banca Examinadora:

São Bernardo do Campo,

\begin{tabular}{|c|c|}
\hline \multicolumn{2}{|c|}{ MEMBROS DA BANCA EXAMINADORA } \\
\hline Prof. Dr. Baltus Cornelius Bonse & Ass.: \\
\hline Prof. a Dr.a Adriana Martinelli Catelli de Souza & Ass.: \\
\hline Prof. Dr. Suel Eric Vidotti & Ass.: \\
\hline
\end{tabular}

\footnotetext{
A Banca Julgadora acima-assinada atribuiu ao aluno o seguinte resultado:

APROVADO $\bigotimes$

REPROVADO
}

\section{VERSÃO FINAL DA DISSERTACÃO}

APROVO A VERSÃO FINAL DA DISSERTAÇ̃̃O EM QUE FORAM INCLUÍDAS AS RECOMENDAÇÕES DA BANCA EXAMINADORA
Aprovação do Coordenador do Programa de Pós-graduação

Prof. Dr. Rodrigo Magnabosco 


\section{AGRADECIMENTOS}

A Deus primeiramente e acima de tudo por ter me concedido mais uma chance de vida e poder lutar pelos meus sonhos.

Aos meus pais Jose Souza Freitas e Maria Aleide de Sousa Freitas (in memorian), que sempre me incentivaram ao estudo.

À minha esposa pelo apoio e incentivo.

Ao meu Orientador, Professor Dr. Baltus Cornelius Bonse pela amizade, orientações e incentivo fornecido durante esta etapa.

Aos técnicos e funcionários do Laboratório de Materiais da FEI pelo profissionalismo, comprometimento e atenção durante a realização dos ensaios.

À empresa Aditive pela doação do HDPE.

À empresa FAEX Soluções Ambientais LTDA pela doação do XLPE.

À empresa Karina Ind. e Com. de Plásticos pela micronização do XLPE.

À Faculdade SENAI de Tecnologia Ambiental por disponibilizar a peneira magnética e a calandra.

Aos amigos Edilene de Cassia Dutra Nunes, Juliana Satie Watai, Leandro José dos Santos, Louise Mariano Ruiz Silva, Rafael Galdino Bringel e Rafael Rocha pela amizade e incentivo. 
"Existem durante nossa vida, sempre dois caminhos a seguir: aquele que todo mundo segue e aquele que a nossa imaginação nos leva a seguir. O primeiro pode ser mais seguro, o mais confiável, o menos crítico, o que você encontrará mais amigos ... mas, você será apenas mais um a caminhar. O segundo, com certeza vai ser o mais difícil, mais solitário, o que você terá maiores críticas; mas também, o mais criativo, o mais original possível. Não importa o que você seja, quem você seja, ou que deseja na vida, a ousadia em ser diferente reflete na sua personalidade, no seu caráter, naquilo que você é. E é assim que as pessoas lembrarão de você um dia.' 


\section{RESUMO}

O descarte incorreto do resíduo de fios e cabos elétricos traz sérios problemas para as indústrias em vista que a utilização do polietileno reticulado (XLPE), material termofixo utilizado como isolante elétrico, não é passível de reciclagem através do reprocessamento no estado fundido como acontece em polímeros termoplásticos, sendo assim, quase todo o resíduo é incinerado ou disposto em aterros. Diante deste fato, tem-se a possibilidade do reaproveitamento deste polímero, através do processo de reciclagem mecânica por micronização para em seguida incorporá-lo em uma matriz termoplástica. No presente trabalho foram produzidos concentrados de XLPE micronizado em HDPE contendo 30\% em massa de XLPE pelo processo de calandragem. A incorporação do concentrado de XLPE em HDPE foi realizada por meio de processo de extrusão com dupla rosca corrotacional, e subsequente injeção de corpos de prova. Foi avaliada a influência dos teores e do tamanho de partícula de XLPE nas propriedades mecânicas e térmicas do composto final, utilizando-se planejamento fatorial $2^{2}$, com ponto central, para teores de XLPE de 1 e $9 \%$ em massa e de tamanho médio de partícula de 74 e $842 \mu \mathrm{m}$. A variável que teve maior efeito nas propriedades avaliadas, foi o teor de XLPE. O aumento do teor de XLPE aumentou significativamente a resistência ao impacto, no entanto, diminuiu as resistências à flexão e à tração, o módulo elástico de flexão e HDT. O aumento do tamanho de partícula de XLPE resultou em um aumento apenas na resistência ao impacto do material, com diminuição na deformação na ruptura e no módulo elástico de flexão. A interação entre as duas variáveis resulta em redução da resistência ao impacto e do módulo elástico de tração. As micrografias mostraram uma forte adesão do XLPE na matriz de HDPE.

Palavras-chaves: Reaproveitamento. Polietileno reticulado XLPE. Tamanho de partícula. Polietileno de alta densidade. 


\begin{abstract}
Improper disposal of waste from electrical wires and cables poses serious problems for the industry since the use of cross-linked polyethylene (XLPE), a thermoset, used as an electrical insulator is not recyclable through remelting as is the case of thermoplastic polymers, so that almost all waste is incinerated or disposed of in landfills. Given this fact, it is possible to reuse this polymer through mechanical recycling by micronizing and then incorporating it into a thermoplastic matrix. In the present work, micronized XLPE/HDPE concentrates containing $30 \mathrm{wt} \%$ XLPE were produced by a calendering process. Incorporation of XLPE concentrate into HDPE was carried out by means of a co-rotating twin-screw extrusion, with subsequent injection molding of specimens. The influence of XLPE particle size and contents on the mechanical and thermal properties of the final compound was assessed by using a $2^{2}$ factorial design, with center point, for XLPE contents at 1 and $9 \mathrm{wt} \%$ and average particle size of 74 and $842 \mu \mathrm{m}$. The variable that had the greatest effect on the assessed properties was XLPE content. Increase in XLPE content significantly increased impact strength, however, flexural and tensile strength, flexural modulus and HDT decreased. Increase in XLPE particle size resulted in an increase only in impact strength of the material, with decrease in strain at break and in flexural modulus. The interaction between the two variables results in reduction in impact strength and tensile modulus. The micrographs showed strong adhesion of XLPE to the HDPE.
\end{abstract}

Keywords: Reuse. Cross-linked polyethylene XLPE. Particle size. High-density polyethylene. 


\section{LISTA DE ILUSTRAÇÕES}

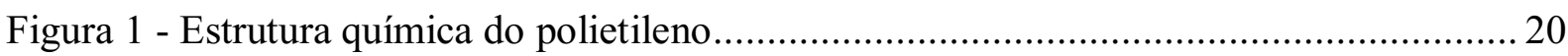

Figura 2 - Representações esquemáticas dos diferentes tipos de polietileno ......................... 23

Figura 3 - Representação esquemática de polietileno não reticulado e reticulado .................. 24

Figura 4 - Reticulação por peróxido de dicumila (DCP) ….............................................. 25

Figura 5 - Reações químicas por radiação ..................................................................... 26

Figura 6 - Método de reticulação por silano.......................................................................... 27

Figura 7 - Estrutura química do XLPE obtido por adição de silano ..................................... 28

Figura 8 - Propriedade mecânica do XLPE em função da temperatura................................. 29

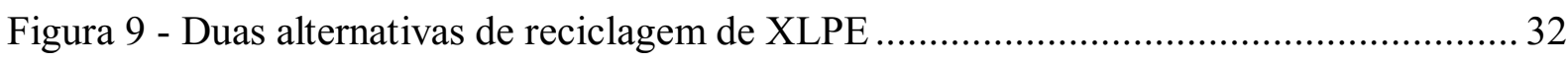

Figura 10 - XLPE moído recebido da empresa FAEX Soluções Ambientais Ltda................. 37

Figura 11 - Agitador vibratório de peneiras modelo Analysette3 Pro da marca Fritsch ......... 38

Figura 12 - Inicio do processamento com adição de HDPE................................................. 40

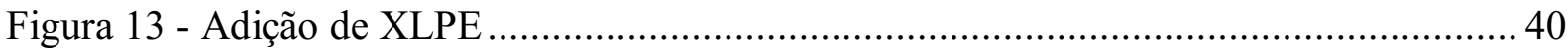

Figura 14 - Mistura e homogeneização do concentrado de XLPE ...................................... 41

Figura 15 - Retirada do concentrado em forma de manta ................................................ 41

Figura 16 - Mantas do concentrado de XLPE em HDPE e HDPE controle .......................... 42

Figura 17 - Perfil de rosca modular utilizado para extrusão dos compostos HDPE/XLPE e

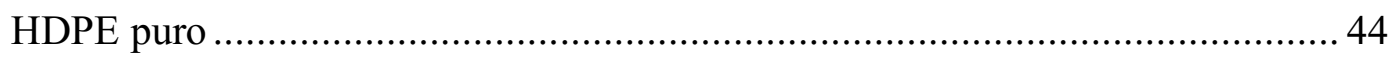

Figura 18 - Distribuição do tamanho de partícula do XLPE após micronização .................... 48

Figura 19 - Distribuição bimodal de partículas do XLPE ....................................................... 49

Figura 20 - Distribuição do tamanho de partícula XLPE - $100 \mu \mathrm{m}$...................................... 50

Figura 21 - Micrografia das partículas de XLPE $100 \mu \mathrm{m}$ (50x)...................................... 51

Figura 22 - Distribuição de tamanho de partícula XLPE - $500 \mu \mathrm{m}$...................................... 52

Figura 23 - Micrografia do tamanho de partícula XLPE - $500 \mu \mathrm{m}(25 \mathrm{x})$........................... 53

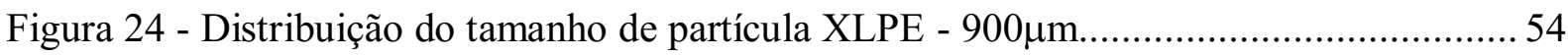

Figura 25 - Micrografia do tamanho de partícula XLPE - $900 \mu \mathrm{m}(15 \mathrm{x})$.............................. 55

Figura 26 - Representação gráfica do módulo de elasticidade em tração .............................. 57

Figura 27 - Representação gráfica da resistência à tração ................................................ 57

Figura 28 - Representação gráfica da deformação na ruptura ............................................ 58

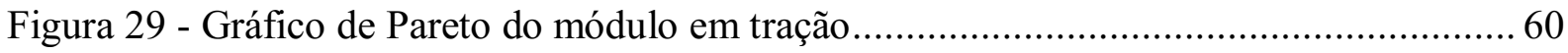

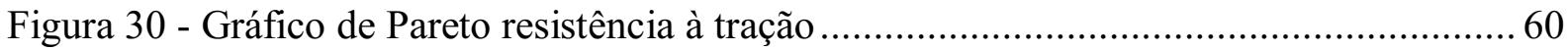

Figura 31 - Gráfico de Pareto da deformação na ruptura.................................................... 61 


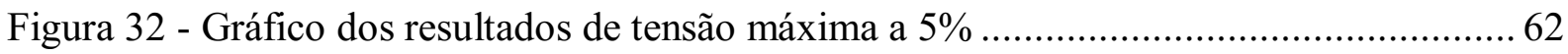

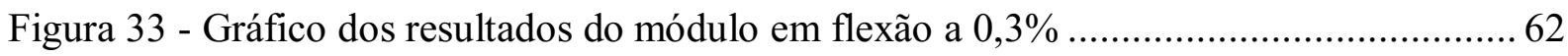

Figura 34 - Gráfico de Pareto da resistência a flexão .......................................................... 63

Figura 35 - Gráfico de Pareto para módulo de flexão a deformação de $0,3 \%$....................... 64

Figura 36 - Resistência ao impacto dos compostos contendo XLPE e do HDPE puro ........... 65

Figura 37 - Gráfico de Pareto ilustrando a influência da adição de XLPE variando o

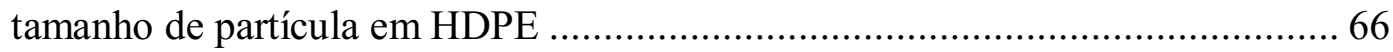

Figura 38 - Resultado desejado para maximizar as propriedades...................................... 67

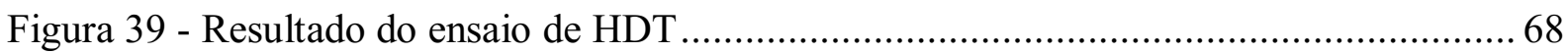

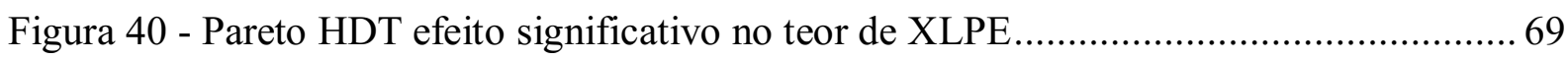

Figura 41 - Fotomicrografia de MEV da superfície fraturada dos compostos: ..................... 71

Figura 42 - Curva ensaio de tração HDPE controle $(50 \mathrm{~mm} / \mathrm{min}$.) ................................... 78

Figura 43 - Curva ensaio de tração HDPE controle $(500 \mathrm{~mm} / \mathrm{min}$.$) ...................................... 78$

Figura 44 - Curva ensaio de tração XLPE 1\%-100 (50mm/min.) …................................... 79

Figura 45 - Curva ensaio de tração XLPE 1\%-100 (500mm/min.) …................................. 79

Figura 46 - Curva ensaio de tração XLPE 1\%-900 (50mm/min.) ...................................... 80

Figura 47 - Curva ensaio de tração XLPE 1\%-900 (500mm/min.) …................................. 80

Figura 48 - Curva ensaio de tração XLPE 5\%-500 (50mm/min.) ...................................... 81

Figura 49 - Curva ensaio de tração XLPE 5\%-500 (500mm/min.) …................................ 81

Figura 50 - Curva ensaio de tração XLPE 9\%-100 (50mm/min.) ....................................... 82

Figura 51 - Curva ensaio de tração XLPE 9\%-100 (500mm/min.) …................................. 82

Figura 52 - Curva ensaio de tração XLPE 5\%-900 (50mm/min.) ........................................ 83

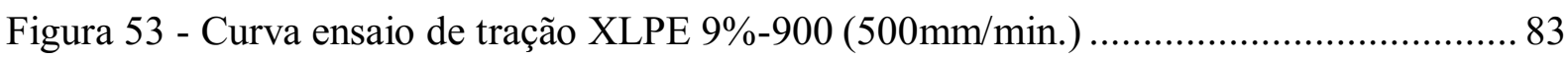

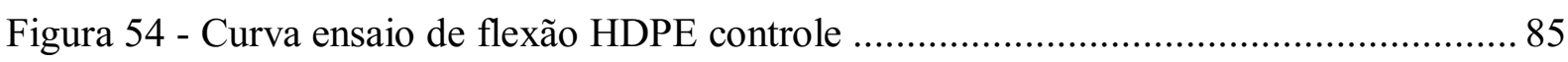

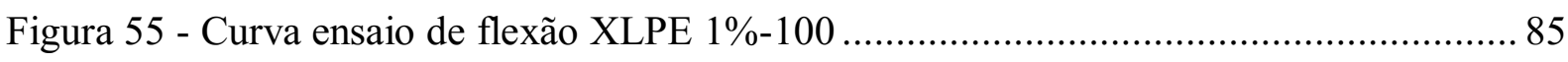

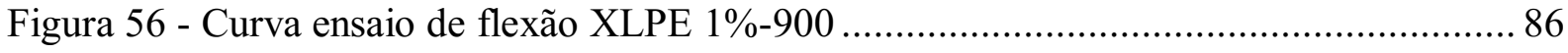

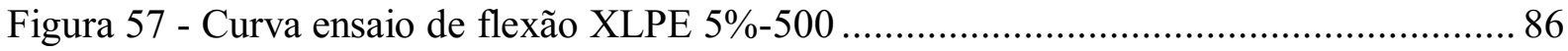

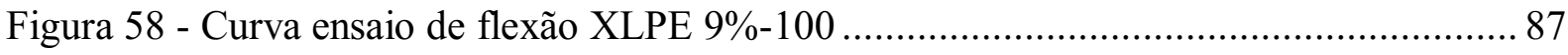

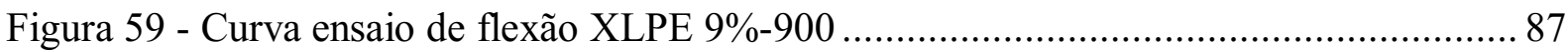




\section{LISTA DE TABELAS}

Tabela 1 - Tipos de isolante polimérico para revestimento de fios e cabos elétricos com suas

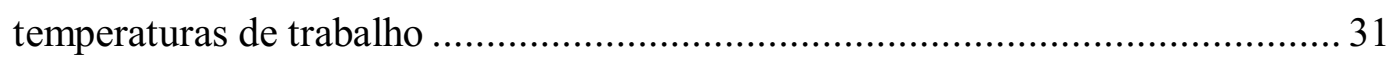

Tabela 2 - Propriedades do material Polietileno de Alta Densidade GE7252 Braskem. ........ 36

Tabela 3 - Tempos de processamento do concentrado XLPE em HDPE ….......................... 39

Tabela 4 - Planejamento experimental $2^{2}$ com ponto central ......................................... 43

Tabela 5 - Parâmetros de processamento por extrusão …................................................... 44

Tabela 6 - Parâmetros de processo de injeção dos corpos de prova ..................................... 45

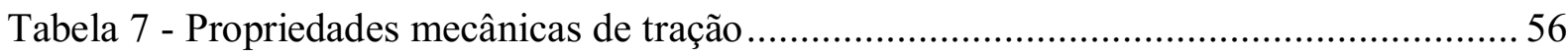

Tabela 8 - Coeficiente das equações polinomiais dos ajustes de segunda ordem .................. 59

Tabela 9 - Resultados da propriedade de flexão ........................................................... 61

Tabela 10 - Coeficiente das equações polinomiais dos ajustes de segunda ordem ensaio de

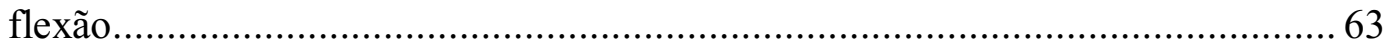

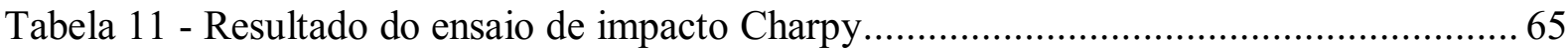

Tabela 12 - Coeficientes das equações polinomiais dos ajustes de segunda ordem para a

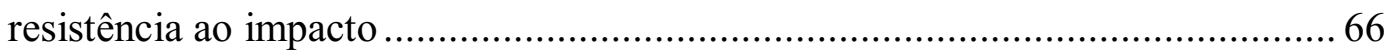

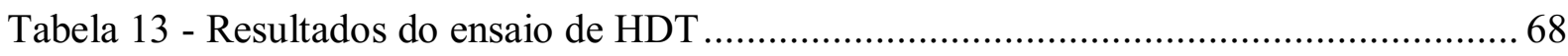

Tabela 14 - Coeficiente das equações polinomiais dos ajustes de segunda ordem da HDT .... 69

Tabela 15 - Comparação do intercepto do modelo do planejamento estatístico com os resultados do ponto central 


\section{LISTA DE ABREVIATURAS E SIGLAS}

$\begin{array}{ll}\text { ASTM } & \text { American Society for Testing and Materials } \\ \text { DCP } & \text { Peróxido de dicumila } \\ \text { EVA } & \text { Etileno vinil acetato } \\ \text { FR-EP } & \text { Etileno-propileno com retardante de chama } \\ \text { HCl } & \text { Ácido clorídrico } \\ \text { HDPE } & \text { Polietileno de alta densidade } \\ \text { HDT } & \text { Temperatura de distorção ao calor (Heat Deflection Temperature) } \\ \text { HF } & \text { Ácido fluorídrico } \\ \text { LDPE } & \text { Polietileno de baixa densidade } \\ \text { LLDPE } & \text { Polietileno linear de baixa densidade } \\ \text { MEV } & \text { Microscopia eletrônica de varredura } \\ \text { NO } & \text { Óxidos de nitrogênio } \\ \text { PE } & \text { Polietileno } \\ \text { PVC } & \text { Poli (cloreto de vinila) } \\ \text { SENAI } & \text { Serviço nacional de aprendizagem industrial } \\ \text { TGA } & \text { Ensaio de Análise Termogravimétrica } \\ \text { UHMWPE } & \text { Polietileno de ultra massa molar } \\ \text { ULDPE } & \text { Polietileno de ultrabaixa densidade } \\ \text { VLDPE } & \text { Polietileno de densidade muito baixa } \\ \text { XLPE } & \text { Polietileno reticulado } \\ \text { XLPO } & \text { Poliolefina reticulada } \\ & \end{array}$




\section{SUMÁRIO}

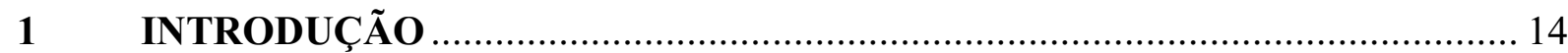

1.1 MOTIVAÇÃO DO PRESENTE TRABALHO ................................................... 15

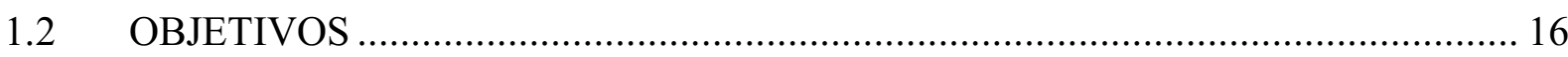

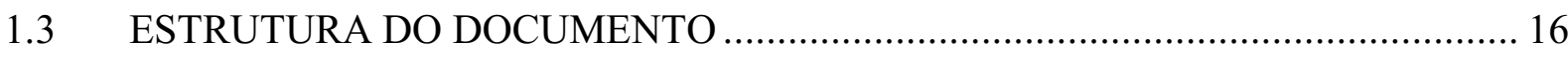

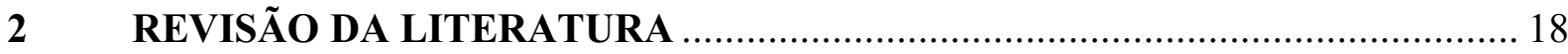

2.1 CLASSIFICAÇÃO DOS POLÍMEROS SEGUNDO A SUA FUSIBILIDADE ........ 18

2.2 TIPOS DE RECICLAGEM DE POLÍMEROS ................................................... 18

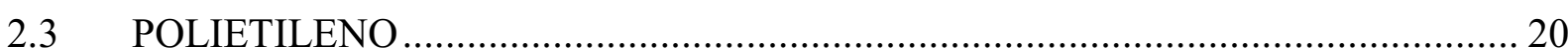

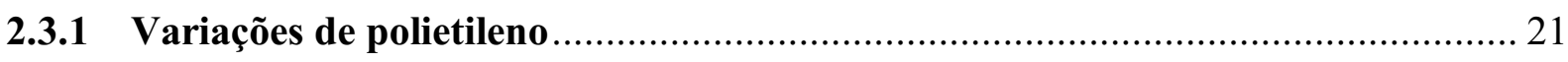

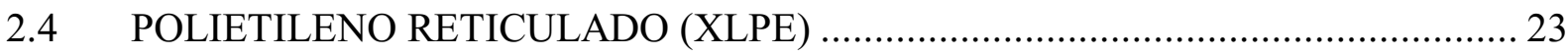

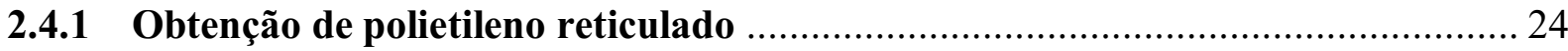

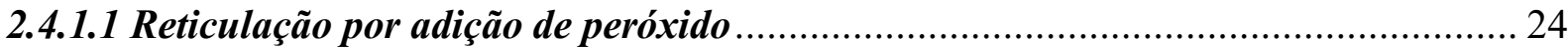

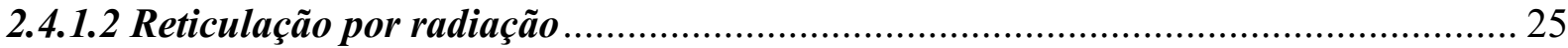

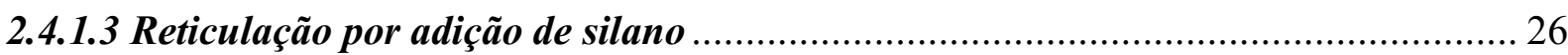

2.5 EFEITOS DA RETICULAÇÃO NAS PROPRIEDADES DO POLIETILENO ........ 28

2.6 APLICAÇÕES DO POLIETILENO RETICULADO .......................................... 29

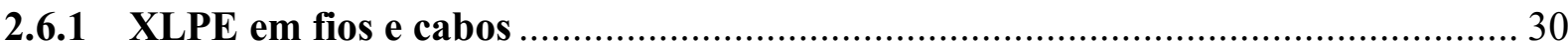

2.7 TÉCNICAS DE RECICLAGEM E REUTILIZAÇÃO DE XLPE............................ 31

3 MECANISMO DE TENACIFICAÇÃO DOS POLÍMEROS ............................. 34

3.1 EFEITO DO TAMANHO DE PARTÍCULA NA TENACIFICAÇÃO .................... 35

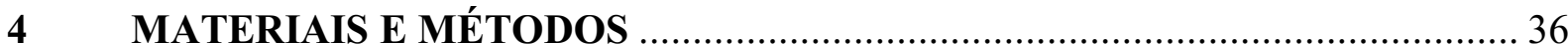

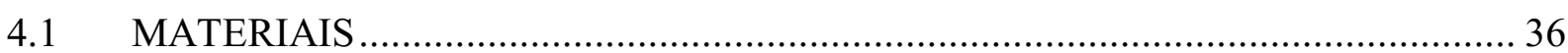

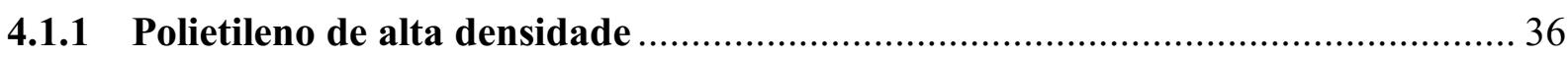

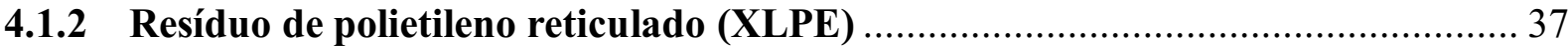

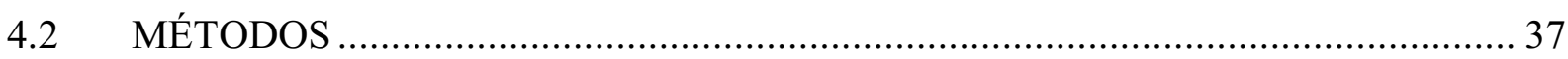

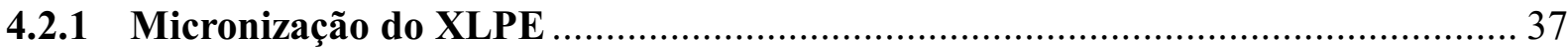

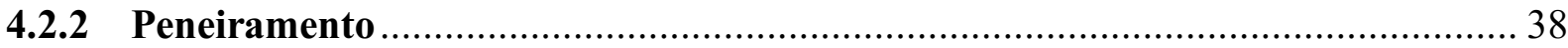

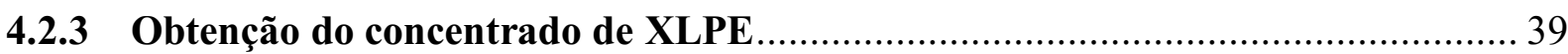

4.2.4 Moagem das mantas do concentrado de XLPE em HDPE ................................ 42

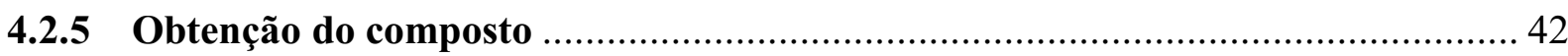

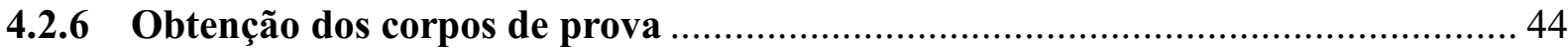

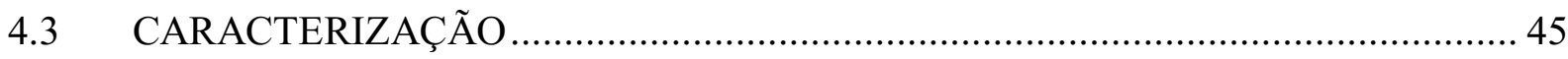


4.3.1 Análise da distribuição do tamanho de partícula ............................................ 46

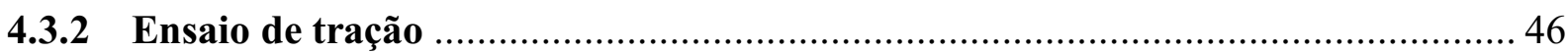

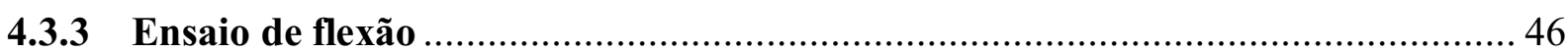

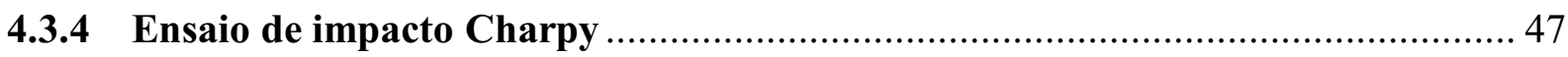

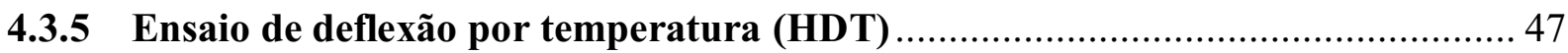

4.3.6 Análises por microscopia eletrônica de varredura (MEV) ................................ 47

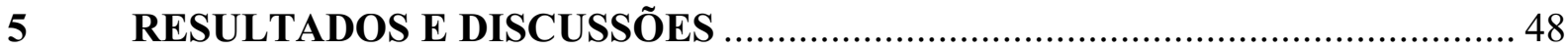

5.1 ANÁLISE DA DISTRIBUIÇÃO DO TAMANHO DE PARTÍCULA ...................... 48

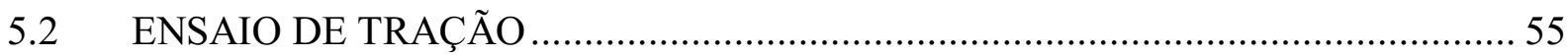

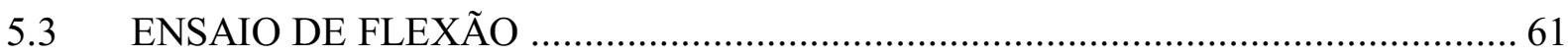

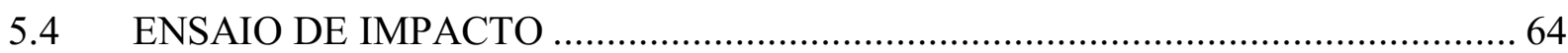

5.5 OTIMIZAÇÃO DAS PROPRIEDADES DE TRAÇÃO, FLEXÃO E IMPACTO

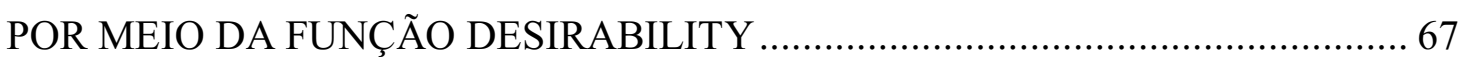

5.6 ENSAIO DE DEFLEXÃO POR TEMPERATURA (HDT) …................................. 67

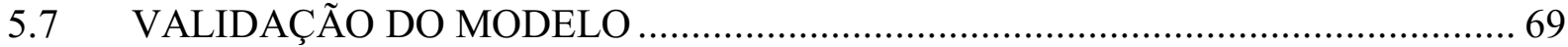

5.8 ANÁLISE POR MICROSCOPIA ELETRÔNICA DE VARREDURA (MEV) ........ 70

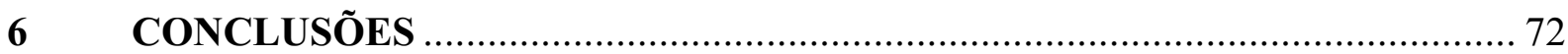

6.1 SUGESTÕES PARA TRABALHOS FUTUROS ............................................... 73

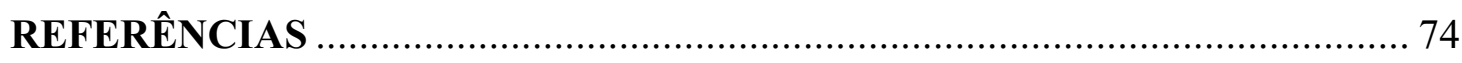

APÊNDICE A - CURVAS ENSAIO DE TRAÇÃO …....................................... 77

APÊNDICE B - CURVAS ENSAIO DE FLEXÃO .......................................... 84

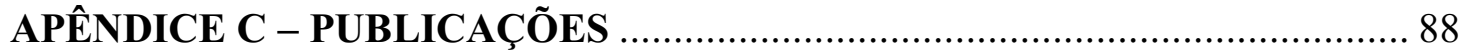




\section{INTRODUÇÃO}

O desenvolvimento tecnológico e produtivo para esse século mostra que o padrão de produção e consumo dos recursos naturais não renováveis, projetado pelo modelo de industrialização do século passado, não é mais sustentável. A reciclagem apresenta uma solução para prolongar a vida dos recursos não renováveis na qual indústrias buscam o desenvolvimento de novos projetos. As regulamentações ambientais forçam as empresas a buscar atividades em nome da responsabilidade social fazendo com que a indústria comece a ser administrada não só em termos técnicos e econômicos, mas também ambientais (MEDINA, 2007).

A reciclagem mecânica de resíduos termoplásticos é relativamente simples, no qual o resíduo passa por processo de moagem para posterior moldagem no estado fundido. Já no caso dos polímeros termofixos, a natureza infusível, conferida pelas ligações cruzadas, dificulta a reciclagem gerando assim resíduos e rejeitos que muitas vezes são incinerados ou descartados, como no caso do polietileno reticulado (XLPE), utilizado como isolante termofixo em fios e cabos elétricos. Atualmente, porém, as restrições ecológicas mais severas tornam imperativa a procura de meios alternativos para resgatar um pouco do valor destes rejeitos termofixos (PICKERING, 2013).

Como em qualquer atividade industrial, resíduos são gerados durante a fabricação de fios e cabos e quando os mesmos são rejeitados. Os resíduos podem consistir de vários tipos de materiais tais como metais, plásticos, borracha, papel e fibras de vidro. Porém, o principal motivo para reciclar os resíduos de cabos elétricos é para recuperar os metais valiosos, como cobre e alumínio. A reciclagem de componentes plásticos é cada vez mais encorajada, especialmente na Europa, pois o descarte em aterros não é mais aceita. O descarte por outros meios está associado a custos e, portanto, a indústria é encorajada a encontrar novas soluções econômicas para o tratamento dos resíduos de fios e cabos elétricos (BOSS et al. 2011).

Os principais componentes de plástico nos resíduos de fios e cabos elétricos hoje são (PVC) e polietileno, tanto na forma reticulada XLPE quanto na forma termoplástica (PE). As técnicas de separação em uso hoje permitem a separação efetiva dos dois tipos principais. A fração de PVC pode ser refundida e processada em novos produtos. O resíduo de XLPE, por ser reticulado, não pode ser reprocessado no estado fundido. Uma opção é recuperar a energia do PE e do XLPE. Uma vez que esses materiais são originários de hidrocarbonetos e possuem uma capacidade de energia semelhante ao óleo. Como as técnicas de separação de resíduos de cabos elétricos produzem uma fração leve muito limpa, ela pode ser usada em aplicações 
como combustível complementar em instalações de aquecimento urbano ou em fornos de cimento (BOSS et al. 2011).

No entanto, demonstrou-se que uma mistura de PE virgem com até $60 \%$ de resíduos de XLPE fornece uma mistura que pode ser reprocessada. Isso resulta em um material com boas propriedades mecânicas que pode ser usado, por exemplo, em artigos moldados por injeção. Como o mercado de produtos moldados à base de poliolefinas recicladas representa vários milhares de toneladas por ano, isso oferece muitas oportunidades (BOSS et al. 2011).

Fonseca e Bonse (2015) conseguiram incorporar com êxito 5, 10 e 20\% em massa de XLPE em uma matriz de (LDPE) no qual obtiveram aumento nas propriedades mecânicas em torno de $5 \%$ para a resistência à tração, $11 \%$ para a deformação na ruptura e $70 \%$ para a resistência ao impacto utilizando uma distribuição bimodal de tamanho de partícula de XLPE de 400 e $1000 \mu \mathrm{m}$.

Cucchiara e Bonse (2015) incorporaram 5, 10, 20 e 30\% de XLPE em (HDPE) e observaram que a incorporação de 5\% XLPE resultou em um aumento na resistência ao impacto de quase 10 vezes em relação ao HDPE. A partir deste teor, houve uma queda gradual, porém, ainda mantendo valores muito superiores ao do HDPE puro.

Diante disso, o objetivo principal do trabalho foi estudar o efeito da incorporação de polietileno reticulado XLPE em polietileno de alta densidade nas propriedades mecânicas, térmicas e morfológica do compósito final, utilizando baixos teores de XLPE, de 1 e 9\% em massa, e tamanho de partícula de 100 e $900 \mu \mathrm{m}$ conforme um planejamento experimental $2^{2}$ com ponto central.

\subsection{MOTIVAÇÃO DO PRESENTE TRABALHO}

Os polímeros derivados do petróleo surgiram a partir da Segunda Guerra mundial. Com o avanço da utilização de artefatos poliméricos surgiram os problemas relacionados ao descarte destes produtos que ocupam um grande volume nos aterros sanitários trazendo complicações na degradação de materiais biologicamente degradáveis, pois estes resíduos formam uma camada impedindo a troca de líquidos e gases. Diante destes problemas, surgiram estudos de reaproveitamento desses materiais a partir da reciclagem (GORNI, 2003).

Os polímeros se dividem em configurações específicas, dentre elas estão os polímeros termoplásticos, termorrígidos (termofixos) e elastômeros (termoplásticos e termofixo), os termoplásticos possuem um sistema de reciclagem bem difundido, já os termofixos por 
possuir característica infusível não são passíveis de reprocessamento no estado fundido e a partir deste problema surge à necessidade da reutilização deste resíduo.

\subsection{OBJETIVOS}

Reutilizar o resíduo de polietileno termofixo XLPE proveniente de fios e cabos em uma matriz termoplástica de polietileno de alta densidade com a finalidade de dar um destino ao resíduo que hoje é descartado em aterros sanitários e ou incinerados e aprimorar os resultados do composto elaborado por (CUCCHIARA; BONSE, 2015).

\subsection{ESTRUTURA DO DOCUMENTO}

A presente dissertação está estruturada em cinco capítulos como segue:

a) capitulo 1: Abrange uma breve introdução sobre o objeto de estudo e objetivos a serem atingidos;

b) capitulo 2: Aborda uma revisão da literatura enfatizando os conceitos relacionados ao polietileno, com foco no polietileno de alta densidade e o polietileno reticulado apresentando os conceitos de obtenção do polietileno reticulado, tipos de reticulação, aplicação de polietileno reticulado, XLPE em fios e cabos e técnicas de reciclagem e reutilização de XLPE;

c) capitulo 3: Explica a tenacificação e mecanismo de deformação dos polímeros;

d) capitulo 4: Apresenta os materiais utilizado no desenvolvimento do trabalho e os métodos experimentais para caracterização e obtenção do composto;

e) capitulo 5: Aborda a discussão e os resultados obtidos por meio das análises experimentais;

f) capítulo 6: Apresenta as conclusões; 
g) capítulo 7: Sugestões para trabalhos futuros e por fim, as referências utilizadas no desenvolvimento do trabalho. 


\section{REVISÃO DA LITERATURA}

No presente capítulo serão apresentadas as características dos polímeros e em específico dos polietilenos, tipos de reciclagem, polietileno reticulado, tipos de reticulação, efeito da reticulação, aplicação do polietileno reticulado, XLPE em fios e cabos e técnicas de reciclagem de XLPE.

\subsection{CLASSIFICAÇÃO DOS POLÍMEROS SEGUNDO A SUA FUSIBILIDADE}

Polímeros são macromoléculas compostas por dezenas de milhares de unidades de repetição (meros) ligadas por ligações covalentes, formados a partir de monômeros (CANEVAROLO, 2006).

Quanto à fusibilidade, os polímeros podem ser agrupados em termoplásticos e termofixos. Os polímeros termoplásticos possuem a capacidade de amolecer e fluir quando submetidos à temperatura e pressão e quando estes são retirados, o mesmo se solidifica dando forma a um produto (CANEVAROLO, 2006), ou seja, os polímeros termoplásticos fundem quando aquecidos e solidificam por resfriamento em um processo reversível (MANO; MENDES, 2004).

Polímeros classificados como termofixo, quando submetidos ao calor, ou outra forma de tratamento, assumem uma estrutura reticulada, após o qual o polímero torna-se infusível (MANO; MENDES, 2004).

Segundo Canevarolo (2006), o termofixo é um polímero que amolece uma vez com o aquecimento passa pelo processo de cura onde ocorre uma transformação química irreversível formando ligações cruzadas e quando submetido novamente ao calor, não mais altera seu estado físico, ou seja, o polímero não amolece, tornando-se infusível e insolúvel.

\subsection{TIPOS DE RECICLAGEM DE POLÍMEROS}

Spinacé e De Paoli (2005) citam que a reciclagem de polímeros pode ser classificada em quatro classes, são elas: primária, secundária, terciária e quaternária.

A reciclagem primária consiste, de forma geral, na conversão dos resíduos poliméricos, gerados na indústria durante os métodos de processamento padrão (resíduos pós- 
industriais), em produtos com características semelhantes aquelas dos produtos originais processados com polímero virgens.

A reciclagem secundária consiste na conversão dos resíduos poliméricos que provêm dos resíduos sólidos urbanos (resíduos pós-consumo) através de um processo ou uma combinação de processos em produtos que possuem uma menor exigência em relação aos produtos obtidos com polímero virgem.

A reciclagem primária e a secundária são conhecidas também como reciclagem mecânica ou física (SPINACÉ; DE PAOLI 2005). A reciclagem mecânica pode ser viabilizada através do reprocessamento por extrusão, injeção, termoformagem, moldagem por compressão, entre outros. Ela consiste em algumas etapas quais sejam: separação do resíduo polimérico, moagem, lavagem, secagem, reprocessamento e por fim, a transformação do polímero em produto acabado. A finalidade da reciclagem é obter um produto acabado que possua propriedades mais semelhantes possíveis às do polímero virgem, para que assim seja empregado na produção de materiais com aplicações mais nobres. Os termoplásticos são mais favoráveis à reciclagem mecânica do que os termofixos, que não podem ser refundidos e reconformados.

A reciclagem terciária, também chamada de química, consiste na produção de matéria prima básica na forma de monômeros ou misturas de hidrocarbonetos, a partir de resíduos poliméricos, que poderão ser reutilizados como produtos químicos em refinarias ou centrais petroquímicas.

Segundo Harper (2006), os polímeros mais propensos à reciclagem química são os de condensação tais como PET, náilon e poliuretano, pois a maioria dos polímeros de adição, tais como as poliolefinas, poliestireno e PVC, produz uma mistura de produto complexa que é difícil de usar economicamente como matéria-prima química, enquanto que os polímeros de condensação geralmente produzem fluxos de um ou dois componentes relativamente puros.

A reciclagem quaternária, também chamada de energética, envolve processos tecnológicos de recuperação de energia através do processo de incineração, para usar resíduos poliméricos como combustíveis na geração de energia elétrica. Segundo Harper (2006), esta última categoria geralmente não é considerada uma reciclagem verdadeira.

De acordo com Silvia et al. (2011), o polímero possui um alto poder calorífico e por este motivo, é considerado um componente importante no processo de reciclagem energética. Esta alternativa é recomendada para os polímeros não recicláveis, ou seja, os termofixos, pois no caso dos termoplásticos, a reciclagem mecânica é mais eficiente. 
O processo de reciclagem energética pode apresentar problemas quando polímeros em sua estrutura química contenham halogênios como cloro ou flúor que durante a combustão são liberados na forma de $(\mathrm{HCl})$ ou $(\mathrm{HF})$, podendo também ser uma fonte de emissão de dioxinas. Para este tipo de problema, são utilizados gases de lavagem que reduzem a emissão de $\mathrm{HCl}$ a níveis legais. Há também polímeros que contêm nitrogênio em sua estrutura que no processo de combustão liberam $\mathrm{NO}_{\mathrm{x}}$. Além destes problemas apresentados na combustão de polímeros outros compostos podem ser liberados como metais, compostos orgânicos provenientes de tintas, pigmentos, cargas ou estabilizantes que estão presentes nos polímeros (SPINACÉ; DE PAOLI, 2005).

\subsection{POLIETILENO}

Segundo Peacock (2000), uma molécula de polietileno é constituída por uma espinha dorsal de um grande número de átomos de carbono ligados de forma covalente com um par de átomos de hidrogênio ligados a cada carbono onde as extremidades da cadeia são terminadas por grupos metila conforme a figura 1. A resina de polietileno quimicamente pura consiste em alcanos com a fórmula $\mathrm{C}_{2} \mathrm{nH}_{4} \mathrm{n}_{+2}$, onde $n$ é o grau de polimerização, isto é, o número de monômeros de etileno polimerizados para formar a cadeia. Tipicamente, o grau de polimerização é bem acima de 100 e pode ser tão elevada como 250.000 ou mais, o que equivale a uma massa molar que varia de 1400 a mais de $3.500 .000 \mathrm{~g} / \mathrm{mol}$. Estas moléculas podem ser ramificadas em vários graus e conter relativamente pequenas quantidades de insaturação. Molécula de baixa massa, entre 8 e 100 g/mol, são sólidos cerosos que não possuem propriedades normalmente associadas a um polímero, estas, são chamadas de oligômeros e moléculas abaixo de $8 \mathrm{~g} / \mathrm{mol}$ são gases ou líquidos a temperaturas e pressões normais.

Figura 1 - Estrutura química do polietileno

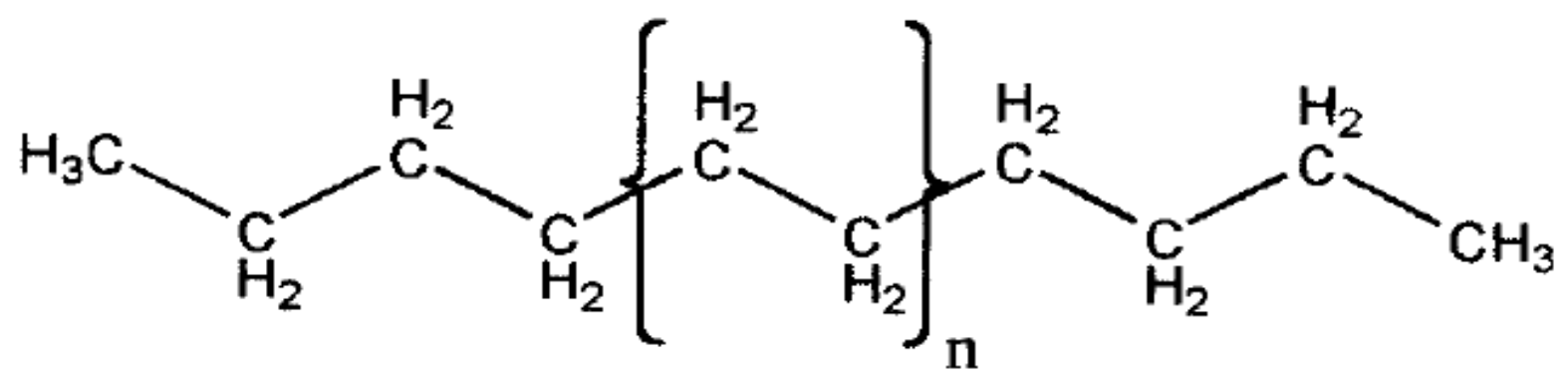

Fonte: Peacock, 2000 
O polietileno é geralmente encontrado em sua forma estrutural semicristalina podendo possuir uma macroestrutura conhecida como esferulito, no qual o cristal do polietileno exibe polimorfismo, apresentando estrutura cristalina ortorrômbica ou monoclínica. As dimensões da célula unitária ortorrômbica nas condições normais de temperatura e pressão são $\mathrm{a}=0,741$ $\mathrm{nm}, \mathrm{b}=0,494 \mathrm{~nm}$ e $\mathrm{c}=0,255 \mathrm{~nm}$ onde o comprimento e a espessura da lamela são, respectivamente, da ordem de $10 \mathrm{~nm}$ e 10-20 nm. O esferulito possui um diâmetro de aproximadamente 10 $\mu \mathrm{m}$ (YOUNG; LOVELL 1991).

\subsubsection{Variações de polietileno}

Peacock (2000) cita que existem muitos tipos de polietileno que possuem essencialmente o mesmo esqueleto de átomos de carbono com hidrogênios ligados covalentemente. Variações surgem principalmente a partir de ramificações que modificam a natureza do material. Existem muitos tipos de ramificações, que vão desde grupos alquilo simples a funcionalidades de ácido e éster. As variações surgem de defeitos na estrutura do polímero que consistem principalmente de grupos vinilo, que são frequentemente associados com as extremidades da cadeia. As regiões cristalinas são mais compactas, a densidade global de uma resina de polietileno aumenta à medida que o grau de cristalinidade aumenta. Geralmente, quanto maior a concentração de ramificações, menor a densidade do sólido. Os principais tipos de polietileno estão ilustrados esquematicamente na figura 2 e descrito a seguir.

a) Polietileno de alta densidade: HDPE é quimicamente o mais próximo em estrutura ao polietileno teórico. É constituído principalmente por moléculas pouco ramificadas, com poucas falhas para manter sua linearidade. A forma geral de HDPE é representada na figura 2a. Um nível relativamente baixo de defeitos, que impedem a organização, resulta em elevado grau de cristalinidade, o que gera resinas com elevada densidade em relação aos outros tipos de polietileno. Algumas resinas deste tipo são copolimerizadas com uma pequena concentração de 1alcenos, a fim de reduzir ligeiramente o nível de cristalinidade. Resinas de polietileno de alta densidade possuem tipicamente densidades no intervalo de 0,94 $0,97 \mathrm{~g} / \mathrm{cm}^{3}$; 
b) Polietileno de baixa densidade: LDPE é caracterizado por possuir ramificações. As ramificações consistem principalmente de grupos etila e butila, juntamente com cadeias longas. Uma representação simplificada da estrutura de polietileno de baixa densidade é observada na figura $2 b$. As numerosas ramificações que são características do polietileno de baixa densidade inibem a sua capacidade para cristalizar, reduzindo a densidade relativa comparada à resina do HDPE. Resinas de polietileno de baixa densidade possuem tipicamente densidades entre 0,90-0,94 $\mathrm{g} / \mathrm{cm}^{3}$;

c) Polietileno Linear de Baixa Densidade: (LLDPE) são resinas que consistem de moléculas com cadeia principal linear que estão ligadas a grupos alquila curtos em intervalos aleatórios. Estes materiais são produzidos pela copolimerização de etileno com 1-alcenos. A estrutura geral de resinas de polietileno linear de baixa densidade é representada na figura 2c. As ramificações mais comumente encontradas são grupos etila, butila ou hexila, mas pode ser uma variedade de outros grupos alquila, tanto lineares como ramificadas. Uma típica separação média de ramificações ao longo da cadeia principal é de 25-100 átomos de carbono. Resinas de polietileno linear de baixa densidade, também podem conter pequenos níveis de ramificação curta, mas não é o mesmo grau de ramificação como encontrado em polietileno de baixa densidade. Os grupos laterais impedem a cristalização e a densidade fica entre $0,90-0,94 \mathrm{~g} / \mathrm{cm}^{3}$;

d) Polietileno de muito baixa densidade: (VLDPE) conhecidos também como polietileno de ultrabaixa densidade (ULDPE) é uma forma especial do polietileno linear de baixa densidade que tem uma concentração muito mais elevada de ramificações curtas. A estrutura geral de polietileno de densidade muito baixa é observada na figura 2d. A distância típica das ramificações está na faixa de 7-25 átomos de carbono da cadeia principal. $\mathrm{O}$ alto nível de ramificação inibe a cristalização de forma muito eficaz, resultando em um material que é predominantemente não cristalino. Os altos níveis de distúrbio são refletidos nas densidades muito baixas, que se enquadram entre $0,86-0,90 \mathrm{~g} / \mathrm{cm}^{3}$;

e) Polietileno de ultra massa molar: (UHMWPE) é um polietileno de média densidade, semicristalino de poucas ramificações produzido a partir do gás eteno assim como 
os demais polietilenos. O diferencial do UHMWPE em relação aos demais polietilenos é o seu elevadíssimo peso molecular que o classifica como um polímero de engenharia com alto valor e desempenho que pode apresentar tamanho de cadeia até 30 vezes maior em relação ao HDPE.

Figura 2 - Representações esquemáticas dos diferentes tipos de polietileno

(a)

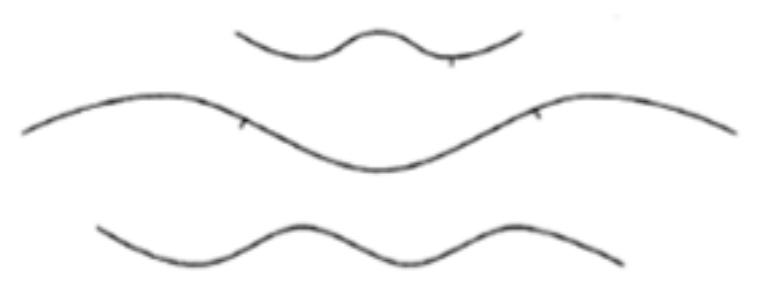

(b)

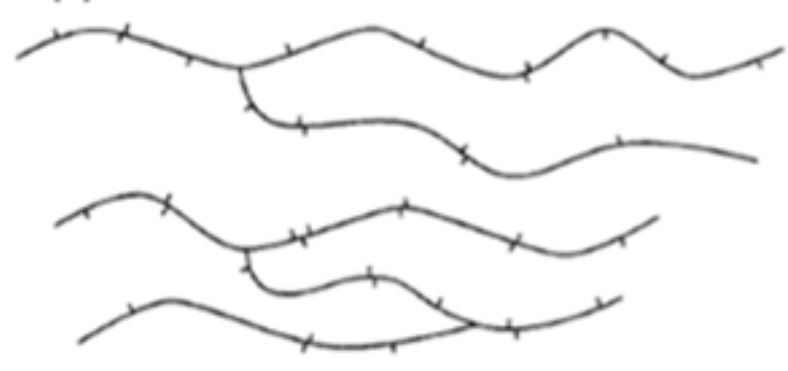

(c)

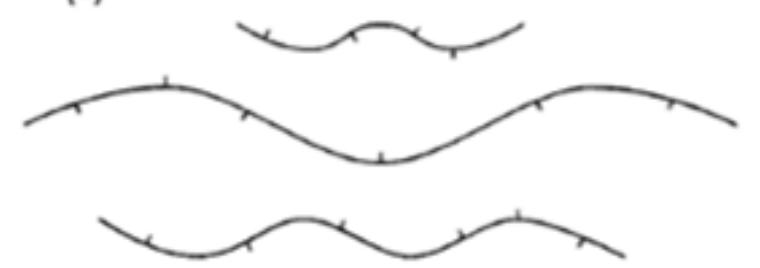

(d)

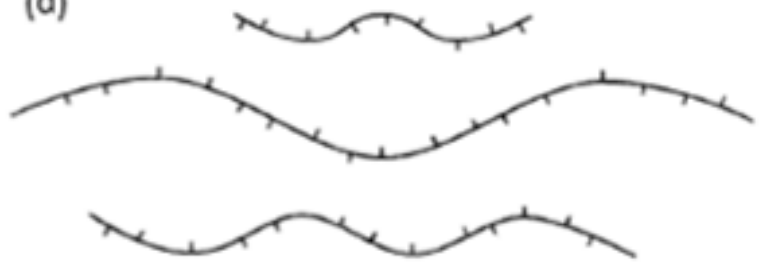

(e)

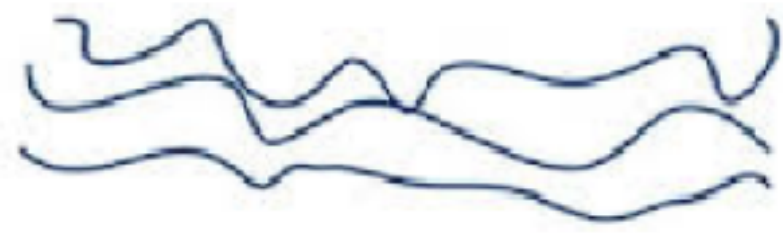

Fonte: Autor "adaptado de" Peacock, 2000

Legenda: (a) polietileno de alta densidade; (b) polietileno de baixa densidade; (c) polietileno linear de baixa densidade; (d) polietileno de muito baixa densidade; (e) polietileno de ultra massa molar

\subsection{POLIETILENO RETICULADO (XLPE)}

Os polietilenos (PE) são termoplásticos por natureza e, portanto podem ser reprocessados repetidamente. Entretanto, quando submetidos a temperaturas entre 80 e $130^{\circ} \mathrm{C}$ 
eles amolecem e escoam, perdendo propriedades físicas, o que limita as suas aplicações. Como todo termoplástico, o PE sofre fluência que aumenta com o aumento da temperatura. A manutenção de suas propriedades a temperaturas acima de $80^{\circ} \mathrm{C}$ pode ser alcançada pela reticulação, que muda a natureza do polímero de termoplástica para termofixa, ou seja, insolúvel, infusível e mais durável. A reticulação, que é a formação de ligações químicas primárias entre as cadeias poliméricas adjacentes é mais favorável em polímeros ramificados do que em lineares. As ligações podem ocorrer entre átomos de carbono ou formar uma ponte química ligando dois ou mais átomos de carbono (TAMBOLI; MHASKE; KALE, 2004).

A reticulação reduz o índice de fluidez e alongamento na ruptura, e aumenta as resistências ao impacto, à fluência, ao crescimento de trincas e a trincas por tensão ambiental (environmental stress cracking). A densidade e resistência à tração do PE são pouco afetadas pela reticulação. A reticulação pode ser realizada por radiação, peróxidos ou compostos de silano, formando ligações cruzadas C-C ou Si-O-Si (QUDAIH; JANAJREH; VUKUSIC, 2011). A figura 3 ilustra a representação esquemática do polietileno não reticulado e reticulado.

Figura 3 - Representação esquemática de polietileno não reticulado e reticulado

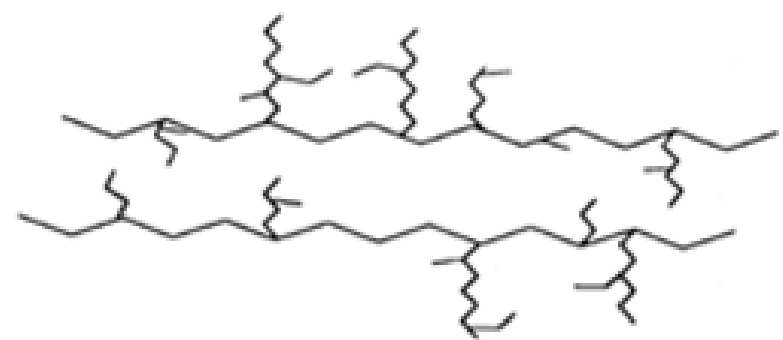

LDPE não reticulado

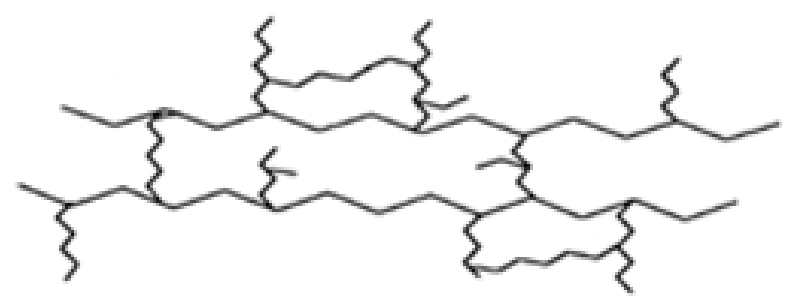

LDPE reticulado

Fonte: Autor “adaptado de" Tamboli; Mhaske; Kale, 2004

\subsubsection{Obtenção de polietileno reticulado}

Podem-se obter os polietilenos reticulados de três maneiras distintas: adição por peróxido, por radiação ou adição por silano (GULMINE, 2004).

\subsubsection{Reticulação por adição de peróxido}

Gulmine (2004) cita que a reação de reticulação se dá pela decomposição térmica homolítica de um peróxido que geralmente é o peróxido de dicumila (DCP) produzindo 
radicais livres. Este peróxido é um sólido cristalino com energia de ativação para decomposição de $37 \mathrm{kcal} / \mathrm{mol}(154,81 \mathrm{~kJ} / \mathrm{mol})$ e tempo de meia vida de 14 minutos a $150^{\circ} \mathrm{C}$. Esses radicais atacam uma molécula do polímero formando um radical através da abstração do hidrogênio para em seguida formar ligações entre dois radicais. A concentração utilizada de peróxido em polietileno é em torno de $2 \%(\mathrm{~m} / \mathrm{m})$ antes da extrusão. A figura 4 ilustra a reticulação do PE utilizando peróxido de dicumila.

Figura 4 - Reticulação por peróxido de dicumila (DCP)
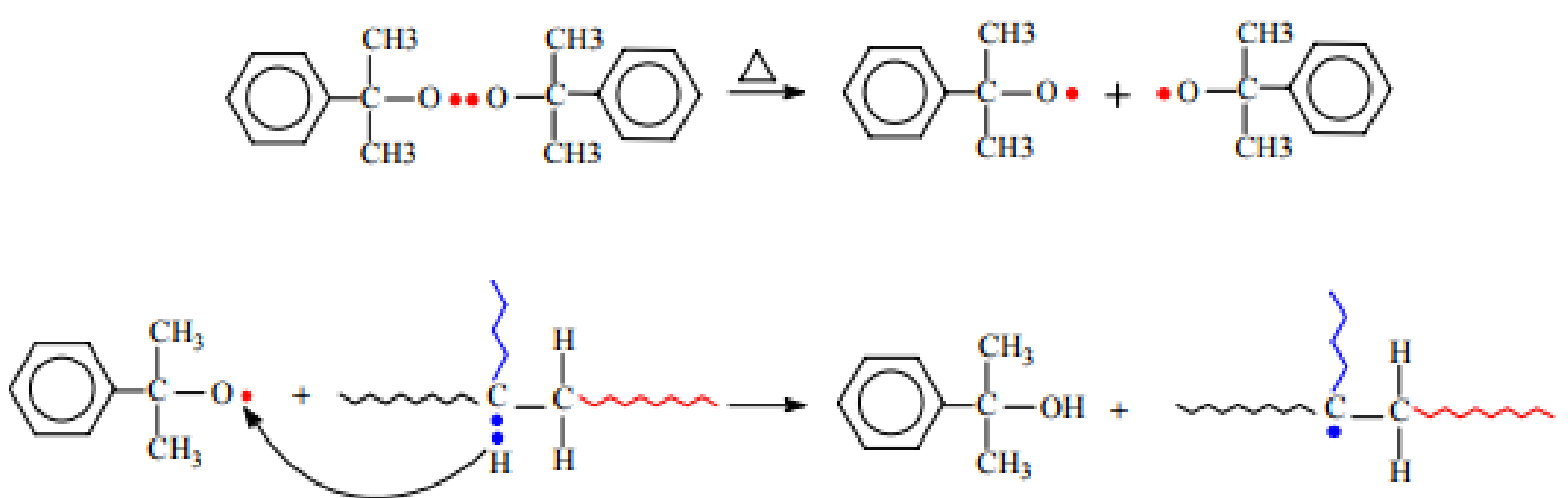

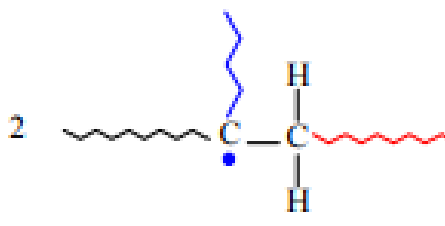

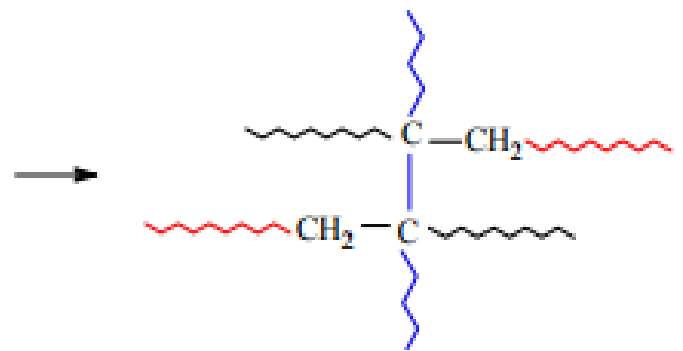

Fonte: Gulmine, 2004

\subsubsection{Reticulação por radiação}

O método de reticulação por radiação consiste em bombardear o polietileno com radiação proveniente de feixe de elétrons de alta energia ou radiação ultravioleta com a finalidade de provocar a formação de radicais livres nas cadeias causando a reticulação subsequente à retirada do hidrogênio. No processo de reticulação por radiação, o grau de reticulação é limitado pela profundidade de alcance do feixe de elétrons ou radiação ultravioleta ao longo da espessura do material (GULMINE, 2004). A figura 5 demonstra a reação química de obtenção do XLPE por meio de radiação. 
Figura 5 - Reações químicas por radiação

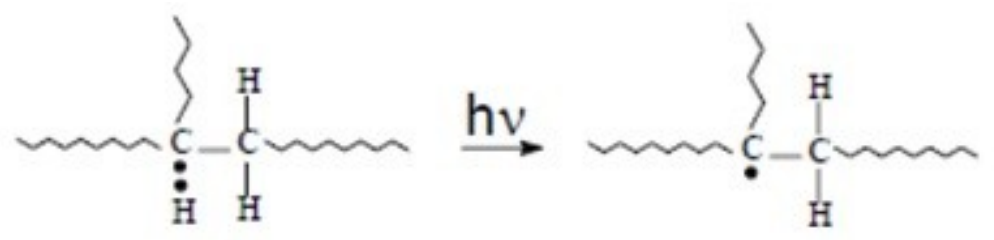

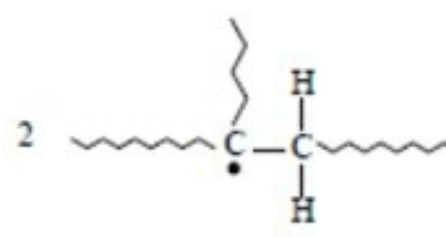

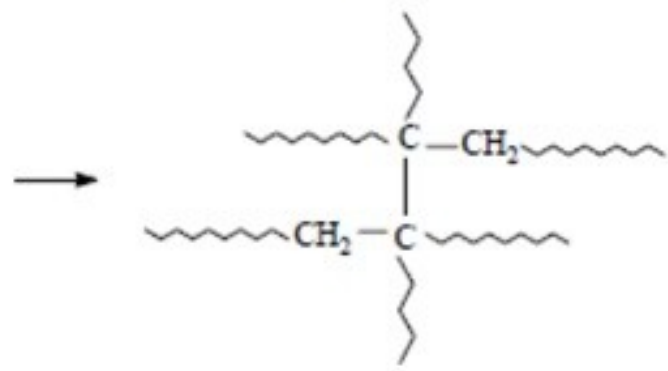

Fonte: Gulmine, 2004

\subsubsection{Reticulação por adição de silano}

O processo de reticulação envolvendo a adição de um organossilano ocorre em duas etapas, a primeira etapa consiste na graftização de viniltrietoxisilano ou viniltrimetoxisilano na cadeia principal do polietileno com auxílio de uma pequena quantidade de peróxido como iniciador. A segunda etapa o polímero é reticulado por hidrólise do silano e reação de condensação do silanol para a formação das ligações siloxano (GULMINE, 2004). A figura 6 mostra o método de reticulação por silano. 
Figura 6 - Método de reticulação por silano<smiles>CCCCC(CC)CCC[Si](OC)(OC)OC</smiles>

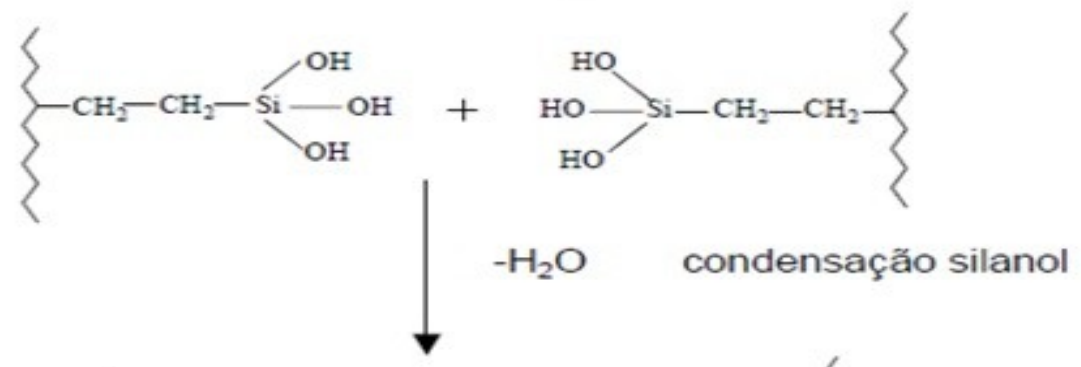<smiles>CCCCC(CC)CCCC(CCCC)CCCC</smiles>

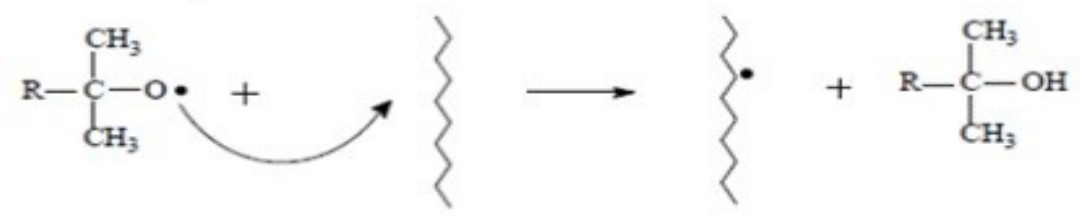

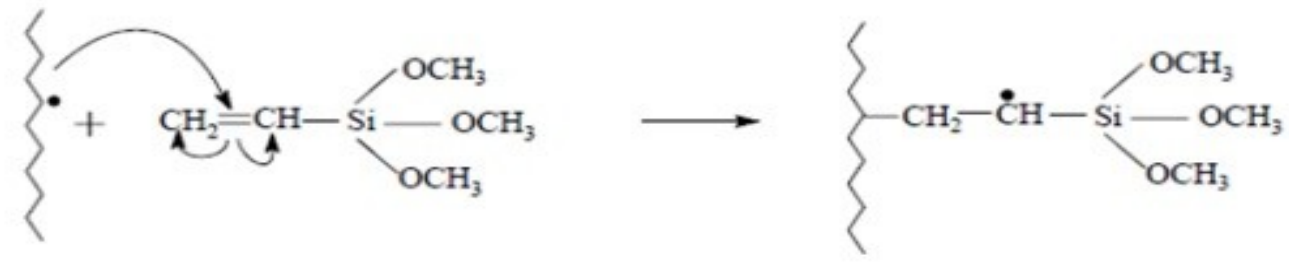

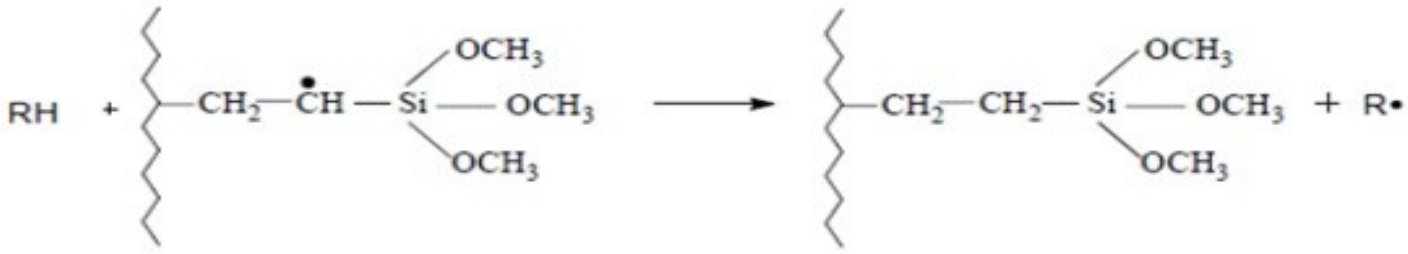

Fonte: Gulmine, 2004

A figura 7 ilustra a estrutura química do XLPE obtido através da adição de silano. 
Figura 7 - Estrutura química do XLPE obtido por adição de silano

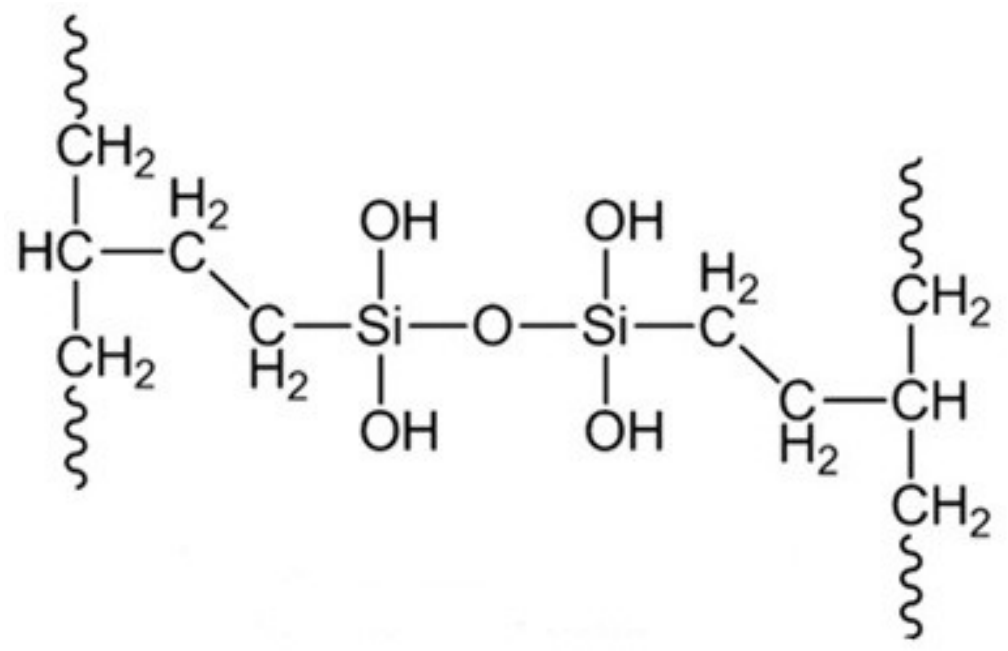

Fonte: Sirisinha e Chuaythong, 2014

\subsection{EFEITOS DA RETICULAÇÃO NAS PROPRIEDADES DO POLIETILENO}

Tamboli; Mhaske; Kale (2004) citam que os fatores positivos da reticulação do polietileno são: o aumento na resistência ao impacto, aumento à resistência à fissuração causada pelo meio ambiente (environmental stress cracking), resistência à fluência, sem afetar a resistência à tração e o módulo de flexão. A reticulação influencia positivamente no aumento da estabilidade dimensional quando este está sob a influência de temperaturas elevadas.

Tamboli; Mhaske; Kale (2004) citam que a mudança de termoplástico para termofixo aumenta o valor da viscosidade e diminui o índice de fluidez do polímero, e que o controle da reticulação num processo contínuo, como a extrusão de perfis, se torna muito complicado pois durante o processo, a formação excessiva de reticulação provoca a formação de tensões ao longo do perfil extrudado, gerando deformação e instabilidade dimensional.

Com relação às propriedades térmicas o polietileno termoplástico plastifica-se por volta de $120^{\circ} \mathrm{C}$, já o XLPE não sofre alteração devido à reticulação de suas cadeias moleculares (NEXANS, 2008).

A figura 8 mostra o comportamento mecânico do XLPE em comparação com PE termoplástico onde se observa um melhor desempenho do XLPE quando o mesmo é submetido à deformação na qual a temperatura de $110^{\circ} \mathrm{C}$ o XLPE apresenta uma deformação por volta de $15 \%$ já o polietileno termoplástico, apresenta $35 \%$ de deformação. Em tração, 
nota-se que a $100{ }^{\circ} \mathrm{C}$ o polietileno termoplástico não possui resistência a tração já o XLPE apresenta $0,4 \mathrm{kgf} / \mathrm{mm}^{2}$ (NEXANS, 2008).

Figura 8 - Propriedade mecânica do XLPE em função da temperatura
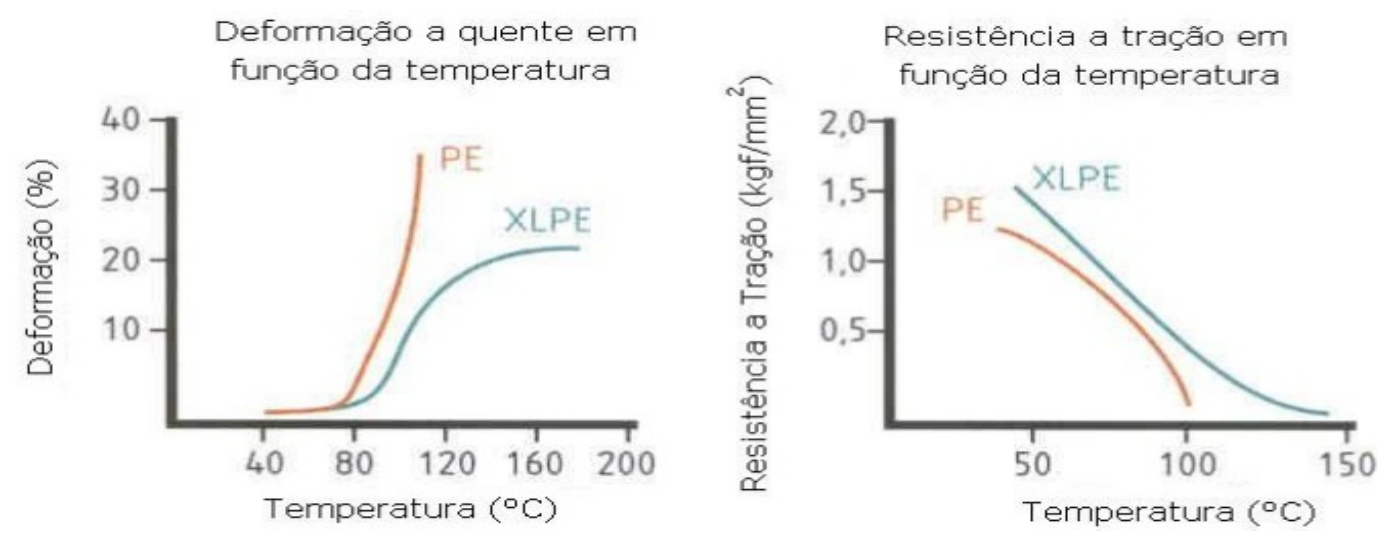

Fonte: Nexans, 2008

Com relação a propriedade elétrica, Nexans (2008) cita que a tensão de perfuração no XLPE é superior ao do polietileno termoplástico e mantém-se praticamente igual para temperaturas baixas. Para tensão de perfuração por impulsos, o mesmo permanece semelhante ao polietileno termoplástico. De modo geral, as propriedades elétricas do polietileno reticulado, tais como resistividade volumétrica, constante dielétrica e fator de perda são melhores ou iguais às do polietileno termoplástico.

\subsection{APLICAÇÕES DO POLIETILENO RETICULADO}

O polietileno reticulado pode ser utilizado em embalagens, isolamento elétrico, aplicações em espumas para isolamento e tubos para aquecimento de água. Em aplicações de embalagens é geralmente utilizado em filmes multicamadas, onde a camada reticulada fornece uma série de efeitos, incluindo o aumento da resistência à temperatura especialmente para esterilização à quente. Especialmente para a embalagem de forma irregular onde ao submeter ao calor, ocorre o encolhimento do filme. Em espumas, é utilizado em aplicações, como isolamento térmico, flutuação, guarnição automotiva e artigos esportivos onde as vantagens da reticulação, antes da formação de espuma, promove estrutura de células fechadas de alta qualidade que pode resultar nos seguintes benefícios: propriedades mecânicas aumentadas; aumento da resistência e recuperação da deformação; aumento da resistividade térmica. A principal aplicação de tubo de polietileno reticulado é para aplicação doméstica no qual água 
aquecida percorre através dos tudos, o benefício da reticulação do polietileno torna-se evidente em temperaturas acima da ambiente, onde é observada uma redução na taxa de fluência do tubo (TAMBOLI; MHASKE; KALE, 2004).

\subsubsection{XLPE em fios e cabos}

A área mais avançada de aplicação de polietileno reticulado é na utilização deste material como isolamento de cabos de média e alta voltagem (entre 10 e $110 \mathrm{kV}$ ). Embora não interfira nas propriedades dielétricas do polietileno, a reticulação fornece ao material certa resistência ao fluxo e à deformação permanente acima do ponto de amolecimento, ou seja, permite que o material não tenha problemas em ser utilizado em temperaturas pouco acima do que o estabelecido para o material virgem. No caso da utilização como reforço de fios e cabos elétricos, pode-se aumentar a temperatura do condutor, fazendo com que reduza o nível necessário de proteção contra curtos-circuitos e sobrecargas (SAECHTLING, 1995).

Segundo o USA Wire \& Cable, Inc. (2014), os tipos de isolantes poliméricos usados para revestir fios e cabos elétricos podem ser termoplásticos ou termofixos. Ao ser aquecido o isolante termoplástico torna-se liquido e flui para ser extrudado sobre os fios e é resfriado em água fria para solidificar novamente.

O isolante polímerico termofixo é extrudado sobre o fio e depois quando submetido a calor e pressão sofre uma mudança química conhecida como, reticulação ou cura. O processo fixa as propriedades físicas de modo que quando exposto novamente ao calor o material não venha a fundir, não flua e nem goteje. Na tabela 1 é apresentado os termofixos usados para aplicações de baixa tensão $(\leq 2 \mathrm{kV})$ e de alta tensão $(>2 \mathrm{kV})$ (USA WIRE \& CABLE, INC., 2014). 
Tabela 1 - Tipos de isolante polimérico para revestimento de fios e cabos elétricos com suas temperaturas de trabalho

\begin{tabular}{l|c}
\hline Polímero termofixo isolante para baixa tensão & Temperatura normal de trabalho $\left({ }^{\circ} \mathrm{C}\right)$ \\
\hline Polietileno reticulado (XLPE) & 90 \\
\hline Poliolefina reticulada (XLPO) & 90 \\
\hline Etileno-propileno com retardante de chama (FR-EP) & 90 \\
\hline Borracha de silicone & 90 \\
\hline Hypalon (PE clorosulfonado) & 90 \\
\hline
\end{tabular}

Fonte: Autor “ adaptado de" USA Wire \& Cable, Inc., 2014

\subsection{TÉCNICAS DE RECICLAGEM E REUTILIZAÇÃO DE XLPE}

Para a reciclagem de polietileno reticulado, existe um problema ao invés que termofixos por suas características inerentes são insolúveis e infusíveis, ou seja, para haver uma reciclagem deste tipo de material, há a necessidade de buscar soluções e técnicas alternativas (TAMBOLI; MHASKE; KALE, 2004).

Ainda não foi possível determinar uma maneira completamente eficiente de reciclagem de polímeros reticulados, porém, existem algumas alternativas que podem ser de grande utilidade como, por exemplo: (a) provocar uma trituração do material na temperatura ambiente e (b) uma sugestão de aplicar o método de cisalhamento em altas temperaturas, que gera a destruição parcial das ligações cruzadas de um polímero reticulado (OHKI, 2009).

A Figura 9 mostra a diferença nas aplicações dos dois métodos. No primeiro processo, a quebra dos resíduos de XLPE é feito por uma máquina cisalhante, um moinho, por exemplo, em temperatura ambiente, sem aquecimento ou resfriamento resultando em um pó fino de XLPE. O segundo processo já se mostra um pouco diferente, para que seja possível a execução, é necessário que o material seja cisalhado em altas temperaturas onde ocorrera a cisão de cadeia do XLPE. Este tipo de processo pode ser feito por uma extrusora de dupla rosca. 
Figura 9 - Duas alternativas de reciclagem de XLPE

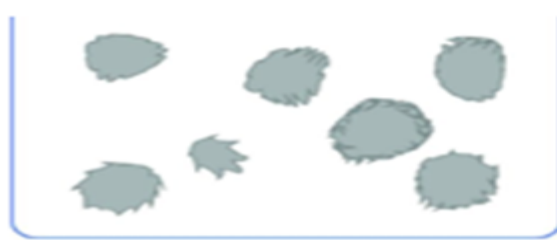

Resíduo de XLPE

Método de Cisalhamento no Estado Fundido
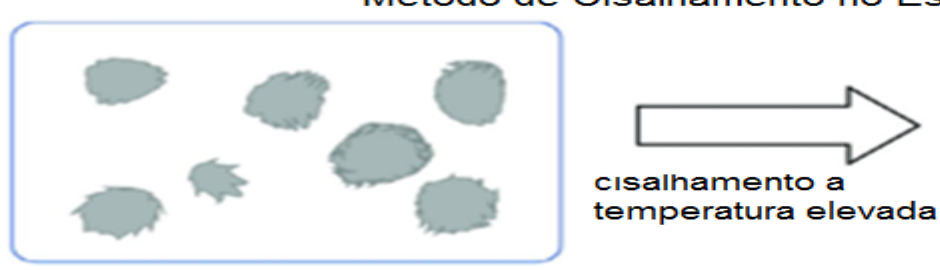

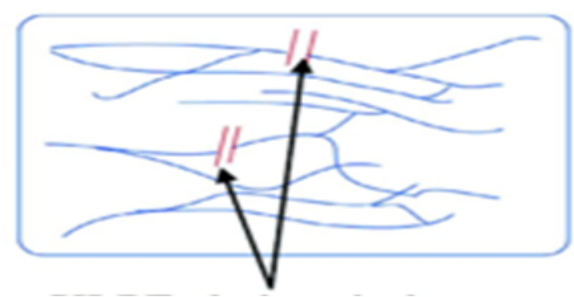

Cisão de cadeias de XLPE, ligações cruzadas destruídas

Fonte: Autor "adaptado de" Ohki, 2009

Kalyon; Hallouch; Fares (1984) citam que uma das sugestões viáveis para o reuso de resíduos termofixos é a moagem e incorporação em matriz termoplástica como carga de enchimento. Este processo geralmente possui dois estágios que consiste em micronizar a carga para posterior incorporação utilizando extrusora dupla-rosca.

Ogando (1992) conseguiu incorporar até 25\% em massa de XLPE micronizado em PE virgem. A mistura resultante pode, então, ser utilizada em rotomoldagem, moldagem por injeção e moldagem por sopro. Ensaios com amostras rotomoldadas revelaram que o tamanho da partícula faz uma grande diferença para o acabamento da superfície interior da peça; partículas de malha $35(0,5 \mathrm{~mm})$ resultaram em peças com um acabamento áspero. No entanto, partículas de malha $100(0,15 \mathrm{~mm})$ ou mais finas resultaram em peças com um acabamento de superfície "mais lisa". Observou que o aquecimento do PE reticulado para aproximadamente $175^{\circ} \mathrm{C}$ faz com que a superfície do mesmo se torne pegajosa, permitindolhe ligar-se a outros materiais.

Qudaih; Janajreh; Vukusic (2011) incorporaram 5, 10 e 15\% em massa de pó de XLPE, com tamanho médio de partículas de 1,25 mm, em LDPE virgem. A mistura foi feita em uma mini-extrusora e corpos de prova de tração foram injetados em mini-injetora. A incorporação de 15\% de XLPE no LDPE virgem, resultou em um aumento de 17\% no módulo de tração, $37,2 \%$ na tensão de escoamento, $22,4 \%$ na tensão de ruptura, e uma diminuição de $3,3 \%$ no ponto de fusão em relação ao material virgem.

Cucchiara e Bonse (2015) incorporaram 5, 10, 20 e 30\% em massa de XLPE em HDPE e observaram um aumento na resistência ao impacto de quase 10 vezes em relação ao 
HDPE com a incorporação de 5\% XLPE. A partir deste teor, houve uma queda gradual, porém, ainda mantendo valores muito superiores ao do HDPE puro.

Tokuda et al. (2003) realizaram a reciclagem do XLPE reticulado por peróxido e por silano através do método de cisalhamento onde foi utilizado uma extrusora monorrosca com diâmetro de $40 \mathrm{~mm}$, temperatura do cilindro $160^{\circ} \mathrm{C}$ e matriz $180^{\circ} \mathrm{C}$. Através desta tecnologia tanto o polietileno reticulados com peróxido quanto o reticulado com silano podem se tornar termoplásticos com índice de fluidez que varia de 0,1 a $30 \mathrm{~g} / 10 \mathrm{~min}$.

Tokuda et al. (2003) confirmam que a tecnologia de reciclagem de termoplásticos realizada por cisalhamento de cadeia, permite que o polietileno reticulado seja reutilizado. A tecnologia apresentada é altamente viável do ponto de vista da produtividade e do custo, e parece ser um método efetivo de redução do impacto ambiental ao reutilizar os resíduos de polietileno reticulados que, no passado, foram usados como combustível ou descartados como resíduos industriais. 


\section{MECANISMO DE TENACIFICAÇÃO DOS POLÍMEROS}

Segundo Costa (2009), a tenacidade é a capacidade de absorção deformacional de impacto, ou seja, absorção de energia de um material até a sua fratura. Este parâmetro é um dos mais importantes onde através do resultado, pode-se determina se o polímero pode ser utilizado como material de engenharia. O maior desafio no desenvolvimento de materiais tenacificados utilizando elastômeros, não é somente a melhora no desempenho da resistência à fratura, mas também a mínima perda das propriedades tração, módulo de elasticidade, transparência e viscosidade. Quando se aplica uma tensão em materiais reforçados com elastômeros, as partículas elastoméricas dispersas na matriz termoplástica concentram ou absorvem a tensão aplicada provocando uma mudança do estado de tensão da fase matricial sendo assim, ocorre uma intensa deformação plástica aumentando a resistência ao impacto.

Segundo Canevarolo (2004), os materiais poliméricos são caracterizados mecanicamente com a finalidade de observar seu comportamento quando o mesmo é utilizado em aplicações estruturais. A análise de resistência ao impacto é uma das propriedades mais requisitadas para avaliar o comportamento mecânico de polímeros na qual demonstra a capacidade de um material suportar choques acidentais e decidir se o material suporta tal solicitação para uma determinada aplicação.

A tenacidade pode ser medida através de diversas taxas de solicitação mecânica, ou seja, solicitações em baixas velocidades através de ensaios de tração e flexão convencionais, ou ensaios em alta velocidade como é realizado no ensaio de resistência ao impacto (CANEVAROLO, 2004).

Oliveira (2009) classifica os mecanismos de deformação em polímeros vítreos como escoamento por cisalhamento e escoamento por microfibrilamento. Conforme as características de alguns polímeros podem ocorrer um ou outro mecanismo também podendo ocorrer os dois mecanismos simultaneamente, com ou sem interação um com o outro.

O escoamento por cisalhamento é um importante mecanismo que pode conduzir à deformação plástica em polímeros sob carregamento mecânico. Deformações cisalhantes consistem de uma distorção de forma sem significante mudança de volume. Em materiais semicristalinos o microescoamento por cisalhamento ocorre por escorregamento de planos específicos em regiões sujeitas a altas deformações cisalhantes. Em materiais não cristalinos, as grandes deformações requerem um movimento mais cooperativo dos segmentos moleculares e os processos de cisalhamento são, portanto, menos localizados. A orientação molecular dentro das bandas de cisalhamento é aproximadamente paralela à direção da tensão 
aplicada, e, portanto, normal ao plano em que as trincas são formadas, tendo assim o efeito de limitar o crescimento das trincas. Com o aumento no número de bandas de cisalhamento, o comprimento de novas trincas diminui (CUSTÓDIO, 2010).

Custódio (2010) cita que o escoamento por microfibrilas é responsável pela estabilização dos crazes, que é formado sob condições de tração. Quando submetido à compressão, o escoamento ocorre através da deformação por cisalhamento onde o microfibrilamento múltiplo que está sob tensão é suprimido, este fato é esperado em vista que o microfibrilamento múltiplo sob tensão é um processo dilatacional.

\subsection{EFEITO DO TAMANHO DE PARTÍCULA NA TENACIFICAÇÃO}

Rabello (2000) menciona que o comportamento mecânico do polímero tenacificado por borracha está diretamente relacionado com a sua morfologia onde tamanho de partícula, teor de borracha e grau de adesão entre as fases definem o sucesso do aditivo. Um fato importante é o tamanho das partículas que define a área de contato com a matriz, cuja resistência geralmente aumenta com a redução do tamanho de partícula anisométrica. A distribuição de transferência de tensões é mais eficiente quando a razão de aspecto é alta, ou seja, a maior eficiência se da em partículas esféricas onde a razão de aspecto é igual a um.

Um fato de relevância é a miscibilidade entre as fases onde o recomendado é que não haja, pois a total miscibilidade impede a formação de partículas de borracha que, por ventura, inviabilizaria o mecanismo de tanacificação. $\mathrm{O}$ termo miscibilidade, difere de compatibilidade onde o primeiro, implica na formação de uma fase única com dispersão a nível molecular, já a compatibilidade é ocorre quando a mistura de dois polímeros atinge determinadas propriedades físicas desejadas (RABELLO, 2000). 


\section{MATERIAIS E MÉTODOS}

Nesta seção serão apresentados os materiais utilizados e métodos para obtenção do composto e corpos de prova para análise.

\subsection{MATERIAIS}

Nesta seção serão apresentados os detalhamentos dos materiais empregados para obtenção dos compostos.

\subsubsection{Polietileno de alta densidade}

O polietileno de alta densidade utilizado foi gentilmente cedido pela empresa Aditive Plástico Ltda. na forma de pellets. A especificação do HDPE é o GE7252 que possui IF de 2,0 $\mathrm{g} / 10 \mathrm{~min}\left(190^{\circ} \mathrm{C}\right.$ e $\left.2,16 \mathrm{~kg}\right)$ e densidade de $0,952 \mathrm{~g} / \mathrm{cm}^{3}$, conforme fornecedor Braskem tabela 2.

Tabela 2 - Propriedades do material Polietileno de Alta Densidade GE7252 Braskem.

\begin{tabular}{l|c|c|c}
\hline Propriedade de Controle & Método ASTM & Unidades & Valores \\
\hline & D 1238 & $\mathrm{~g} / 10 \mathrm{~min}$ & 2,0 \\
\hline Índice de fluidez & D 792 & $\mathrm{~g} / \mathrm{cm}^{3}$ & 0,952 \\
\hline Densidade &
\end{tabular}

\begin{tabular}{|c|c|c|c|}
\hline \multicolumn{4}{|l|}{ Propriedades Típicas } \\
\hline \multicolumn{4}{|c|}{ Propriedades de Referência em Placa Prensada Método ASTM D 4703} \\
\hline & $\begin{array}{c}\text { Método } \\
\text { ASTM }\end{array}$ & Unidades & Valores \\
\hline Tensão de Escoamento & D 638 & $\mathrm{MPa}$ & 26 \\
\hline Tensão de Ruptura & D 638 & $\mathrm{MPa}$ & 32 \\
\hline Alongamento no Escoamento & D 638 & $\%$ & 9 \\
\hline Alongamento na Ruptura & D 638 & $\%$ & 400 \\
\hline Módulo de flexão secante 1\% & D 790 & $\mathrm{MPa}$ & 1100 \\
\hline Resistência a Quebra sob Tensão Ambiental & D 1693 B & $\mathrm{h} / \mathrm{F} 50$ & 15 \\
\hline
\end{tabular}

Fonte: Autor, "Adaptado de" Folha de Dados Braskem, 2017 revisão 6 (Dez/15) 


\subsubsection{Resíduo de polietileno reticulado (XLPE)}

O resíduo de XLPE utilizado para incorporação no HDPE é proveniente de rejeitos de uma indústria de revestimento de fios e cabos elétricos, doado pela empresa FAEX Soluções Ambientais Ltda na forma moída conforme figura 10.

Figura 10 - XLPE moído recebido da empresa FAEX Soluções Ambientais Ltda

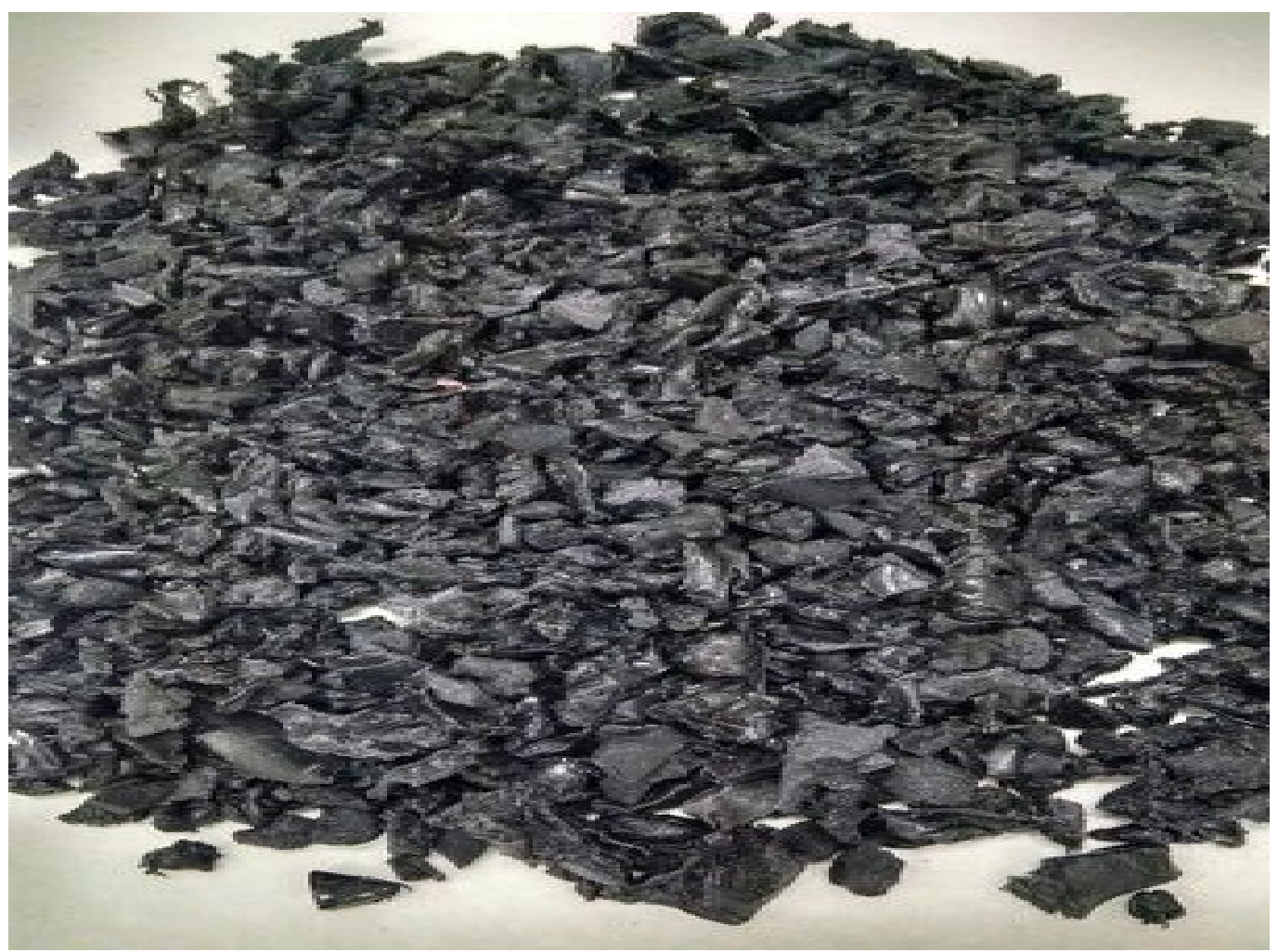

Fonte: Autor

\subsection{MÉTODOS}

Nesta seção serão apresentados a metodologia para obtenção tanto dos compostos como dos corpos de prova.

\subsubsection{Micronização do XLPE}

O resíduo de XLPE foi micronizado na empresa KARINA Indústria e Comercio de Plásticos situada na cidade de Guarulhos - SP. Não foi possível obter dados referentes aos equipamentos utilizados para o processo de micronização. 


\subsubsection{Peneiramento}

O peneiramento que foi realizado para separação do material micronizado em amostras com os tamanhos médios de 100, 500 e $900 \mu \mathrm{m}$, foi realizado na Faculdade SENAI de Tecnologia Ambiental.

O equipamento utilizado para a realização do peneiramento foi um agitador vibratório de peneiras modelo Analysette3 Pro da marca Fritsch.

Para realizar a separação do tamanho de partícula, foi montado um conjunto de 4 peneiras de mesh 35, 45, 100 e 140 que representa $500 \mu \mathrm{m}, 355 \mu \mathrm{m}, 150 \mu \mathrm{m}$ e $106 \mu \mathrm{m}$ respectivamente conforme apresentada na figura 11 .

Figura 11 - Agitador vibratório de peneiras modelo Analysette3 Pro da marca Fritsch

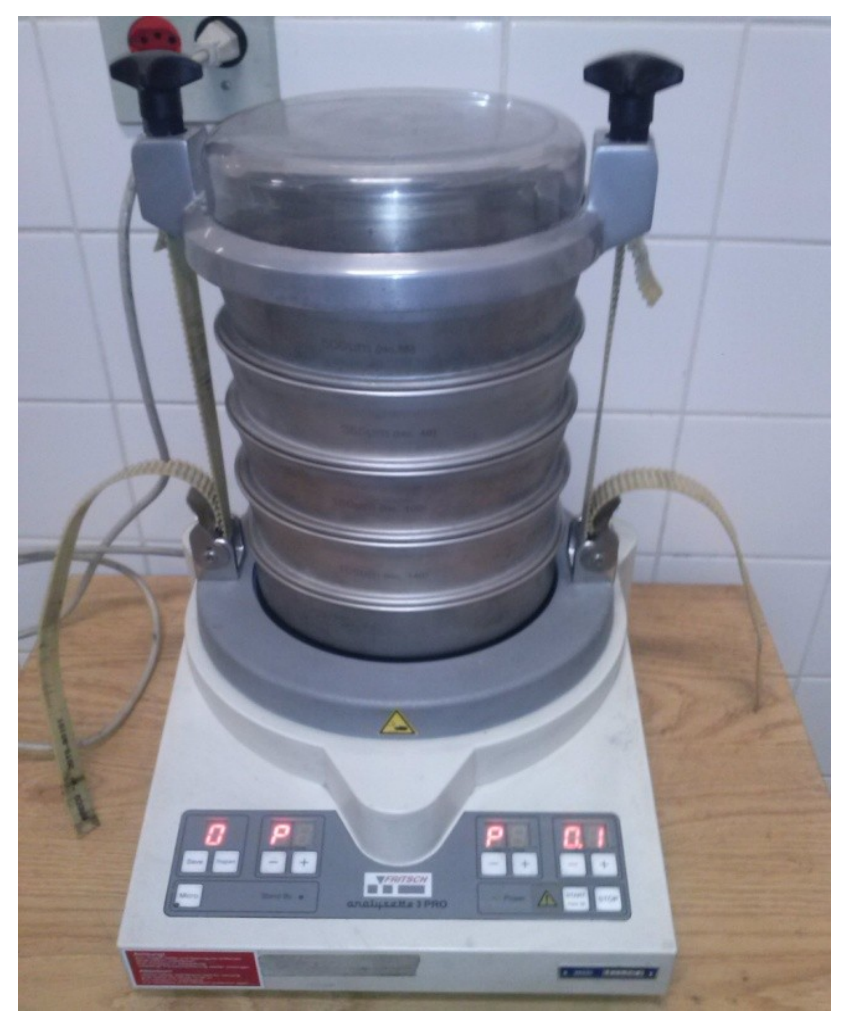

Fonte: Autor

O tempo de peneiramento variou de 20 a 30 minutos e foi utilizada uma amplitude de 0,6 $\mathrm{mm}$. Após este período foi coletado o material que permaneceu retido entre a peneira de 35 e 45 mesh para obtenção do tamanho de partícula de $500 \mu \mathrm{m}$ e o material que ficou condicionado na bandeja abaixo da peneira de 140 mesh para obtenção do tamanho de partícula de $100 \mu \mathrm{m}$. 
Para obter tamanho de partícula de $900 \mu \mathrm{m}$, foi utilizada uma peneira de 20 mesh que representa $850 \mu \mathrm{m}$. Este processo foi realizado separadamente, pois o tempo de 20 a 30 minutos fazia com que as partículas não ficassem retidas na peneira, devido ao formato da partícula e quantidade nesta faixa de tamanho. O tempo de processamento foi de 1 minuto utilizando amplitude de $1 \mathrm{~mm}$.

\subsubsection{Obtenção do concentrado de XLPE}

Após o peneiramento do XLPE nos tamanhos médios de 100, 500 e $900 \mu \mathrm{m}$, observou-se que haveria dificuldade de incorporação devido aos baixos teores de 1, 5 e 9\%, o que poderia implicar em perdas na pré-mistura e na extrusora, além de uma má dispersão. Diante do pressuposto, optou-se por produzir um concentrado de XLPE em HDPE para obter uma melhor dispersão na matriz de HDPE. Para a produção do concentrado, foi utilizada uma composição de 70/30 de HDPE/XLPE. O HDPE utilizado para produção do concentrado foi o mesmo utilizado para produção do composto final.

O concentrado foi produzido em uma calandra da marca Mecanoplast modelo C-400 2M localizada no núcleo do plástico na escola SENAI Mario Amato.

Para a produção do concentrado, foi utilizada uma temperatura de $160^{\circ} \mathrm{C}$ no cilindro traseiro e $166^{\circ} \mathrm{C}$ no cilindro dianteiro. A tabela 3 mostra os tempos de processamento de cada concentrado. Foi processada uma amostra somente de HDPE para controle.

Tabela 3 - Tempos de processamento do concentrado XLPE em HDPE

\begin{tabular}{c|c|c|c|c}
\hline Amostras & $\begin{array}{c}\text { Fusão HDPE } \\
(\mathrm{min} .)\end{array}$ & $\begin{array}{c}\text { Adição de XLPE } \\
(\mathrm{min} .)\end{array}$ & $\begin{array}{c}\text { Mistura } \\
(\min .)\end{array}$ & Total (min.) \\
\hline HDPE controle & $5: 10$ & ----- & $4: 30$ & $9: 40$ \\
\hline HDPE/XLPE $100 \mu \mathrm{m}$ & $05: 30$ & $06: 30$ & $03: 47$ & $15: 47$ \\
\hline HDPE/XLPE $500 \mu \mathrm{m}$ & $03: 20$ & $06: 40$ & $04: 20$ & $14: 20$ \\
\hline HDPE/XLPE $900 \mu \mathrm{m}$ & $05: 50$ & $04: 25$ & $03: 45$ & $14: 00$ \\
\hline
\end{tabular}

Fonte: Autor

A figura 12 ilustra o início do processamento do concentrado, ou seja, a adição de HDPE 
Figura 12 - Inicio do processamento com adição de HDPE

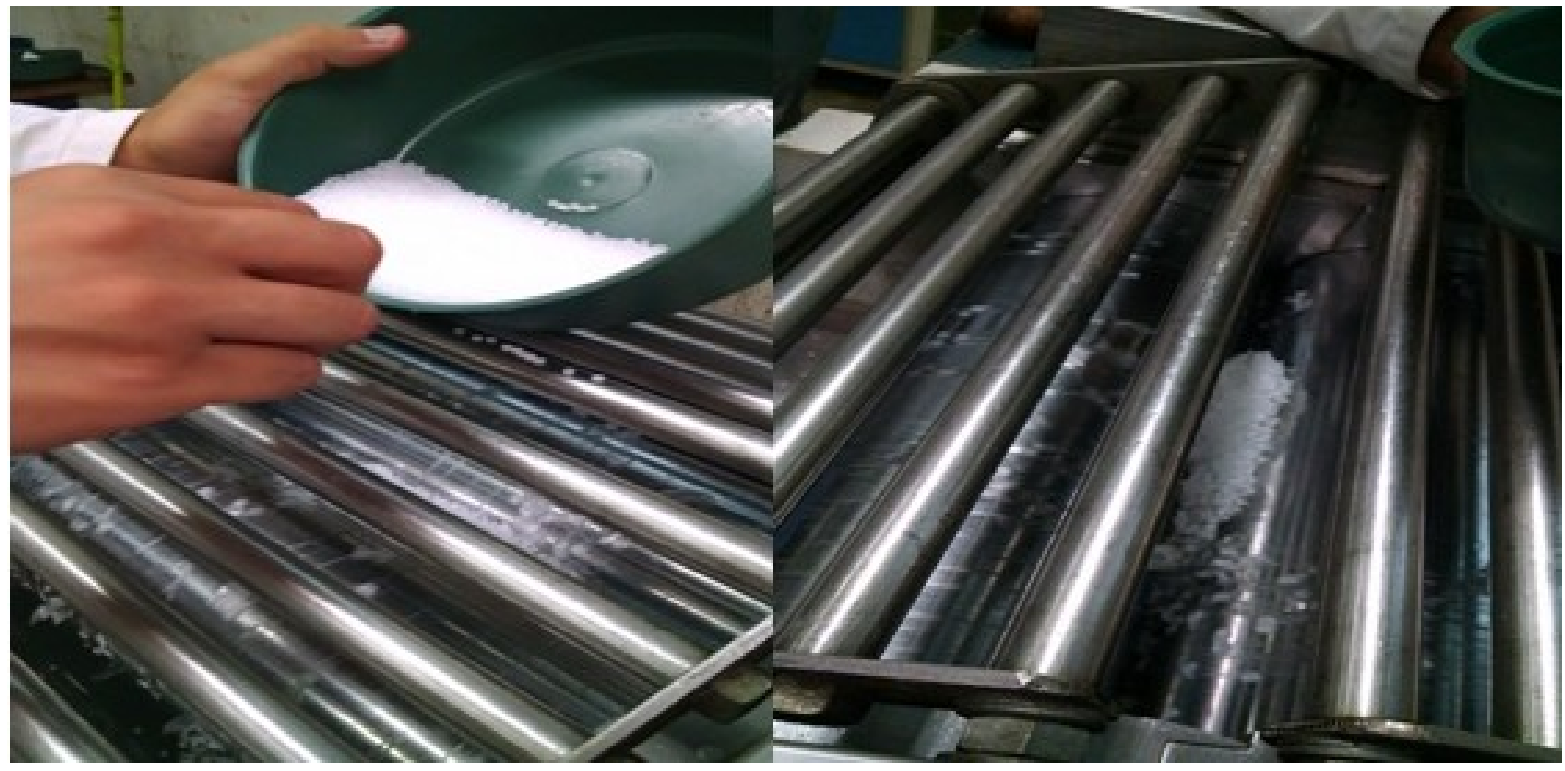

Fonte: Autor

Após a fusão do HDPE, é adicionado o XLPE como mostra a figura 13.

Figura 13 - Adição de XLPE

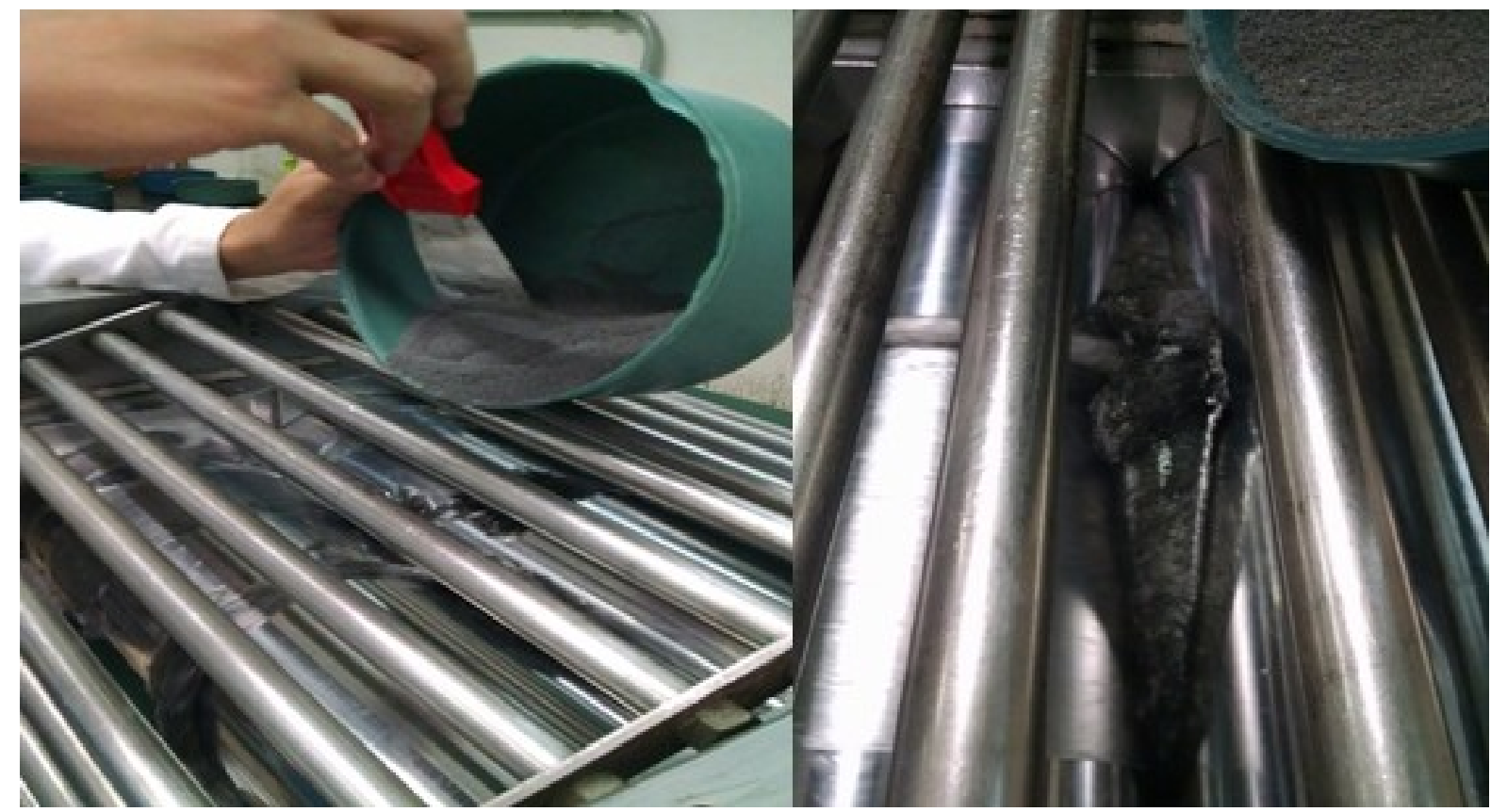

Fonte: Autor

Ao terminar a adição do XLPE, inicia-se o processo de mistura e homogeneização do concentrado conforme figura 14. 
Figura 14 - Mistura e homogeneização do concentrado de XLPE

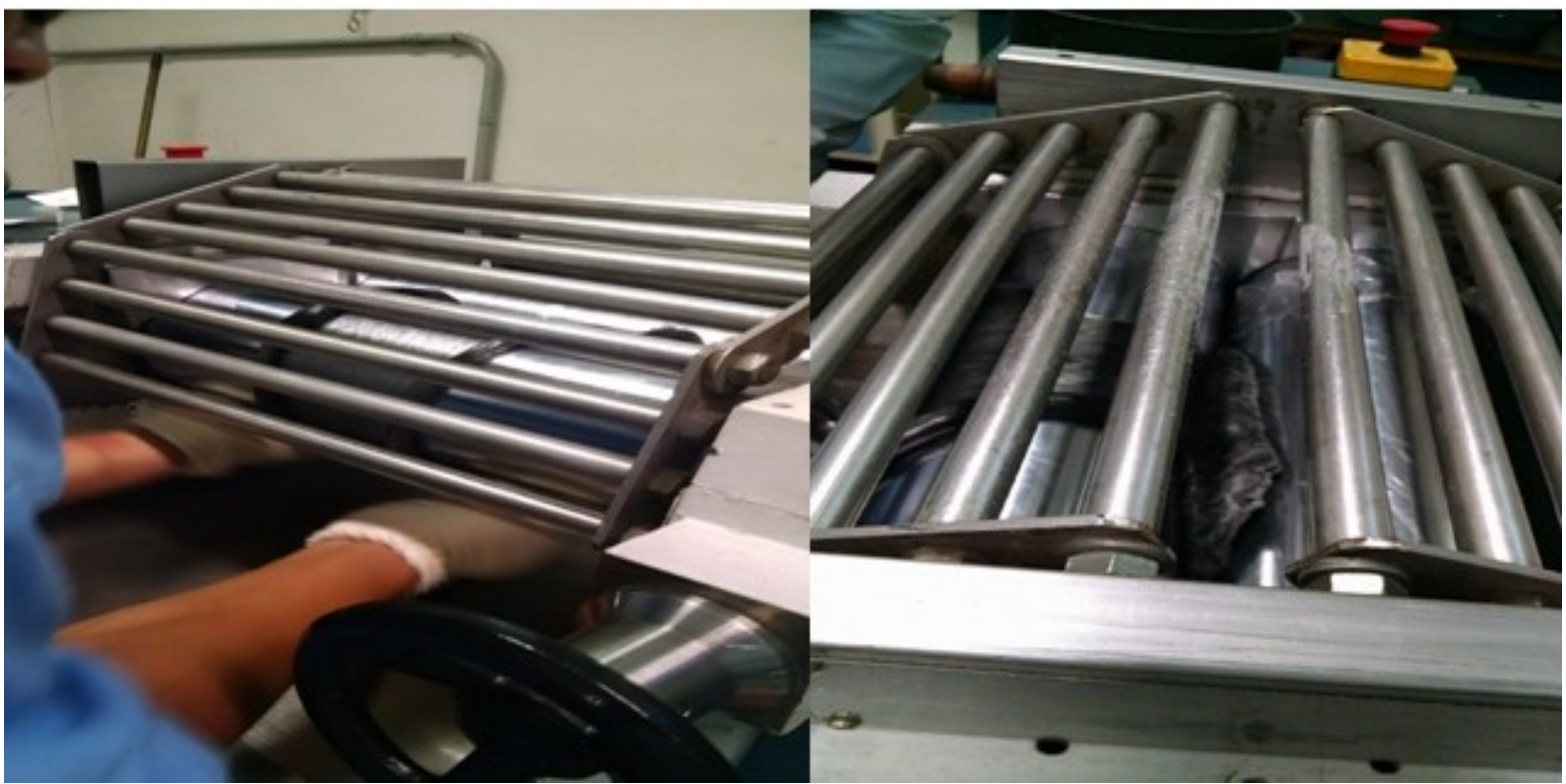

Fonte: Autor

Após mistura e homogeneização do concentrado, o mesmo foi retirado seguindo uma forma de manta para posterior moagem. A figura 15 ilustra a retirada do concentrado no formato de manta.

Figura 15 - Retirada do concentrado em forma de manta

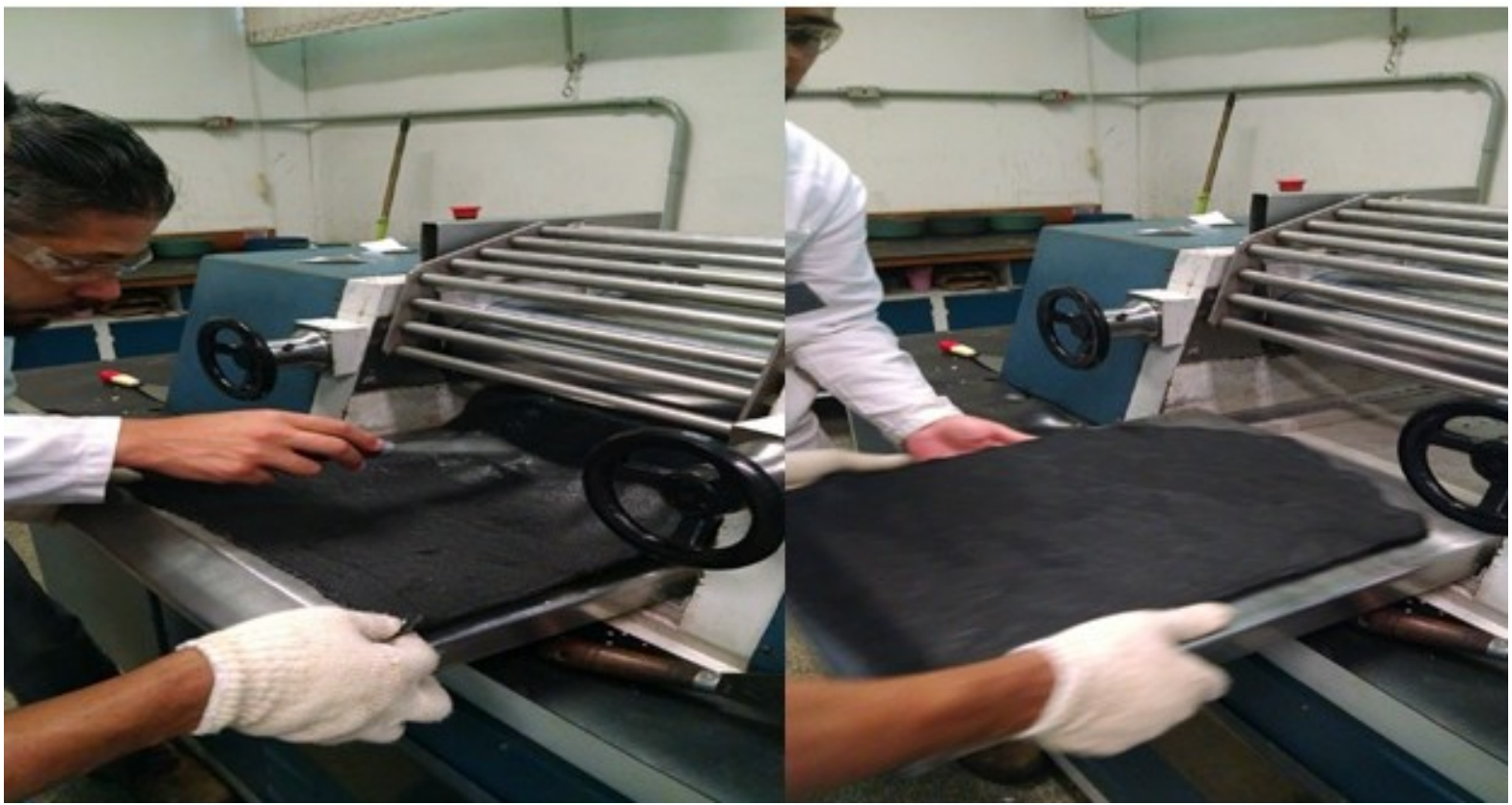

Fonte: Autor 
A figura 16 mostra as mantas dos concentrados de XLPE em HDPE e do HDPE controle.

Figura 16 - Mantas do concentrado de XLPE em HDPE e HDPE controle

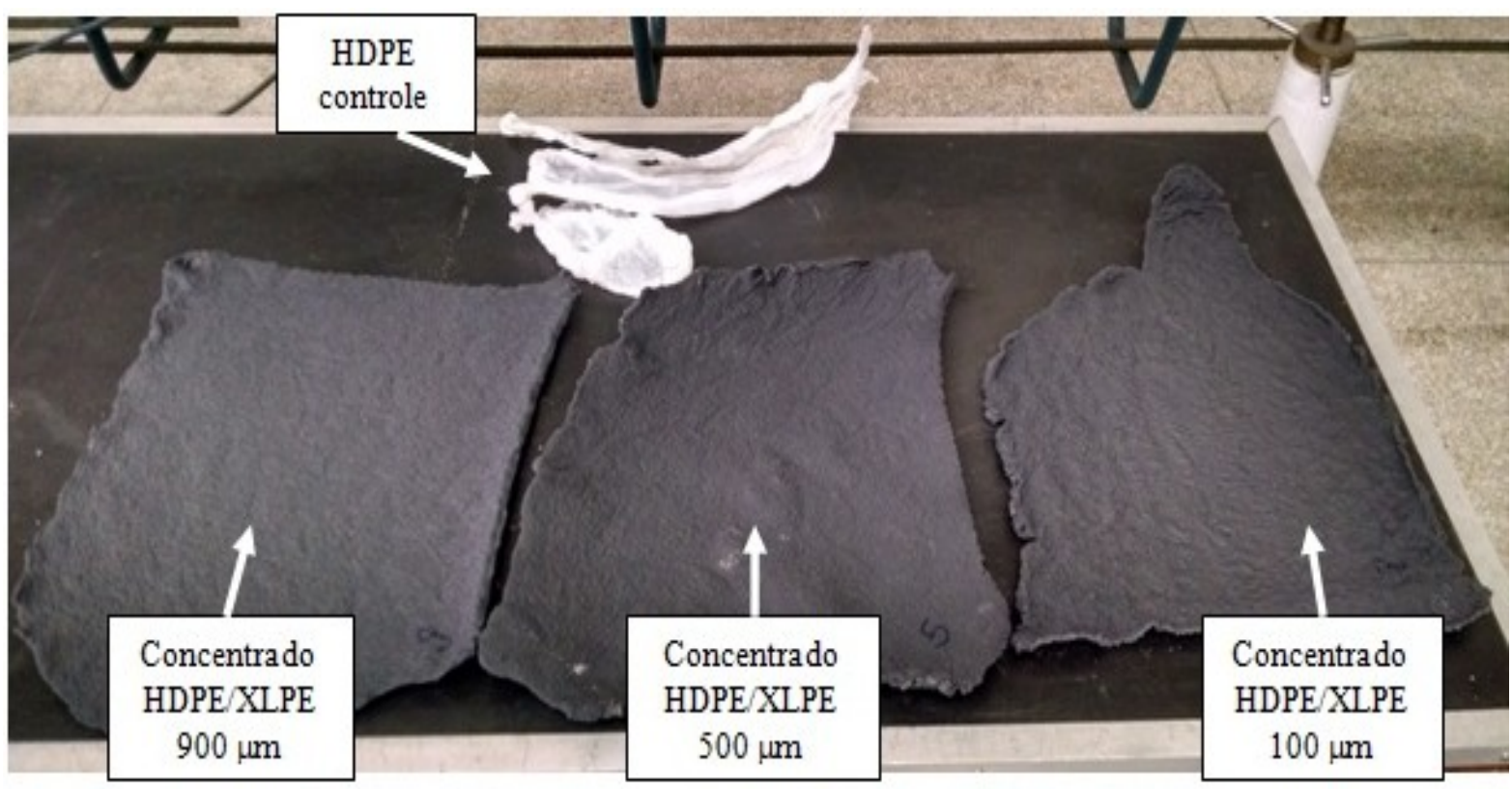

Fonte: Autor

\subsubsection{Moagem das mantas do concentrado de XLPE em HDPE}

Após a produção das mantas do concentrado de XLPE em HDPE, as mesmas passaram por um processo de moagem para posteriormente ser adicionado em HDPE. Antes da realização da moagem, as mantas foram cortadas em pequenos pedaços para facilitar o processo de moagem. $\mathrm{O}$ corte foi realizado com uma tesoura convencional.

Após a realização do corte, os pedaços foram moídos em um moinho de facas da marca Mecanofar modelo MF 230 R localizado no laboratório de materiais do Centro Universitário FEI.

Durante a moagem, foi utilizada uma peneira com abertura de $1,5 \mathrm{~mm}$ para padronizar o tamanho do material moído.

\subsubsection{Obtenção do composto}

Para formular o composto, foi utilizado um planejamento estatístico $2^{2}$, com dois níveis (superior $(+1)$ e inferior $(-1)$ ) e ponto central (0), conforme tabela 4 , variando o teor de XLPE e tamanho de partícula com a finalidade de pesquisar baixos teores de XLPE, já que em 
trabalho anterior Cucchiara e Bonse (2015), ao pesquisar teores de 5, 10, 20 e 30\% de XLPE em HDPE, obtiveram maior resultado na propriedade impacto em teor de 5\% XLPE, a partir deste teor ou seja 10, 20 e 30\% a propriedade diminuía, porém, mantendo valores maiores que a do HDPE puro.

Tabela 4 - Planejamento experimental $2^{2}$ com ponto central

\begin{tabular}{c|c|c|c|c}
\hline & \multicolumn{2}{|c|}{ Variáveis descodificadas } & \multicolumn{2}{c}{ Variáveis codificadas } \\
\hline Composto & $\begin{array}{c}\text { Teor de XLPE } \\
(\%)\end{array}$ & $\begin{array}{c}\text { Tamanho de partícula } \\
(\mu \mathrm{m})\end{array}$ & \%XLPE & $\begin{array}{c}\text { Tamanho de } \\
\text { partícula }\end{array}$ \\
\hline $\begin{array}{c}\text { XLPE } \\
1-100\end{array}$ & 1 & 100 & -1 & -1 \\
\hline XLPE & 1 & 900 & -1 & +1 \\
$1-900$ & 9 & 100 & +1 & -1 \\
\hline $\begin{array}{l}\text { XLPE } \\
9-100\end{array}$ & 9 & 900 & +1 & +1 \\
\hline $\begin{array}{l}\text { XLPE } \\
9-900\end{array}$ & 5 & 500 & 0 & 0 \\
\hline XLPE & & & & \\
$5-500$ & & & & \\
\hline
\end{tabular}

Fonte: Autor

As misturas físicas de HDPE com o XLPE foram obtidas manualmente, em saco plástico, dos sólidos de HDPE e o concentrado de XLPE, devidamente moído.

Após a mistura física, o composto foi processado através de mistura termomecânica em uma extrusora corrotacional de dupla rosca com diâmetro $\mathrm{D}=16 \mathrm{~mm}$ e razão de comprimento sobre diâmetro $\mathrm{L} / \mathrm{D}=25$. O modelo da extrusora é Thermoscientific Haake Rheomex PTW 16 OS, alocada no laboratório de materiais do Centro Universitário da FEI.

Para extrusão dos compostos HDPE/XLPE e HDPE puro, foi utilizado um perfil de rosca com baixo cisalhamento para evitar uma possível degradação no material. A figura 17 ilustra o perfil de rosca utilizado para o processamento dos compostos. 
Figura 17 - Perfil de rosca modular utilizado para extrusão dos compostos HDPE/XLPE e HDPE puro

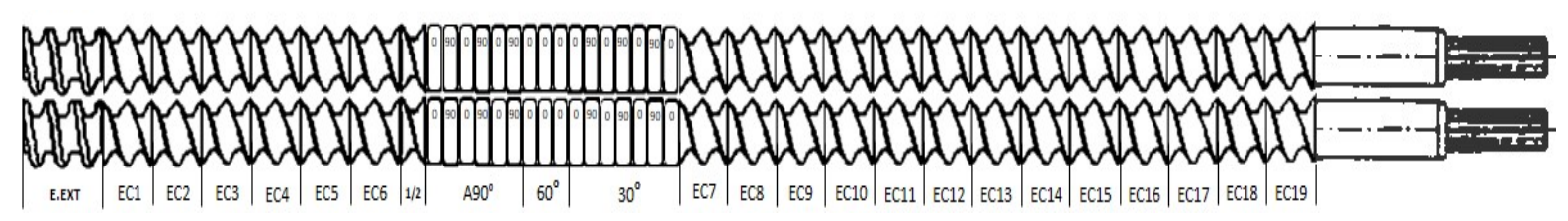

Fonte: Autor

Os fios extrudados foram resfriados em banheira contendo água à temperatura ambiente, para posterior picotamento com a finalidade de deixar o material na forma de pellets para então utilizá-los na injeção de corpos de prova para avaliar as propriedades mecânicas, térmica e morfológica.

Ao término do picotamento os pellets foram colocados em estufa de ar circulante modelo $320 \mathrm{E}$ da marca FANEM a temperatura de $80^{\circ} \mathrm{C}$ por 30 minutos com a finalidade de retirar umidade devido ao processamento.

Os parâmetros de processamento por extrusão são mostrados na tabela 5.

Tabela 5 - Parâmetros de processamento por extrusão

\begin{tabular}{c|c}
\hline Parâmetros de extrusão & Valores \\
\hline Zona de aquecimento TS1 (alimentação) & $190^{\circ} \mathrm{C}$ \\
\hline Zona de aquecimento TS2 & $195^{\circ} \mathrm{C}$ \\
\hline Zona de aquecimento TS3 & $195^{\circ} \mathrm{C}$ \\
\hline Zona de aquecimento TS4 & $195^{\circ} \mathrm{C}$ \\
\hline Zona de aquecimento TS5 & $195^{\circ} \mathrm{C}$ \\
\hline Zona de aquecimento TS6 (cabeçote) & $190^{\circ} \mathrm{C}$ \\
\hline Rotação da rosca principal & $250 \mathrm{rpm}$ \\
\hline Alimentação & $1.3 \mathrm{~kg} / \mathrm{h}$ \\
\hline Torque & 29 à $42 \mathrm{Nm}$ \\
\hline
\end{tabular}

Fonte: Autor

\subsubsection{Obtenção dos corpos de prova}

Os corpos de prova para os ensaios mecânicos e térmicos foram obtidos por injeção realizada em uma máquina injetora modelo Battenfeld HM 60/350 localizada no laboratório de materiais do Centro Universitário da FEI. A moldagem dos corpos de prova foi realizada através de um molde de duas cavidades o qual permite a moldagem simultânea de corpos de 
prova de tração, flexão e impacto seguindo as normas ASTM D638-08 (tipo I), D6160-08 e D790-08.

A tabela 6 demonstra os parâmetros utilizados para injeção dos corpos de prova para caracterização.

Tabela 6 - Parâmetros de processo de injeção dos corpos de prova

\begin{tabular}{l|l}
\hline \multicolumn{2}{c}{ Parâmetros de Injeção } \\
\hline Velocidade de injeção & $50 \mathrm{~mm} / \mathrm{s}$ \\
\hline Pressão de injeção & $700 \mathrm{bar}$ \\
\hline Volume injeção & $20 \mathrm{~cm}^{3} / \mathrm{s}$ \\
\hline Volume recalque & $8,01 \mathrm{~cm}^{3}$ \\
\hline Pressão de Recalque & $560 \mathrm{bar}$ \\
\hline Tempo de recalque & $12 \mathrm{~s}$ \\
\hline Tempo de resfriamento & $15 \mathrm{~s}$ \\
\hline
\end{tabular}

Perfil de temperatura de injeção

\begin{tabular}{l|l}
\hline Temperatura & ${ }^{\circ} \mathrm{C}$ \\
\hline Bico & 220 \\
\hline Molde & 50 \\
\hline Zona 1 & 215 \\
\hline Zona 2 & 210 \\
\hline Zona 3 (alimentação) & 200 \\
\hline
\end{tabular}

Fonte: Autor

\subsection{CARACTERIZAÇÃO}

Os compostos foram caracterizados avaliando as suas propriedades de engenharia: Mecânico: tração, flexão e impacto; Térmico: HDT e Morfológicos: MEV. A seguir será descriminada a metodologia aplicada na execução de cada ensaio inclusive a distribuição do tamanho das partículas do XLPE micronizadas e peneiradas. 


\subsubsection{Análise da distribuição do tamanho de partícula}

O ensaio foi realizado a fim de conhecer a distribuição do tamanho de partícula após o peneiramento do XLPE micronizado. A análise foi realizada em um analisador de partículas a laser Microtrac Bluewave no modo seco. Este equipamento permite analisar distribuição granulométrica tanto em via seca, quanto em via úmida mediante a utilização de acessórios como Turbotrac para via seca e Hydrotrac para via úmida. O ensaio foi realizado com o acessório Turbotrac, o qual utiliza ar como fluido de carregamento das amostras até o detector. O fluxo de ar é gerado por um aspirador de pó, onde a amostra é aspirada do portaamostra e conduzida até o detector. O resultado fornecido pelo equipamento são as curvas de distribuição de tamanho das partículas.

\subsubsection{Ensaio de tração}

No ensaio de tração, aplica-se uma carga uniaxial que provoca o alongamento do material a uma velocidade constante de atuação, registrando simultaneamente a carga instantânea aplicada em função da deformação do corpo de prova. O dimensional do corpo de prova é padronizado e atende os critérios da norma D638 (ASTM, 2014). Para o ensaio foram utilizados cinco corpos de prova seguindo os parâmetros: Temperatura ambiente; Célula de carga: $5 \mathrm{kN}$; Taxa de deformação $50 \mathrm{~mm} / \mathrm{min}$ (para módulo elástico e tensões) e $500 \mathrm{~mm} / \mathrm{min}$ (para deformação na ruptura); Extensômetro de $50 \mathrm{~mm}$ para determinar o módulo de elasticidade; Extensômetro de $500 \mathrm{~mm}$ para ensaio até a ruptura. A velocidade de 500 $\mathrm{mm} / \mathrm{min}$ foi utilizada para analisar o comportamento na ruptura visto que a utilização de velocidade de $50 \mathrm{~mm} / \mathrm{min}$ não ocasionava o rompimento do corpo de prova dentro de 5 minutos.

Os testes foram realizados em uma Máquina Universal de Ensaios Instron 5567.

\subsubsection{Ensaio de flexão}

O ensaio de flexão foi realizado em 5 corpos de prova conforme norma D790 (ASTM, 2017) utilizando uma célula de carga de $5 \mathrm{kN}$, velocidade de $1,3 \mathrm{~mm} / \mathrm{min}$, distância entre apoio de $50 \mathrm{~mm}$ até $5 \%$ de deformação. O ensaio consiste na aplicação de uma carga crescente em pontos de uma barra de geometria padronizada, onde o corpo de prova é submetido a um esforço de flexão que tende a fletir, avaliando o valor da carga versus a deformação. Para o ensaio foi utilizado uma Máquina Universal de Ensaios Instron 5567. 


\subsubsection{Ensaio de impacto Charpy}

Para análise de resistência ao impacto foram utilizados cinco corpos de prova com entalhe em $\mathrm{V}$ de $2 \mathrm{~mm}$ de profundidade para cada composição conforme norma D6110 (ASTM, 2010), utilizando-se uma máquina Instron Ceast Modelo 9050 Italy. O pêndulo utilizado era capaz de fornecer 5,4 J e a distância entre os apoios foi de $100 \mathrm{~mm}$.

\subsubsection{Ensaio de deflexão por temperatura (HDT)}

Os ensaios de deflexão por temperatura Heat Deflection Temperature - HDT foram realizados no equipamento HDT-VICAT Ceast Italy disponível no laboratório de polímeros do Centro Universitário da FEI, conforme a norma D648 (ASTM, 2016), método B. Foi aplicado uma tensão de $1,82 \mathrm{MPa}$, uma taxa de aquecimento de $2^{\circ} \mathrm{C} / \mathrm{min}$ e distância de flexão entre pontos igual a $100 \mathrm{~mm}(+/-0,5 \mathrm{~mm})$. As medidas eram iniciadas quando a temperatura do banho atingia $30^{\circ} \mathrm{C}$, assumindo que para esta temperatura, a deflexão representasse o valor de zero. O término do ensaio dava-se quando a deflexão atingia $0,25 \mathrm{~mm}$, momento no qual a temperatura era registrada. Para o ensaio, foram utilizados três corpos de prova para cada composição.

\subsubsection{Análises por microscopia eletrônica de varredura (MEV)}

As análises morfológicas foram realizadas com a finalidade de verificar a superfície da fratura de corpos de prova resultante de teste de impacto no qual é possível analisar a interação entre a matriz HDPE e o resíduo de XLPE e também o tamanho de partícula. O equipamento utilizado foi o Microscópio de Varredura CamScam CS3200 LV.

Antes da realização do ensaio, as amostras receberam um recobrimento de ouro ionizado, utilizando-se do equipamento da marca Boc Edwards, modelo Scancoar Six para possibilitar a interação do feixe de elétrons fornecido pelo microscópio com a superfície das amostras. 


\section{RESULTADOS E DISCUSSÕES}

Neste capítulo é correlacionado as propriedades e desempenho dos compostos HDPE/XLPE com a sua estrutura, onde variou o teor do XLPE e seu tamanho de partícula na matriz de HDPE.

Os resultados e discussões serão apresentados pela análise da distribuição de tamanho de partículas, propriedades mecânicas, térmicas e morfológicas dos corpos de prova.

\subsection{ANÁLISE DA DISTRIBUIÇÃO DO TAMANHO DE PARTÍCULA}

Após a micronização do resíduo de XLPE foi realizada a análise de distribuição de partículas para posterior separação nos tamanhos médios de 100, 500 e $900 \mu \mathrm{m}$.

A figura 18 ilustra a distribuição do tamanho de partícula após micronização do resíduo de XLPE.

Figura 18 - Distribuição do tamanho de partícula do XLPE após micronização

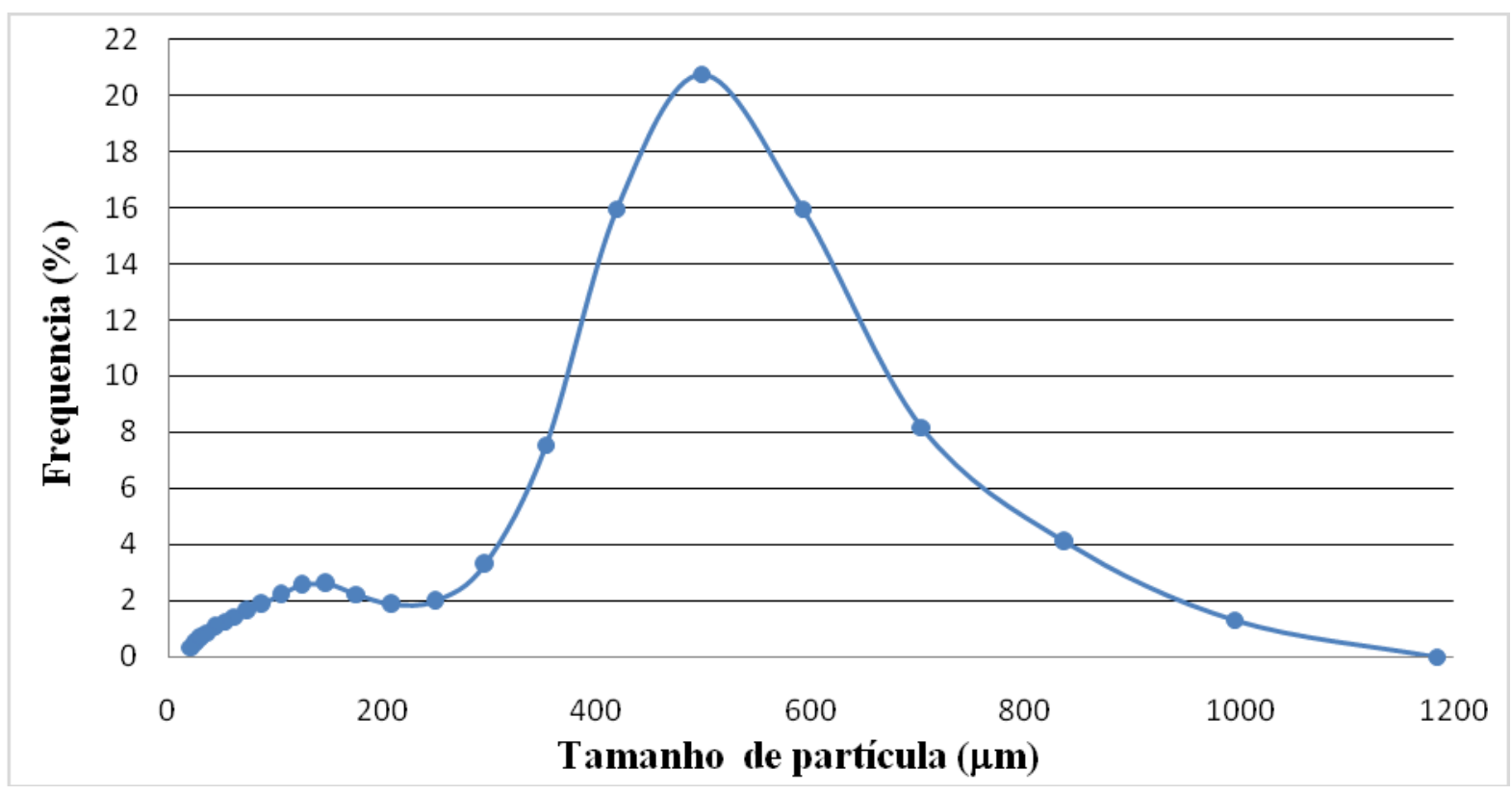

Fonte: Autor

Observa-se que, em termos de distribuição de tamanho de partícula, a micronização apresenta resultado melhor que a trituração em moinho de facas. Por exemplo, Fonseca e Bonse (2015) moeram o mesmo XLPE proveniente de resíduo de fios, em moinho de facas 
para incorporação em LDPE, obtiveram uma distribuição bimodal, numa faixa de 0 a 2000 $\mu \mathrm{m}$, com picos de tamanho de partícula de 400 e $1000 \mu \mathrm{m}$ como mostra a figura 19.

Figura 19 - Distribuição bimodal de partículas do XLPE

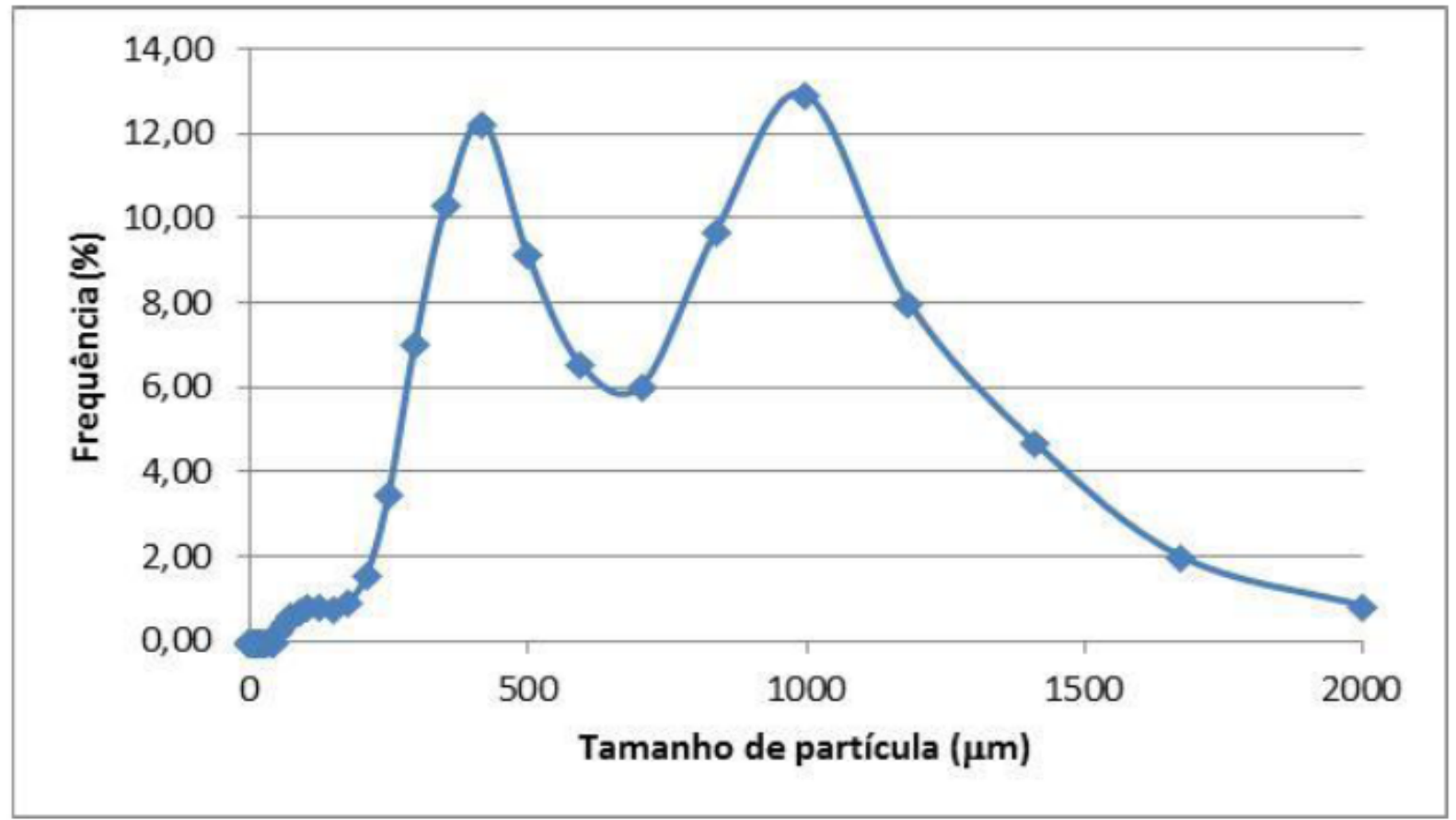

Fonte: Fonseca e Bonse, 2015

A partir do resultado da distribuição do tamanho de partícula após a micronização, foi realizado o peneiramento com intuito de separar em tamanhos médios de 100, 500 e $900 \mu \mathrm{m}$.

O resultado do peneiramento para obtenção do tamanho médio de partícula de XLPE de $100 \mu \mathrm{m}$ é apresentada na figura 20. 
Figura 20 - Distribuição do tamanho de partícula XLPE - $100 \mu \mathrm{m}$

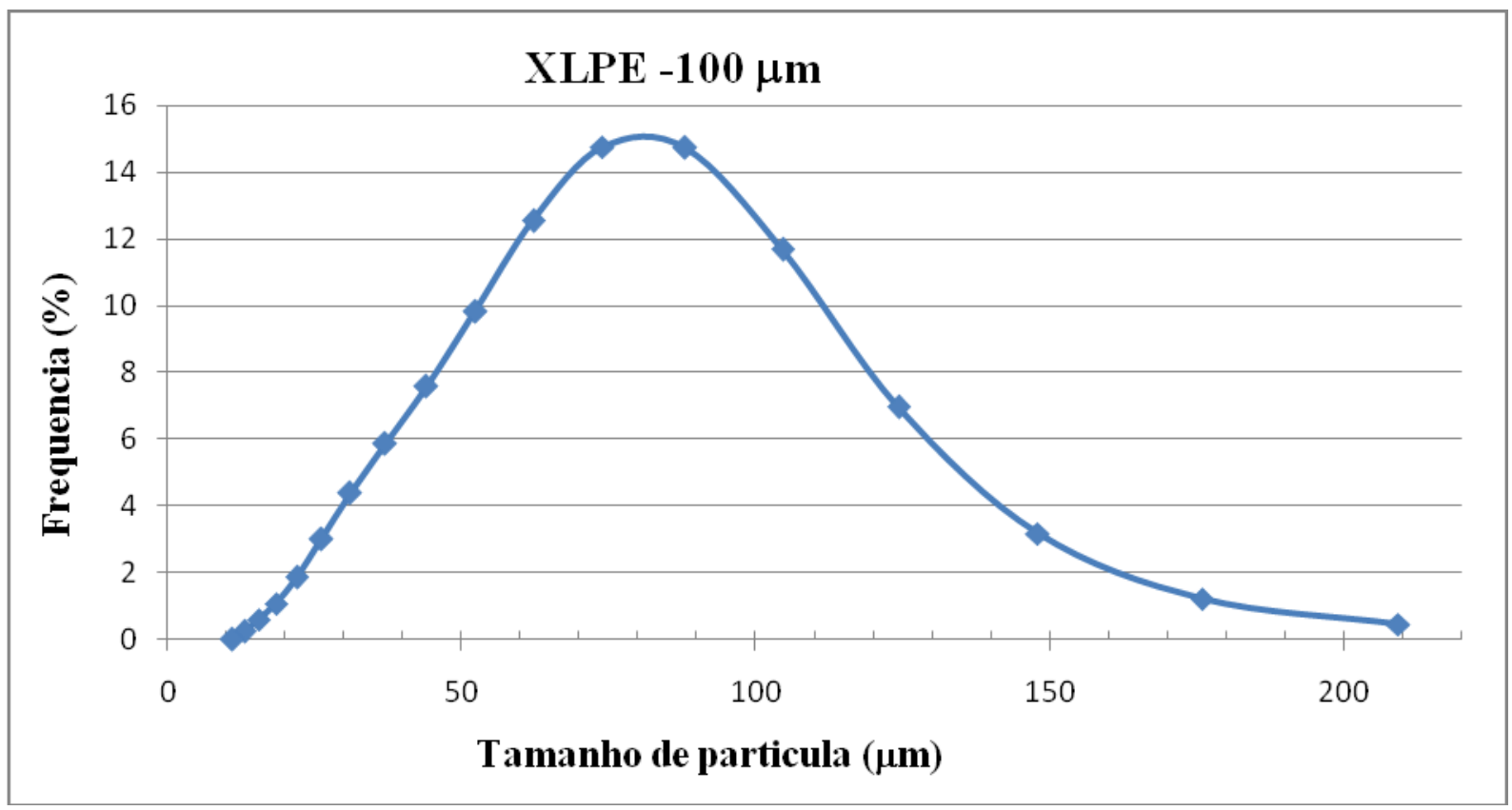

Fonte: Autor

Através do resultado de análise do tamanho médio de partículas, é possível observar uma distribuição que varia de 10 a $210 \mu \mathrm{m}$, com percentual significativo e acima de 11,5\% nos tamanhos entre 60 a $110 \mu \mathrm{m}$. Nota-se um percentual de aproximadamente de $7 \%$ com partículas abaixo de $50 \mu \mathrm{m}$ e acima de $120 \mu \mathrm{m}, 3 \%$ com partículas abaixo de $30 \mu \mathrm{m}$ e pouco mais de $140 \mu \mathrm{m}, 1 \%$ de partículas abaixo de $20 \mu \mathrm{m}$ e acima de $170 \mu \mathrm{m}$. A utilização de uma peneira de 140 mesh que representa $106 \mu \mathrm{m}$, resultou em um pico do tamanho de partícula entre 80 e $90 \mu \mathrm{m}$, porém observam-se também partículas acima de $106 \mu \mathrm{m}$, pois devido à geometria da partícula e amplitude de frequência de vibração, partículas maiores passam pela peneira. O valor médio do tamanho de partícula de XLPE é de $74 \mu \mathrm{m}$. A micrografia das partículas é apresentada na figura 21. 
Figura 21 - Micrografia das partículas de XLPE $100 \mu \mathrm{m}(50 \mathrm{x})$

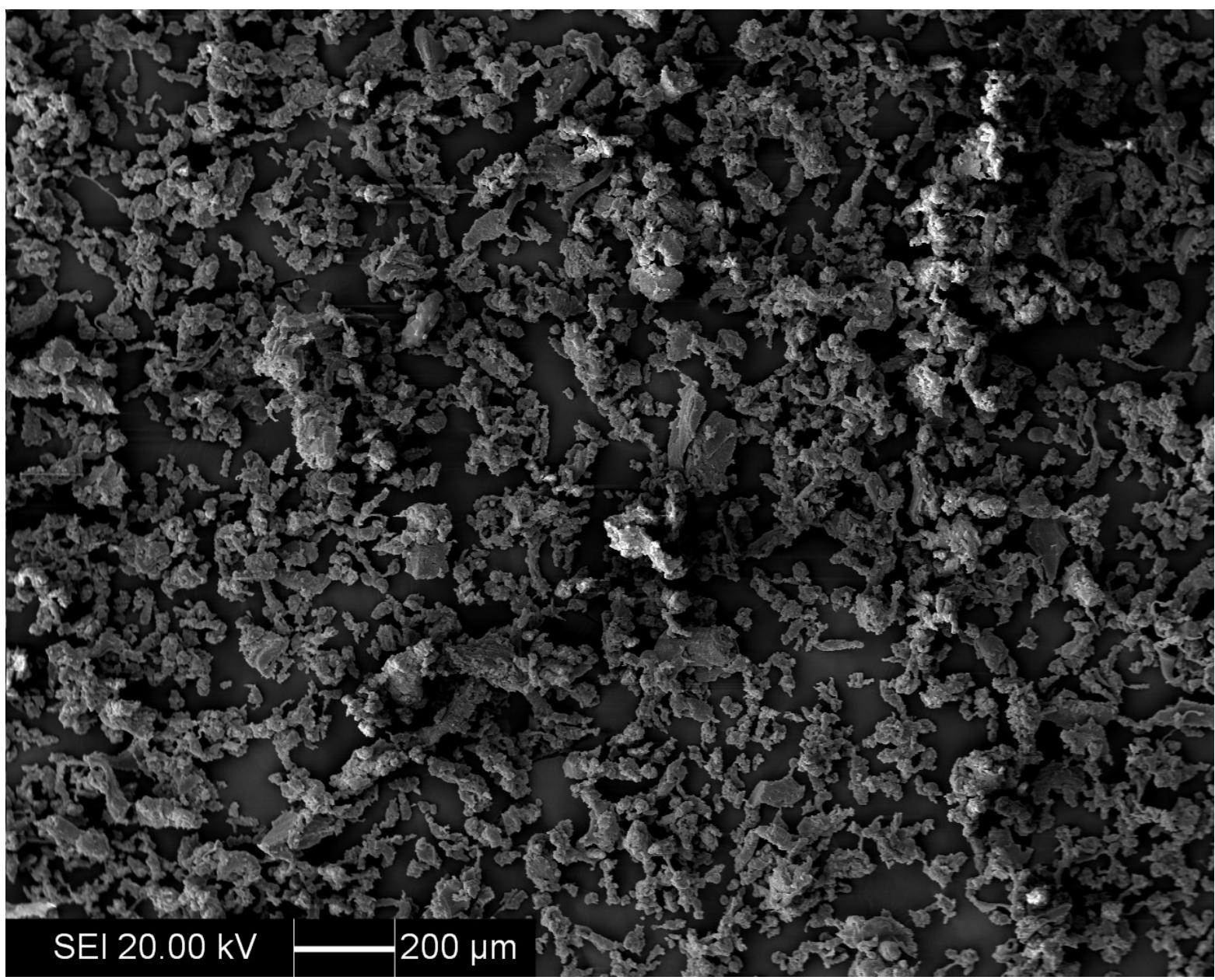

Fonte: Autor

Para a obtenção do tamanho médio de partícula de $500 \mu \mathrm{m}$, foram utilizadas duas peneiras uma com 35 mesh e outra com 45 mesh representando 355 e $500 \mu \mathrm{m}$, respectivamente. A figura 22 apresenta o resultado da distribuição de tamanho de partícula onde se constata uma concentração de aproximadamente $28 \%$ para tamanho de partícula de $500 \mu \mathrm{m}$. O tamanho de partícula variou de 200 a $1200 \mu \mathrm{m}$. Tamanhos abaixo de $355 \mu \mathrm{m}$ ocorreram pelo fato da vibração gerar estática e pequenos grãos acabam aderindo a grãos maiores. Partículas acima de $500 \mu \mathrm{m}$ foram identificadas, pois a forma geométrica da partícula favorece a passagem pela abertura da tela. $\mathrm{O}$ tamanho médio obtido para esta distribuição foi de $509 \mu \mathrm{m}$. A figura 23 apresenta uma micrografia das partículas de XLPE com tamanho médio de $500 \mu \mathrm{m}$. 
Figura 22 - Distribuição de tamanho de partícula XLPE - 500 $\mu \mathrm{m}$

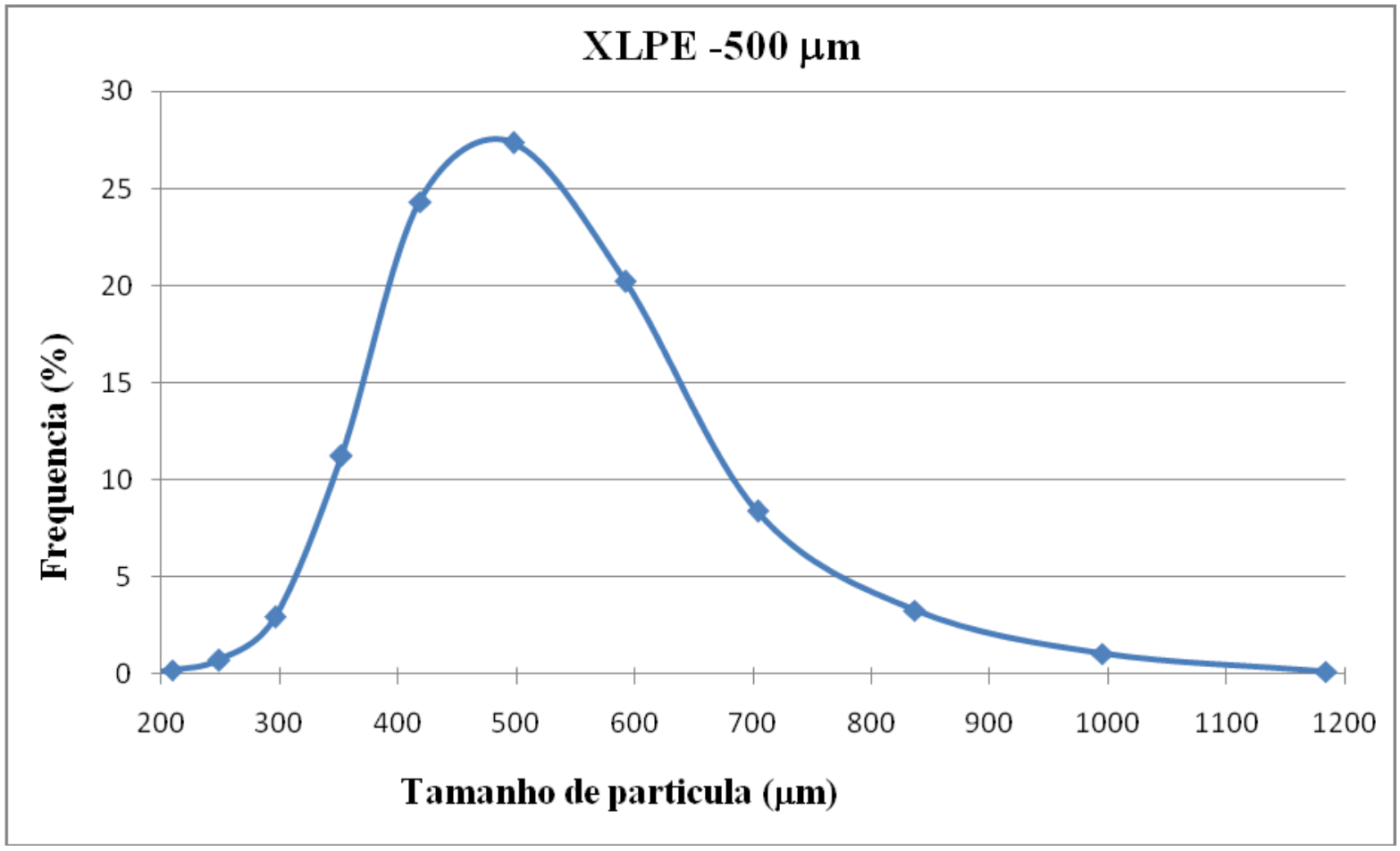

Fonte: Autor 
Figura 23 - Micrografia do tamanho de partícula XLPE - $500 \mu \mathrm{m}(25 \mathrm{x})$

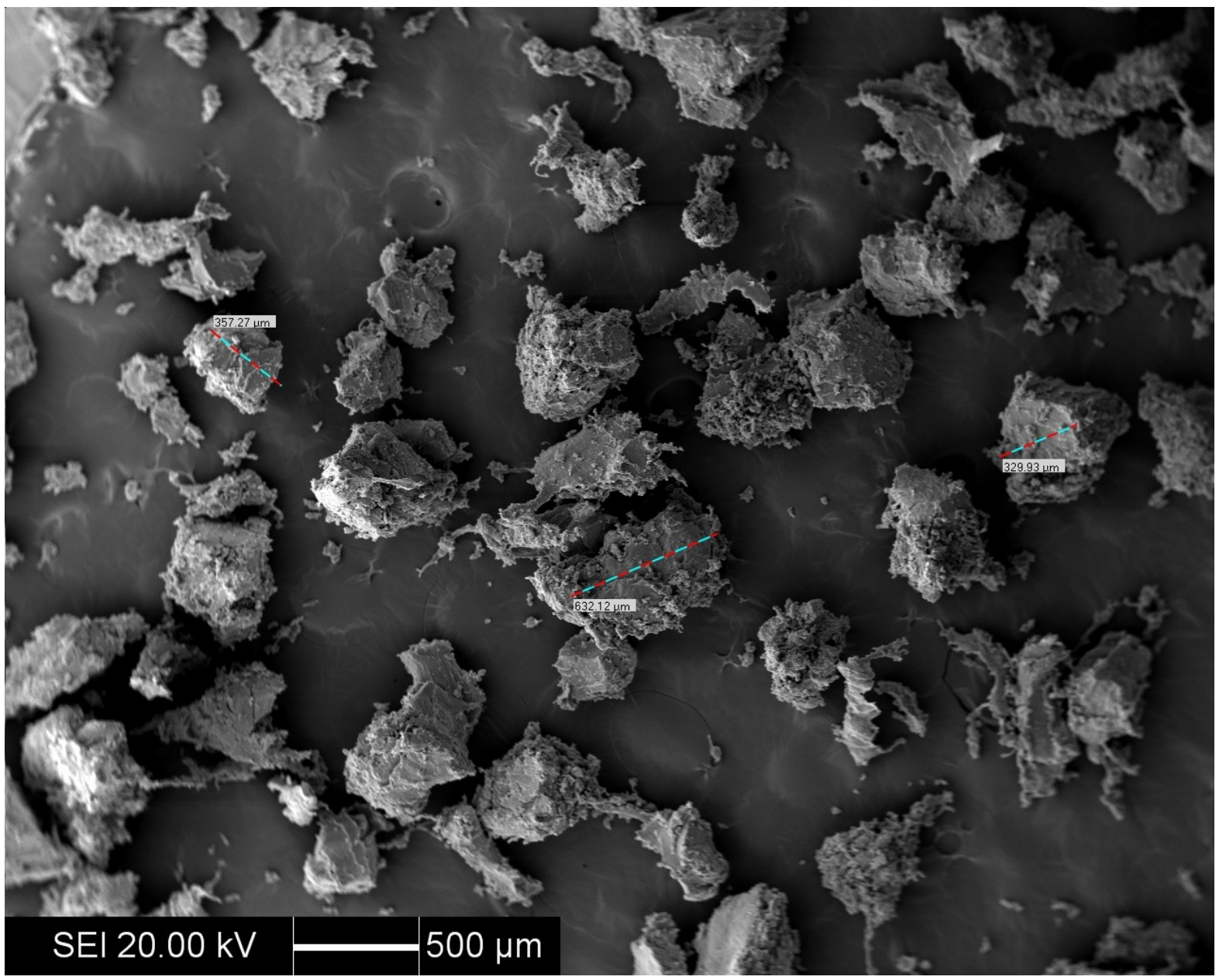

Fonte: Autor

No intuito de obter um tamanho médio de partícula de $900 \mu \mathrm{m}$, utilizou-se uma peneira de 20 mesh que representa $850 \mu \mathrm{m}$. A distribuição do tamanho de partícula é representada na figura 24 . 
Figura 24 - Distribuição do tamanho de partícula XLPE - 900 $\mu$ m

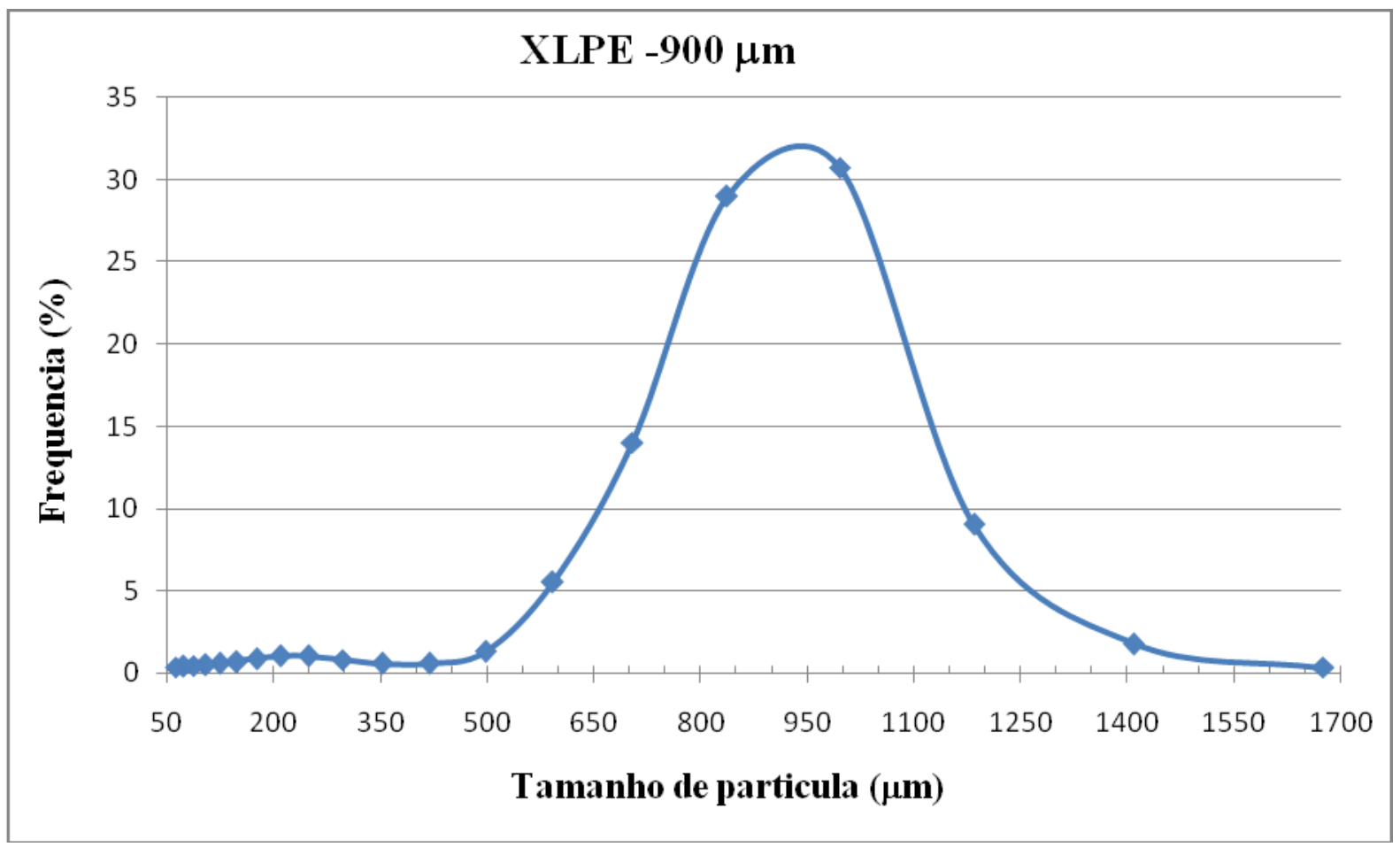

Fonte: Autor

Observam-se tamanhos de partículas abaixo de $850 \mu \mathrm{m}$ ocorrendo o mesmo fenômeno quando se peneirou para obter o tamanho de partícula de $500 \mu \mathrm{m}$ e também devido ao baixo tempo de processo (1 minuto) fazendo com que partículas menores ficassem retidas na peneira. O tamanho médio para esta distribuição foi de $842 \mu \mathrm{m}$. Estas partículas podem ser observadas através da micrografia representada na figura 25 . 
Figura 25 - Micrografia do tamanho de partícula XLPE - $900 \mu \mathrm{m}(15 \mathrm{x})$

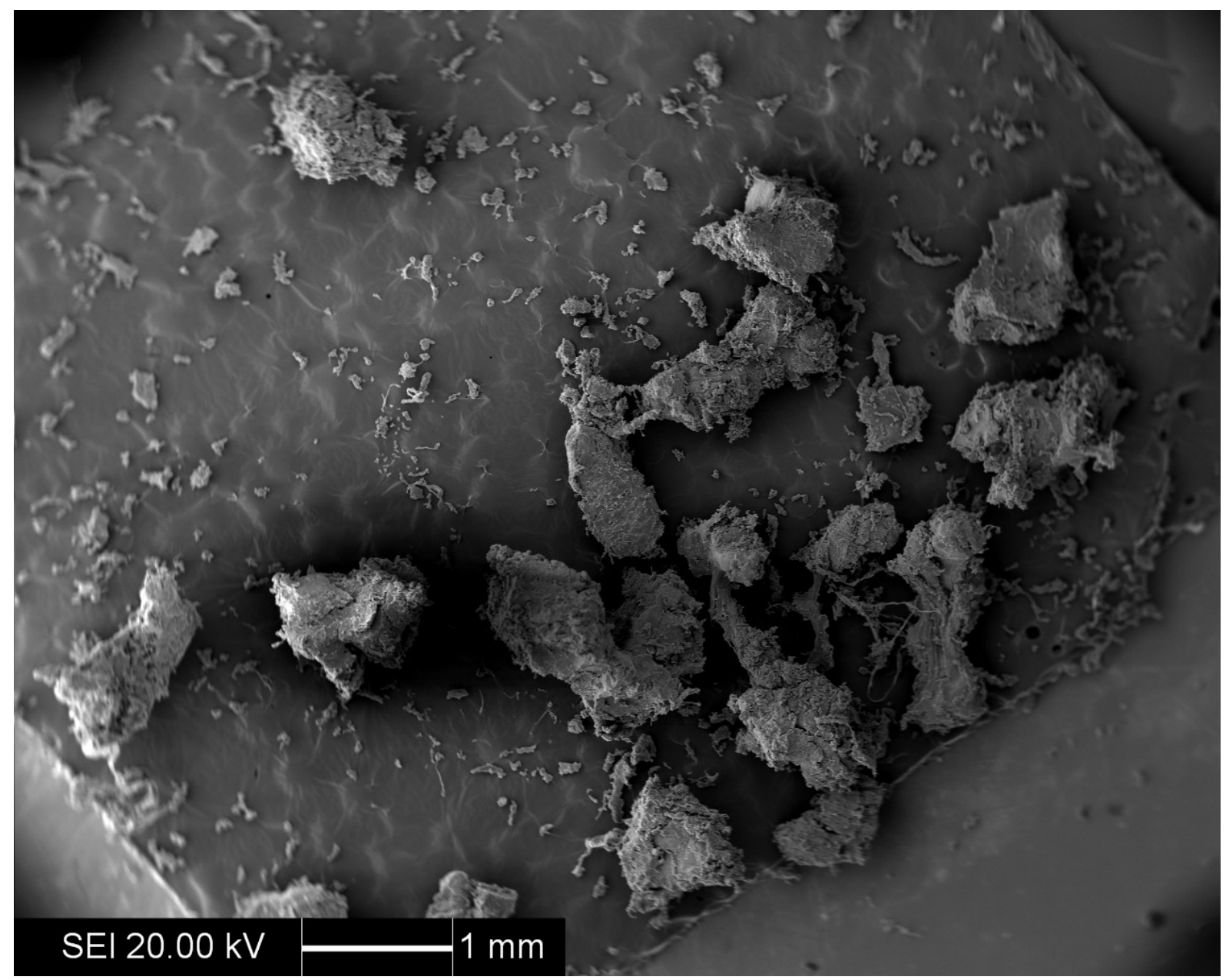

Fonte: Autor

Para facilitar no entendimento no decorrer do trabalho, serão considerados 100 para tamanho médio de partícula de $74 \mu \mathrm{m}, 500$ para tamanho médio de partícula de $509 \mu \mathrm{m}$ e 900 para tamanho médio de partícula de $842 \mu \mathrm{m}$.

\subsection{ENSAIO DE TRAÇÃO}

Os resultados dos ensaios de tração do HDPE puro e aditivado com XLPE são apresentados na tabela 7 e nas figuras 26 , figura 27 , figura 28 e figura 29 , sendo as médias e desvios padrão da resistência à tração, deformação na ruptura e módulo em tração. 
Tabela 7 - Propriedades mecânicas de tração

Ensaios de Tração

\begin{tabular}{l|c|c|c|c|c|c}
\hline Compostos & E(GPa) & Desv. Pad & $\begin{array}{c}\text { RT (MPa) } \\
\text { Escoamento }\end{array}$ & Desv. Pad & $\begin{array}{c}\text { Defor. } \\
\text { Rupt (\%) }\end{array}$ & $\begin{array}{c}\text { Desv. } \\
\text { Pad }\end{array}$ \\
\hline Controle & 0,96 & 0,25 & 22,18 & 0,31 & 110,46 & 9,59 \\
\hline XLPE 1\%-100 & 0,97 & 0,02 & 21,94 & 0,47 & 103,91 & 16,25 \\
\hline XLPE 1\%-900 & 0,74 & 0,06 & 22,00 & 0,33 & 88,19 & 6,36 \\
\hline XLPE 5\%-500 & 0,90 & 0,09 & 20,46 & 0,48 & 94,35 & 5,14 \\
\hline XLPE 9\%-100 & 0,77 & 0,03 & 19,20 & 0,23 & 108,79 & 6,19 \\
\hline XLPE 9\%-900 & 0,86 & 0,07 & 19,67 & 0,12 & 90,04 & 4,05 \\
\hline
\end{tabular}

Fonte: Autor

Com relação às propriedades mecânicas de tração, nota-se que a adição de XLPE não apresentou variação no módulo de elasticidade quando comparado com o HDPE controle. Em relação à resistência à tração, a adição de XLPE não apresentou mudança na propriedade com teor de $1 \%$ de XLPE quando comparado com HDPE puro, já em concentrações de 5 e 9\%, houve queda na propriedade. A queda da propriedade pode ser do fato do XLPE apresentar um aspecto borrachoso, quando comparado com HDPE puro. Para analisar o efeito de tamanho de partícula, foi comparado as formulações 1\%-100 vs 1\%-900 e 9\%-100 vs 9\%900. Para o teor de 1\% de XLPE, o tamanho de partícula praticamente não afetou a resistência à tração, enquanto que para $9 \%$ de XLPE observa-se um pequeno aumento na resistência à tração com o aumento do tamanho médio de partícula. A deformação na ruptura não apresentou variação com o aumento de tamanho médio de partícula para concentrações de $1 \%$, por outro lado, observa-se uma queda na propriedade para concentração de $9 \%$. Para concentração de 5\% de XLPE, e tamanho médio de 500, apresentou semelhança na propriedade deformação na ruptura quando comparado ao composto 1\%-900 e 9\%-900.

Para comparação, Boss e Hagström (2009), ao incorporar 60\% de XLPE em HDPE para avaliar o modulo em tração, observaram uma queda de aproximadamente $60 \%$ em relação ao HDPE puro.

Boss et al. (2011) analisaram o modulo em tração do composto 60/40 XLPE/HDPE e observaram um decréscimo de aproximadamente $50 \%$ da propriedade analisada. 
Figura 26 - Representação gráfica do módulo de elasticidade em tração

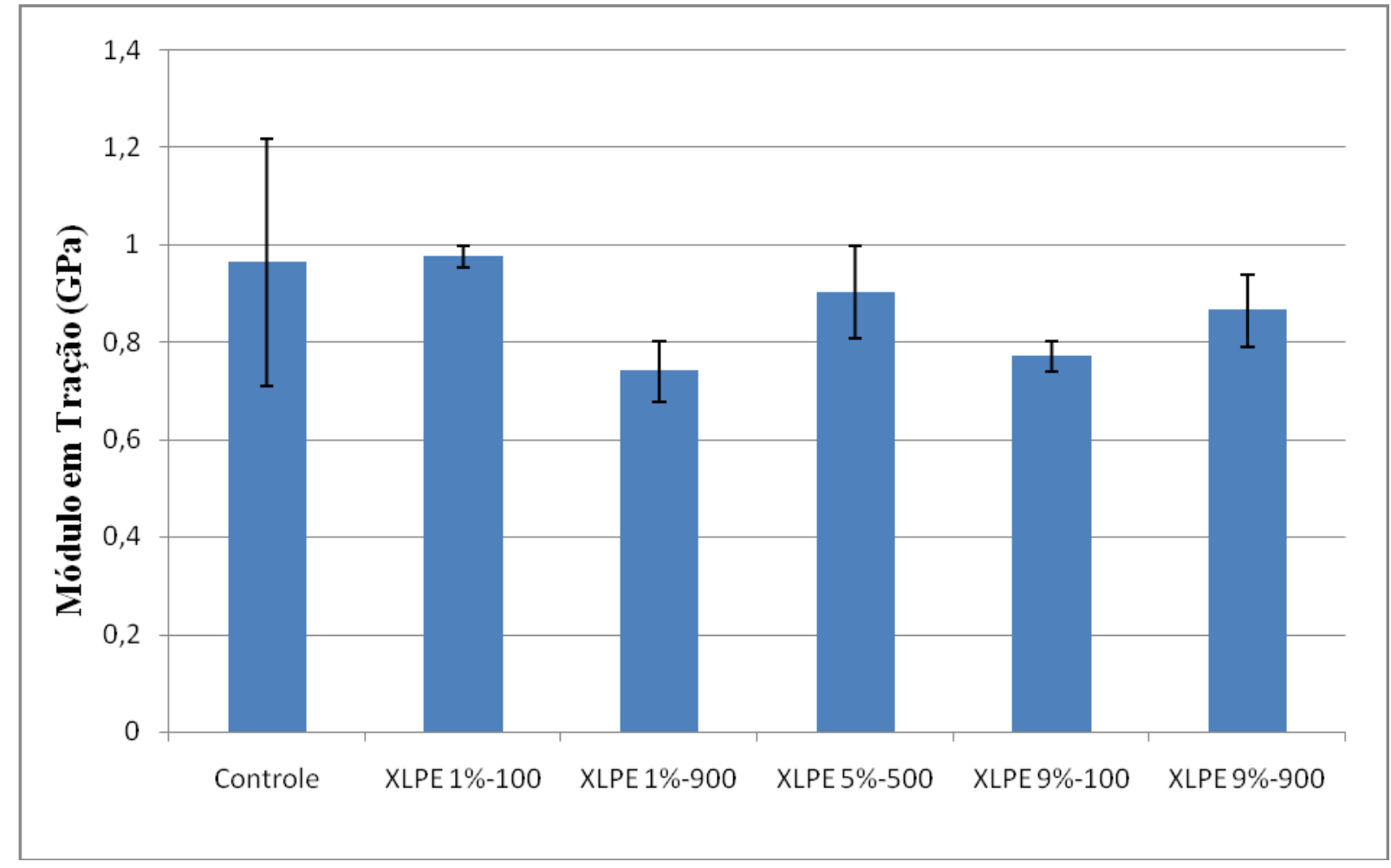

Fonte: Autor

Figura 27 - Representação gráfica da resistência à tração

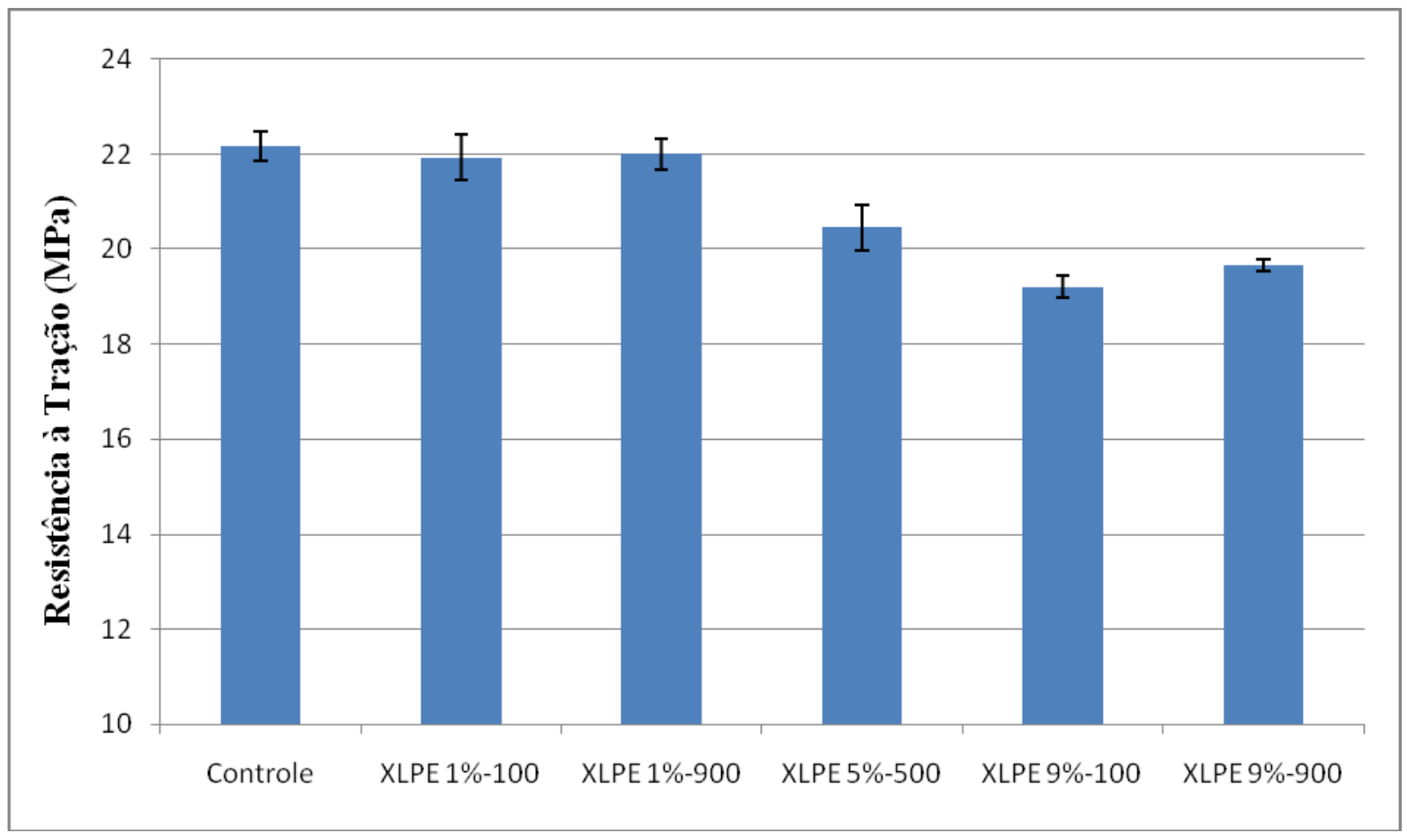

Fonte: Autor 
Figura 28 - Representação gráfica da deformação na ruptura

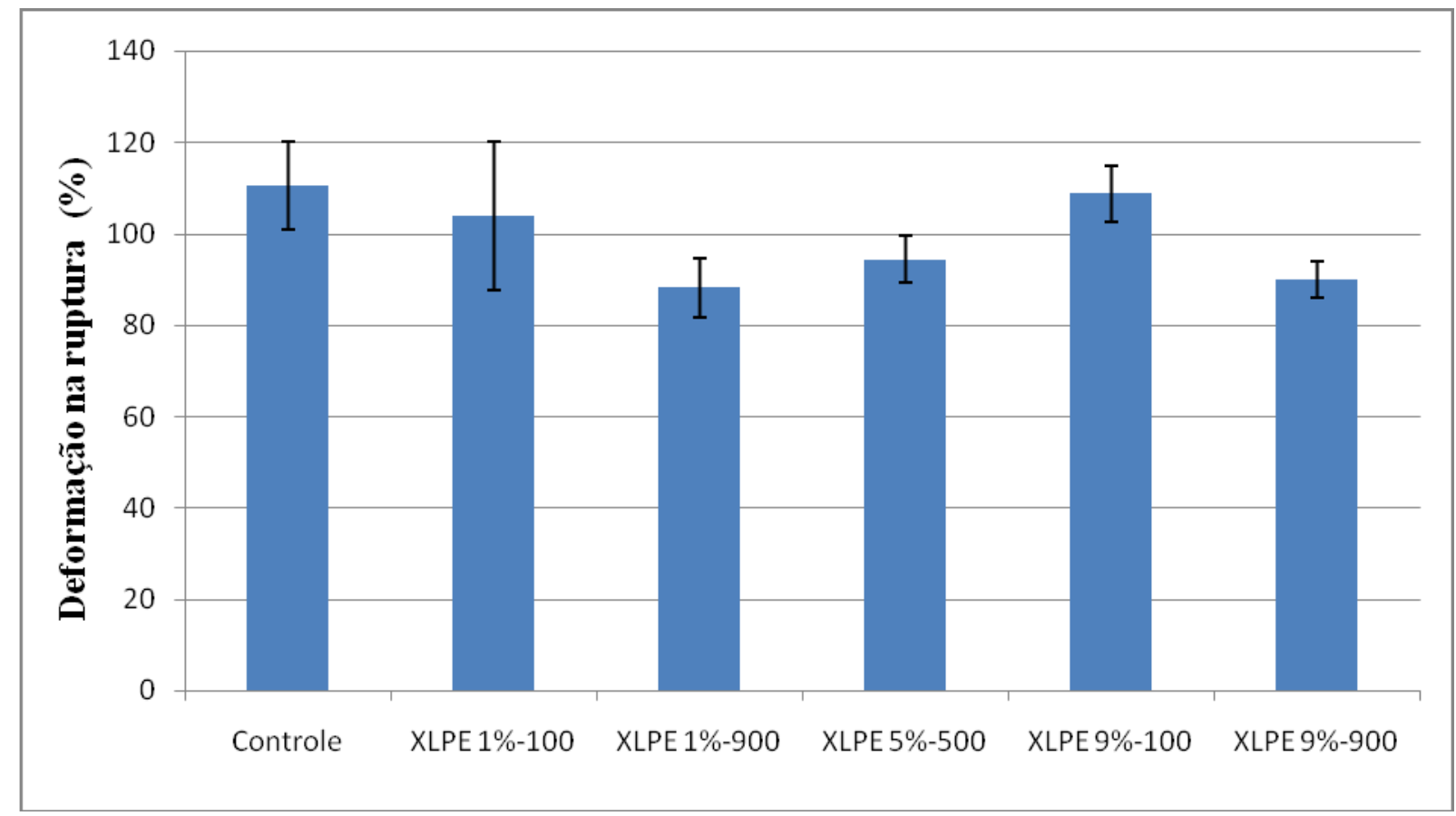

Fonte: Autor

Para uma investigação mais aprofundada do efeito do teor e do tamanho médio de partícula do XLPE, e suas interações nas propriedades mecânicas do composto, realizou-se uma análise estatística através do software Statistica ${ }^{\circledR}$ nos dados compilados. Para a investigação foram considerados os compostos XLPE1\%-100, XLPE1\%-900, XLPE5\%-500, XLPE9\%-100 e XLPE9\%-900. A tabela 8 contém os coeficientes das equações ajustadas: $\mathrm{a}_{0}+$ $\mathrm{a}_{1} \mathrm{x}_{1}+\mathrm{a}_{2} \mathrm{x}_{2}+\mathrm{a}_{3} \mathrm{x}_{1} \mathrm{x}_{2}$, onde $\mathrm{x}_{1}$ e $\mathrm{x}_{2}$ são as variáveis codificadas referentes aos teores de XLPE e tamanho médio de partícula respectivamente. Os termos $a_{0}, a_{1}, a_{2}$ e $a_{3}$, são as respostas onde $\mathrm{a}_{0}$ é o intercepto do modelo quando x1 e x2 é igual a zero, $\mathrm{a}_{1}$ é a resposta para o teor de XLPE, $a_{2}$ é a resposta para o tamanho de partícula e $a_{3}$ é a resposta para interação entre teor e tamanho de partícula e $\mathrm{R}^{2}$ indica a variação dos dados em relação ao modelo. Os valores destacados em vermelho indicam as variáveis cujo efeito é significativo para um intervalo de confiança de $95 \%$. 
Tabela 8 - Coeficiente das equações polinomiais dos ajustes de segunda ordem

\begin{tabular}{l|c|c|c|c|c}
\hline & \multicolumn{4}{c|}{ Termos lineares } & $\mathrm{R}^{2}$ ajustado \\
\hline & $\mathrm{a}_{0}$ & $\mathrm{a}_{1}$ & $\mathrm{a}_{2}$ & $\mathrm{a}_{3}$ & \\
\hline Resistência à tração & $\mathbf{2 0 , 6 5 4 8}$ & $\mathbf{- 2 , 5 3 3}$ & 0,265 & 0,199 & 0,91154 \\
\hline Módulo em tração & $\mathbf{0 , 8 5 8 2 5}$ & $-0,01843$ & $-0,08991$ & $\mathbf{0 , 1 4 7 3 5}$ & 0,333 \\
\hline Deformação na rupture & $\mathbf{9 7 , 0 5 4 4}$ & 3,361 & $\mathbf{- 1 7 , 2 3 7}$ & $-1,515$ & 0,36035 \\
\hline
\end{tabular}

Fonte: Autor

Valores de $\mathrm{R}^{2}$ próximos de um, indicam um bom ajuste entre o modelo e os dados, e os sinais dos coeficientes mostram se uma variável independente tem efeito positivo ou negativo sobre a variável dependente. Os valores de $\mathrm{R}^{2}$ baixos do módulo em tração e da deformação na ruptura indicam que a variância nestas medidas é grande. No caso do módulo elástico medido em tração, o comportamento viscoelástico a deformações pequenas é responsável pela grande variância. No caso da deformação na ruptura, ressalta-se que para que ocorresse a ruptura, foi necessário aumentar a velocidade dez vezes maior ( $500 \mathrm{~mm} / \mathrm{min}$ ) que normalmente utilizado para termoplásticos $(50 \mathrm{~mm} / \mathrm{mim})$. Assim qualquer falha pequena é ampliada. A interação entre as duas variáveis teve uma influência significativa no modulo em tração.

$\mathrm{O}$ aumento do teor de XLPE diminuiu a resistência à tração enquanto o tamanho médio das partículas de XLPE apresentou maior influência na deformação na ruptura.

A figura 29, figura 30 e figura 31, mostram os diagramas de Pareto que apresentam uma visão clara da importância da contribuição de cada variável na propriedade e sua significância, adotando um intervalo de confiança de 95\%. O tamanho da barra mostra a contribuição da variável, e a sua posição a sua significância; ultrapassando o limite de p=0,05 a mesma é significativa para um intervalo de confiança de $95 \%$, caso contrário a mesma não apresenta significância. 
Figura 29 - Gráfico de Pareto do módulo em tração

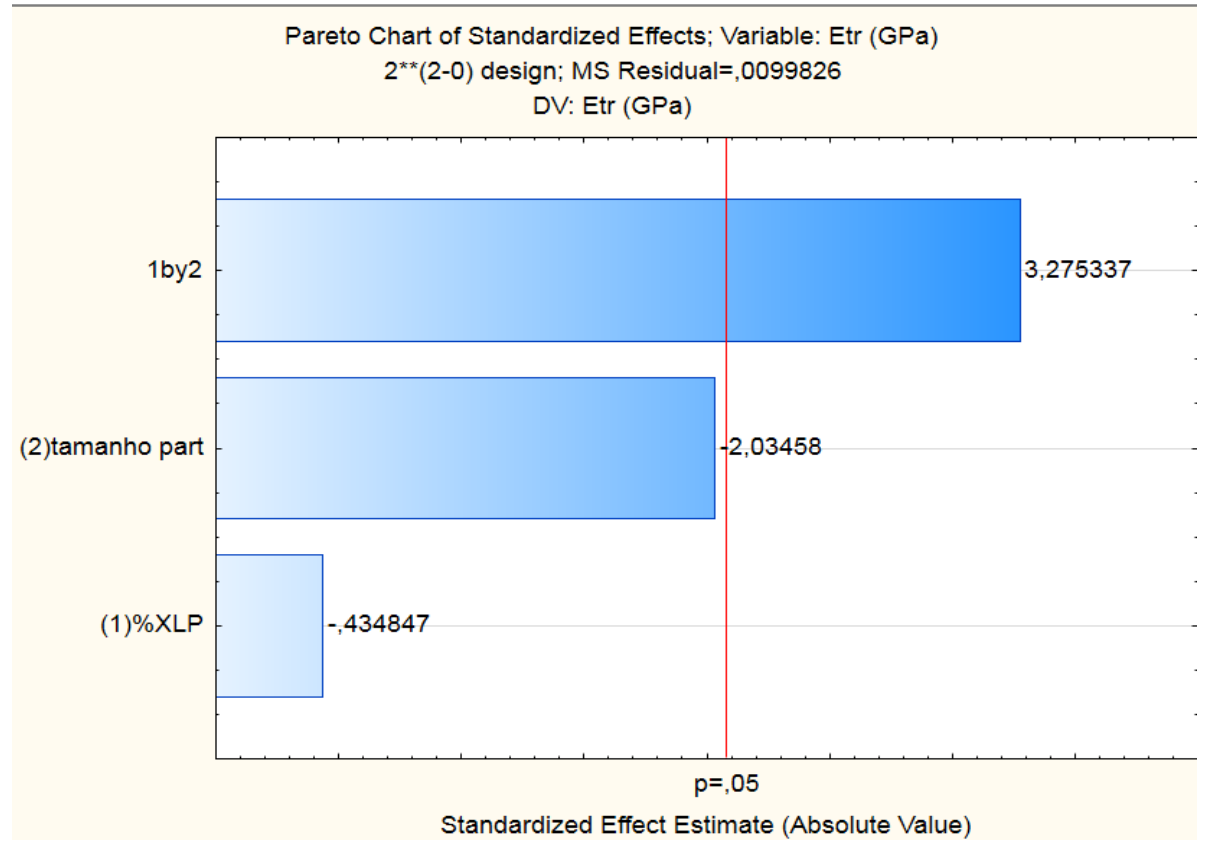

Fonte: Autor

Figura 30 - Gráfico de Pareto resistência à tração

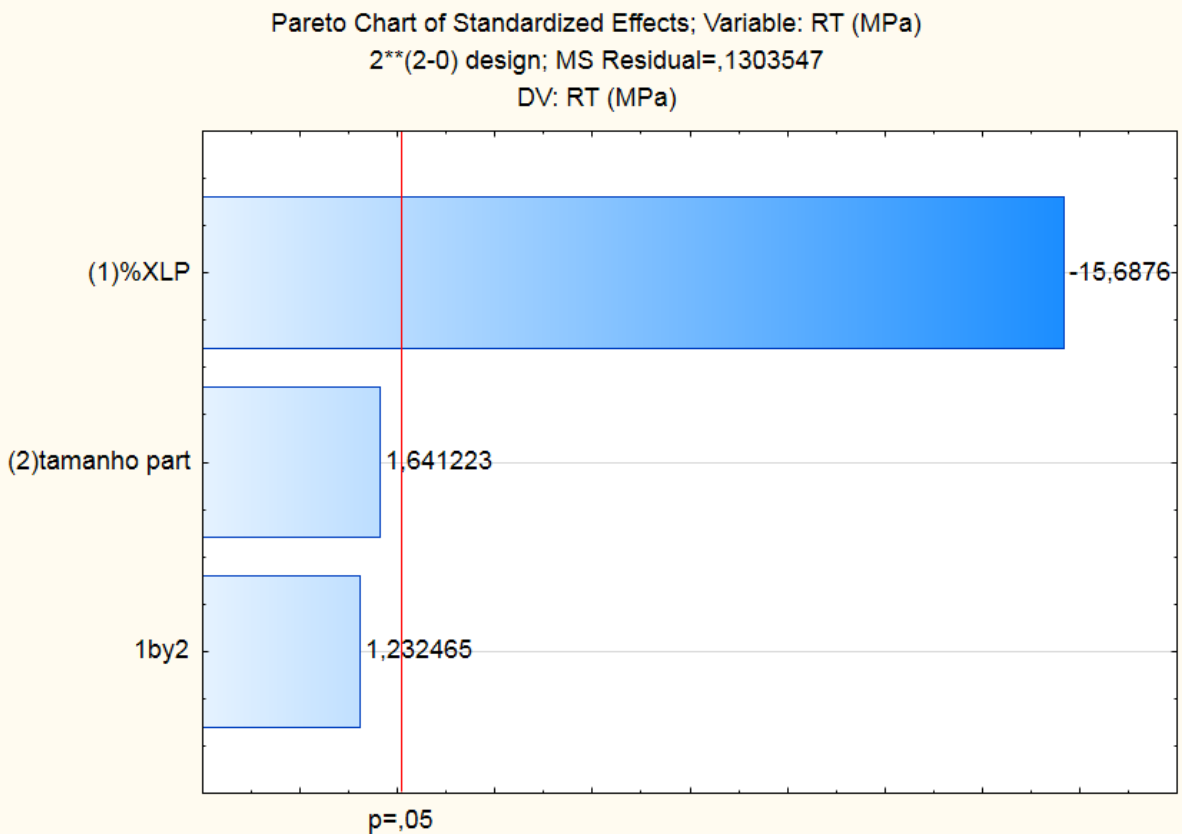

Fonte: Autor 
Figura 31 - Gráfico de Pareto da deformação na ruptura

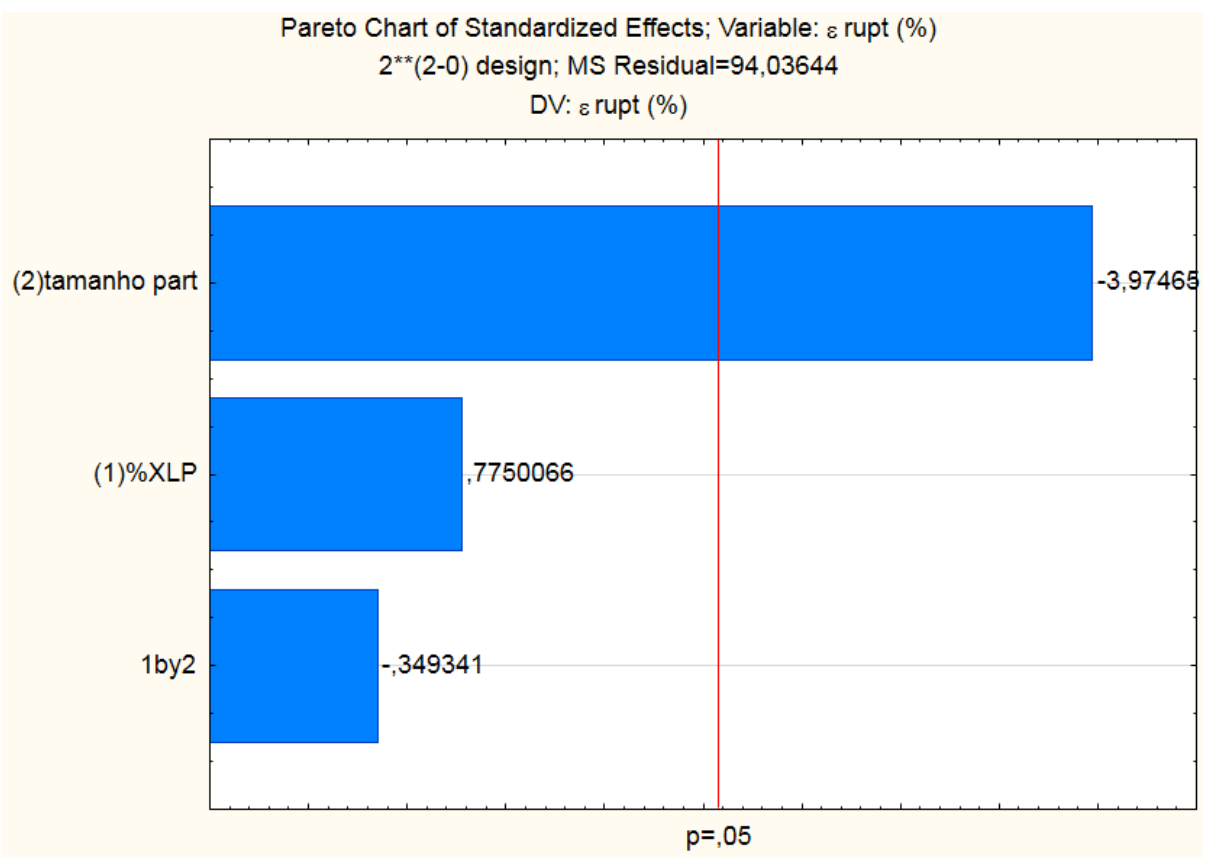

Fonte: Autor

\subsection{ENSAIO DE FLEXÃO}

Para a realização dos ensaios de flexão, foram utilizadas 5 amostras de cada composto na qual foi submetido até a deformação de 5\%. A tabela 9 mostra os resultados do ensaio de flexão que são ilustrados nos gráficos das figuras 32 e figura 33.

Tabela 9 - Resultados da propriedade de flexão

\section{Ensaios de Flexão}

\begin{tabular}{l|c|c|c|c}
\hline Compostos & Tensão a 5\% def. (MPa) & Desv. Pad & E-flex (GPa) & Desv. Pad \\
\hline Controle & 20,18 & 0,24 & 0,80 & 0,01 \\
\hline XLPE 1\%-100 & 20,08 & 0,26 & 0,79 & 0,02 \\
\hline XLPE 1\%-900 & 19,81 & 0,39 & 0,76 & 0,02 \\
\hline XLPE 5\%-500 & 18,89 & 0,13 & 0,73 & 0,01 \\
\hline XLPE 9\%-100 & 18,33 & 0,15 & 0,71 & 0,02 \\
\hline XLPE 9\%-900 & 18,07 & 0,14 & 0,69 & 0,01 \\
\hline
\end{tabular}

Fonte: Autor

Em relação à tensão máxima, inicialmente foram comparados os compostos em relação ao HDPE puro. Para a propriedade flexão, os compostos de XLPE 1\%-100 e 
XLPE1\%-900 são estatisticamente iguais. Ao aumentar o teor de XLPE para 9\%, houve queda em relação ao controle e teor de $1 \%$ para tensão e módulo de flexão. $\mathrm{O}$ aumento do tamanho de partícula, não demonstrou mudança na propriedade para teores de $1 \%$ e $9 \%$. A queda da tensão em teor de $9 \%$ se dá pelo fato do XLPE possuir maior flexibilidade e um comportamento ligeiramente borrachoso em relação ao HDPE.

Figura 32 - Gráfico dos resultados de tensão máxima a 5\%

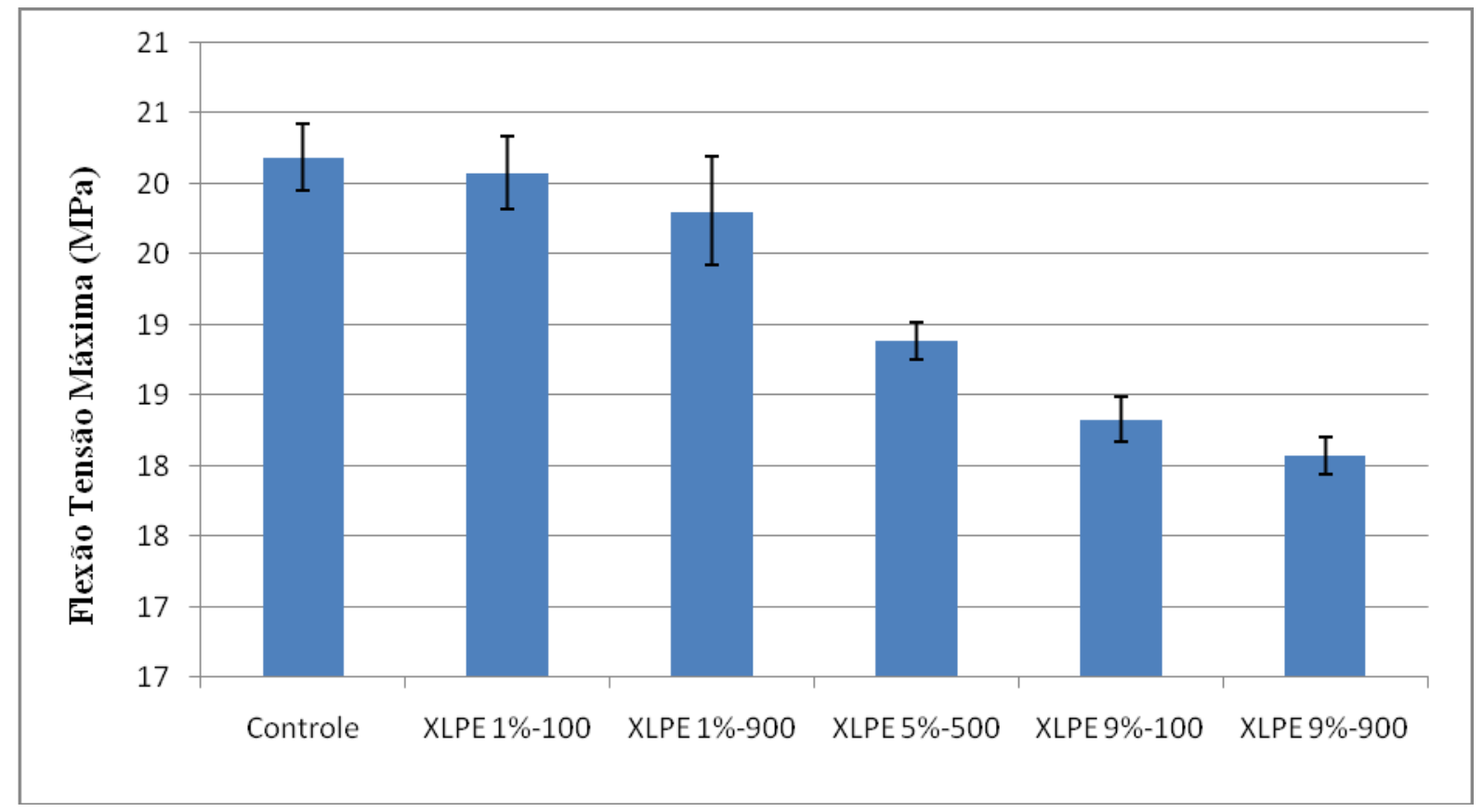

Fonte: Autor

Figura 33 - Gráfico dos resultados do módulo em flexão a $0,3 \%$

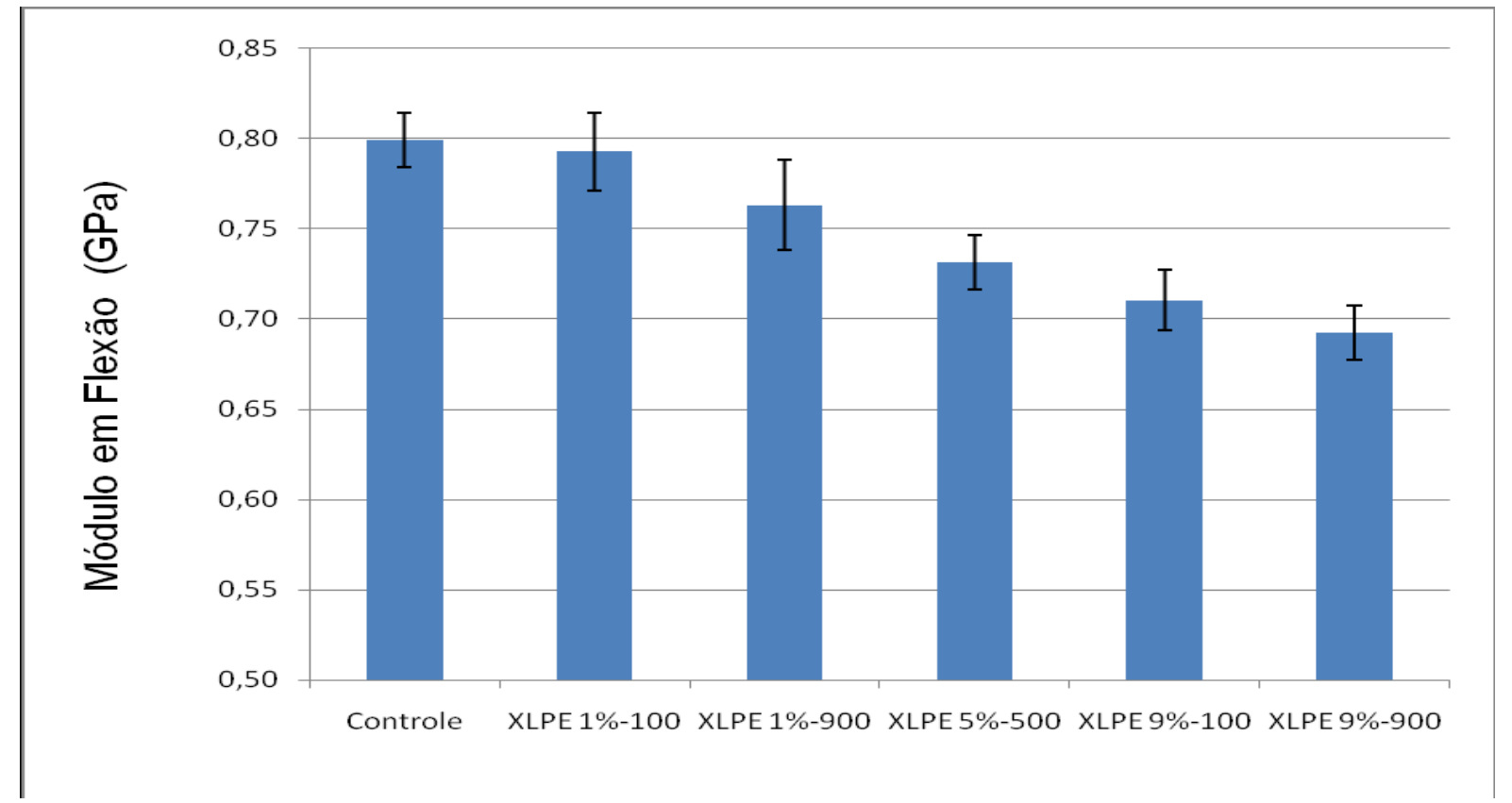

Fonte: Autor 
Segundo Cucchiara e Bonse (2015), ao aumentar o teor de XLPE em HDPE, os valores de resistência a flexão diminuem, este mesmo efeito ocorre no módulo de flexão.

Por meio do software Statistica ${ }^{\circledR}$, foram analisados, possíveis interações nas propriedades mecânica de flexão dos compostos XLPE1\%-100, XLPE1\%-900, XLPE5\%-500, XLPE9\%-100 e XLPE9\%-900. A tabela 10 contém os coeficientes das equações ajustadas: $\mathrm{a}_{0}$ $+\mathrm{a}_{1} \mathrm{x}_{1}+\mathrm{a}_{2} \mathrm{x}_{2}+\mathrm{a}_{3} \mathrm{x}_{1} \mathrm{x}_{2}$, onde $\mathrm{x}_{1}$ e $\mathrm{x}_{2}$ são as variáveis codificadas referentes aos teores de XLPE e tamanho médio de partícula respectivamente.

Tabela 10 - Coeficiente das equações polinomiais dos ajustes de segunda ordem ensaio de flexão

\begin{tabular}{l|c|c|c|c|c}
\hline & \multicolumn{4}{|c|}{ Termos lineares } & $\mathrm{R}^{2}$ ajustado \\
\hline & $\mathrm{a}_{0}$ & $\mathrm{a}_{1}$ & $\mathrm{a}_{2}$ & $\mathrm{a}_{3}$ & \\
\hline Resistência à flexão & $\mathbf{1 8 , 9 9 4 8}$ & $\mathbf{- 1 , 6 4 2}$ & $-0,166$ & $-0,092$ & 0,82684 \\
\hline Módulo em flexão & $\mathbf{0 , 7 3 8 1 4}$ & $\mathbf{- 0 , 0 7 6 3 7}$ & $\mathbf{- 0 , 0 2 3 7 8}$ & 0,00585 & 0,78232 \\
\hline
\end{tabular}

Fonte: Autor

Através da tabela 11 e pelos diagramas de Pareto ilustrados na figura 34 e figura 35 , a tensão em flexão é afetada quando ocorre variação do teor de XLPE. Para o módulo de flexão, o teor de XLPE e tamanho médio de partícula apresentaram influência na propriedade, a combinação do teor e do tamanho médio de partícula não apresenta mudança na propriedade.

Figura 34 - Gráfico de Pareto da resistência a flexão

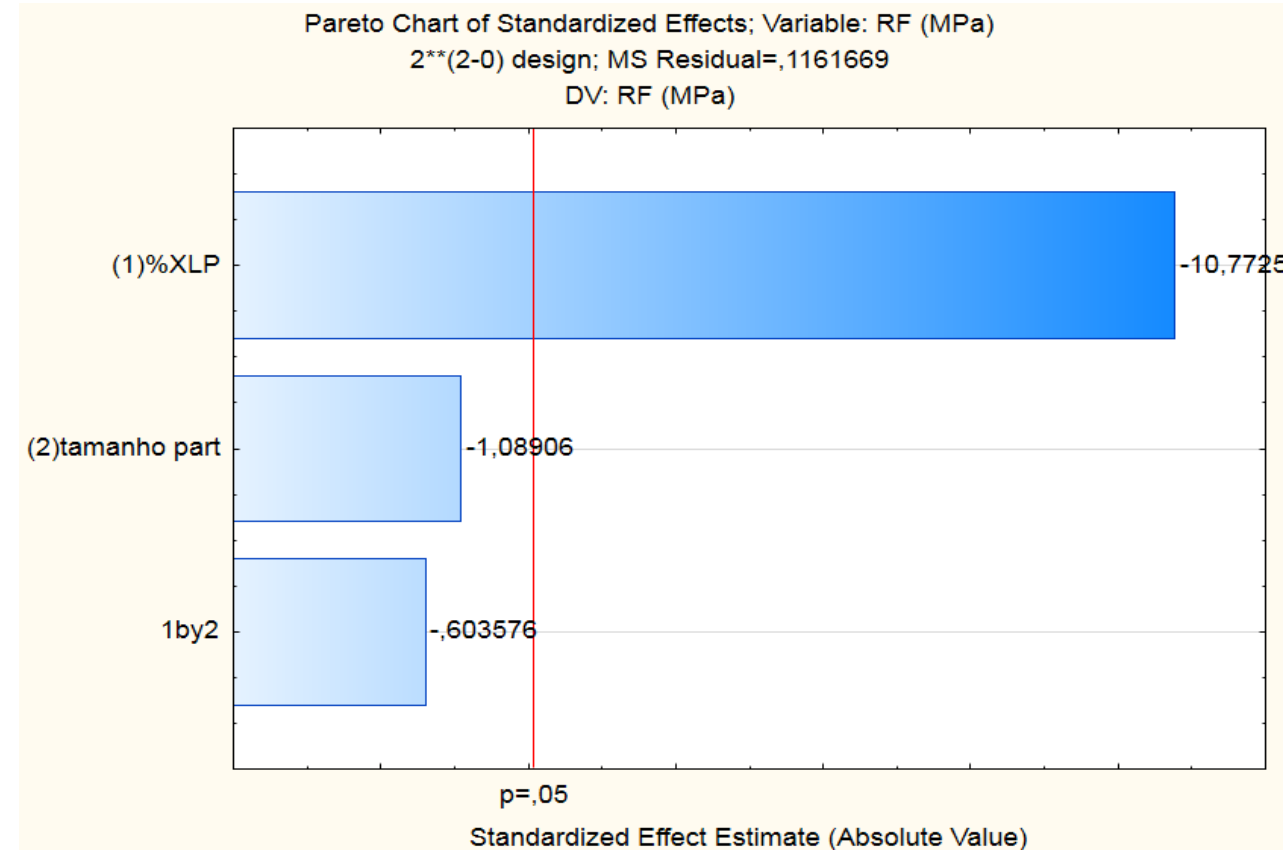

Fonte: Autor 
Figura 35 - Gráfico de Pareto para módulo de flexão a deformação de 0,3\%

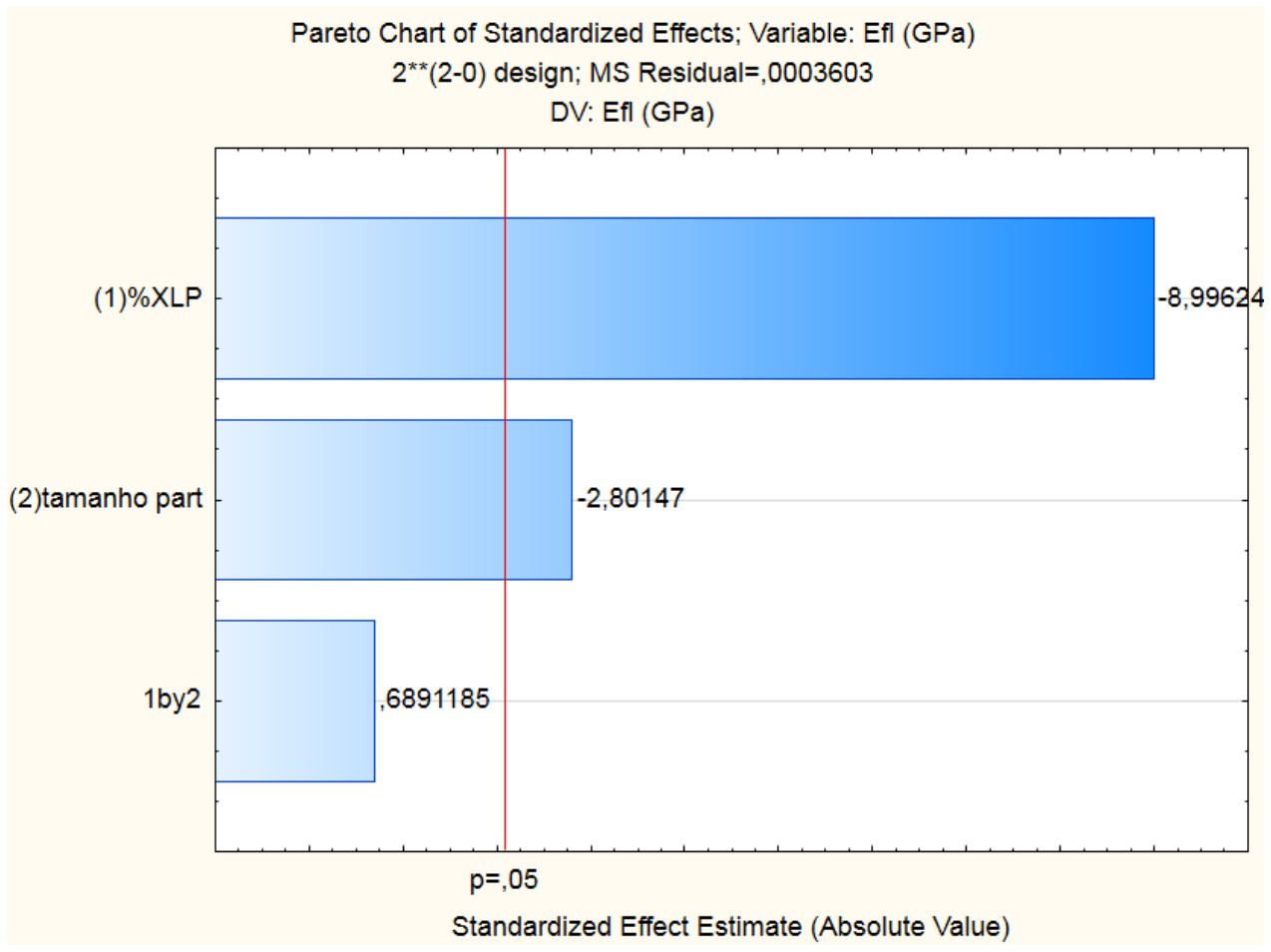

Fonte: Autor

\subsection{ENSAIO DE IMPACTO}

A tabela 11 e figura 36 apresentam os resultados do ensaio de impacto Charpy realizado em 5 amostras de cada composto. Ao comparar os compostos de 1\%-100 vs 1\%-900 nota-se que o efeito do tamanho de partícula influenciou na propriedade. Com relação aos compostos de 9\%-100 vs 9\%-900 o tamanho de partícula não apresentou mudança. Observase que de todas as propriedades mecânicas avaliadas, a resistência ao impacto foi a que mais apresentou mudança quando aumenta o teor de XLPE. Em relação ao controle, o maior aumento na resistência ao impacto foi obtido com a formulação 9\%-100, sendo este aumento em torno de 33\%. Para as outras propriedades avaliadas, as maiores quedas foram em torno de $15 \%, 20 \%, 10 \%$ e 10\%, para a resistência à tração, deformação na ruptura, resistência à flexão e módulo elástico de flexão, respectivamente.

Boss et al. (2011) também observaram aumentos na resistência ao impacto ao incorporar em HDPE, por processo de extrusão, XLPE proveniente de resíduo de fios e cabos com tamanho de partícula que variou de aproximadamente 0,4 a $0,6 \mathrm{~mm}$, ou seja, de 400 a $600 \mu \mathrm{m}$. Obtiveram um aumento na resistência ao impacto Charpy de aproximadamente 2,5 $\mathrm{kJ} / \mathrm{m}^{2}$ para $6,5 \mathrm{~kJ} / \mathrm{m}^{2}$ com teor de $40 \%$ de XLPE. 
Segundo Stepto (1988), a reticulação do PE aumenta a sua resistência ao impacto e ao crescimento de trincas. Assim, ao incorporar o XLPE, na matriz de HDPE, teremos um composto com resistência ao impacto superior ao do HDPE puro visto que existe compatibilidade entre os dois.

Tabela 11 - Resultado do ensaio de impacto Charpy

Ensaios de impacto Charpy com entalhe em V

\begin{tabular}{l|c|c}
\hline Compostos & $\mathrm{kJ} / \mathrm{m}^{2}$ & Desv. Pad \\
\hline Controle & 12,41 & 0,21 \\
\hline XLPE 1\%-100 & 12,41 & 0,11 \\
\hline XLPE 1\%-900 & 13,58 & 0,22 \\
\hline XLPE 5\%-500 & 14,58 & 0,25 \\
\hline XLPE 9\%-100 & 16,55 & 0,17 \\
\hline XLPE 9\%-900 & 16,37 & 0,17 \\
\hline
\end{tabular}

Fonte: Autor

Figura 36 - Resistência ao impacto dos compostos contendo XLPE e do HDPE puro

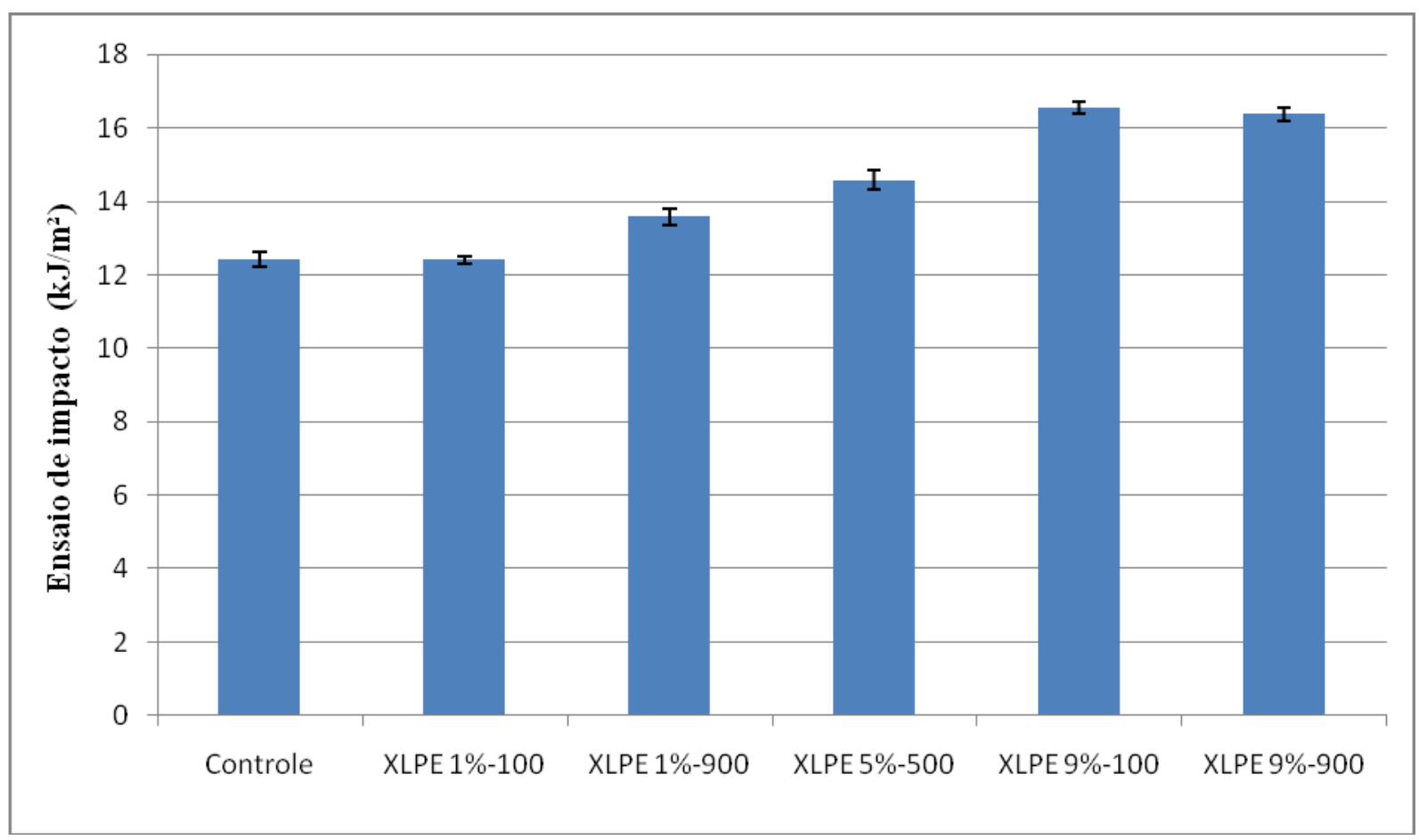

Fonte: Autor

A tabela 12 contém os coeficientes das equações ajustadas: $\mathrm{a}_{0}+\mathrm{a}_{1} \mathrm{x}_{1}+\mathrm{a}_{2} \mathrm{x}_{2}+\mathrm{a}_{3} \mathrm{x}_{1} \mathrm{x}_{2}$, onde $\mathrm{x}_{1}$ e $\mathrm{x}_{2}$ são as variáveis codificadas referentes aos teores de XLPE e tamanho médio de partícula respectivamente. 
Tabela 12 - Coeficientes das equações polinomiais dos ajustes de segunda ordem para a resistência ao impacto

\begin{tabular}{c|c|c|c|c|c}
\hline & \multicolumn{4}{|c|}{ Termos lineares } & $\mathrm{R}^{2}$ ajustado \\
\hline & $\mathrm{a}_{0}$ & $\mathrm{a}_{1}$ & $\mathrm{a}_{2}$ & $\mathrm{a}_{3}$ & \\
\hline Resistência ao impacto & $\mathbf{1 4 , 7 3 8 4}$ & $\mathbf{3 , 4 6 2}$ & $\mathbf{0 , 4 9 8}$ & $\mathbf{- 0 , 6 7 6}$ & 0,97021 \\
\hline
\end{tabular}

Fonte: Autor

Através da tabela 12, é possível observar que o aumento, tanto na concentração de XLPE como no tamanho da partícula contribuem para o aumento da resistência ao impacto do HDPE, sendo que o efeito da concentração é maior que o efeito do tamanho da partícula, o que pode ser atribuída ao comportamento borrachoso e flexível do XLPE e a forte interação entre o HDPE e XLPE. Entretanto, a interação entre as duas variáveis reduz a resistência ao impacto.

A figura 37 ilustra o diagrama de Pareto que fornece uma visão mais clara da importância da contribuição de cada variável na propriedade de impacto e sua significância adotando um intervalo de confiança de $95 \%$.

Figura 37 - Gráfico de Pareto ilustrando a influência da adição de XLPE variando o tamanho de partícula em HDPE

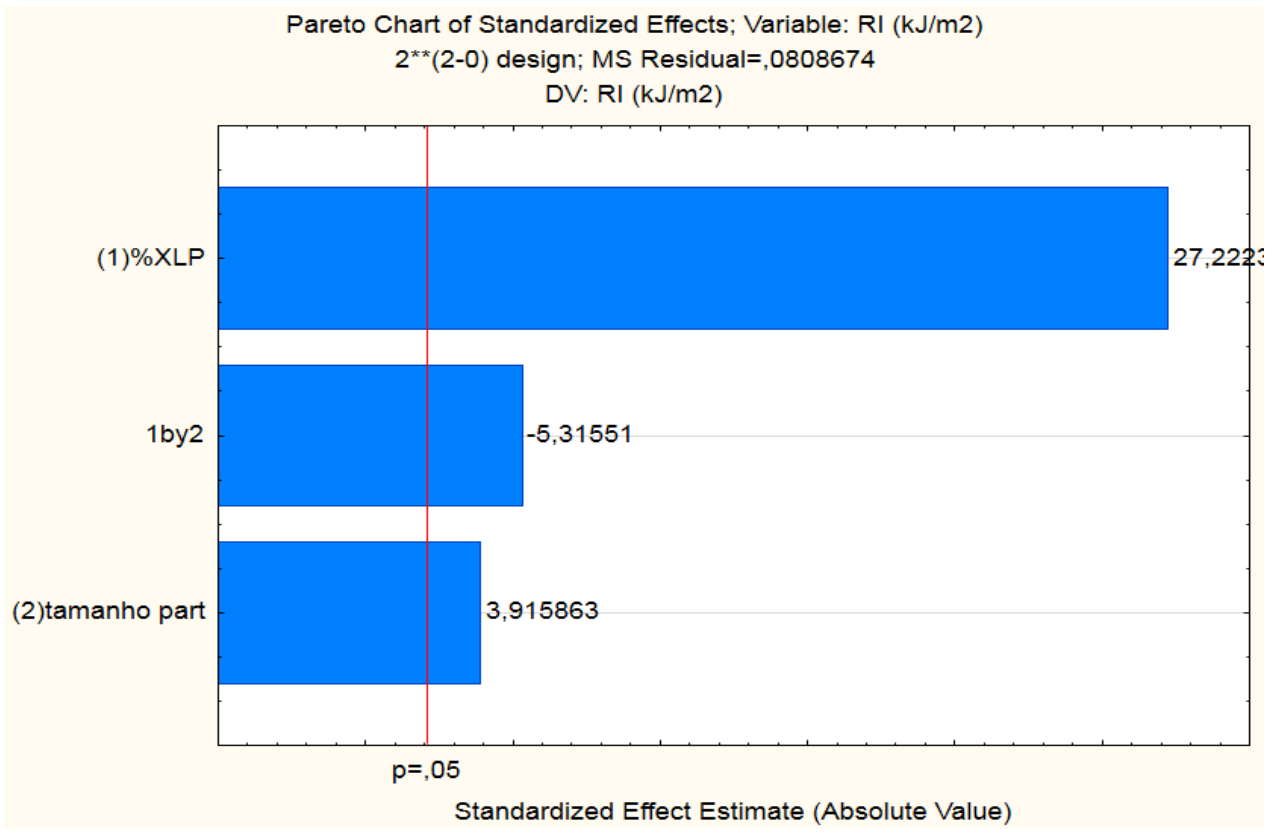

Fonte: Autor 


\subsection{OTIMIZAÇÃO DAS PROPRIEDADES DE TRAÇÃO, FLEXÃO E IMPACTO POR}

\section{MEIO DA FUNÇÃO DESIRABILITY}

Com a finalidade de encontrar o ponto ótimo para as propriedades de impacto, tração, e flexão estudadas, os valores previstos pelo modelo dos teores de XLPE e de tamanho de partícula que maximizariam os resultados, foi utilizado a função "desirability", cujos resultados encontram-se na figura 38 . O ponto ótimo seria então para o tamanho de partícula em nível -1, que corresponde ao tamanho médio de 100, e para o teor de XLPE, o nível -0,5, que corresponde ao teor de $3 \%$.

Figura 38 - Resultado desejado para maximizar as propriedades

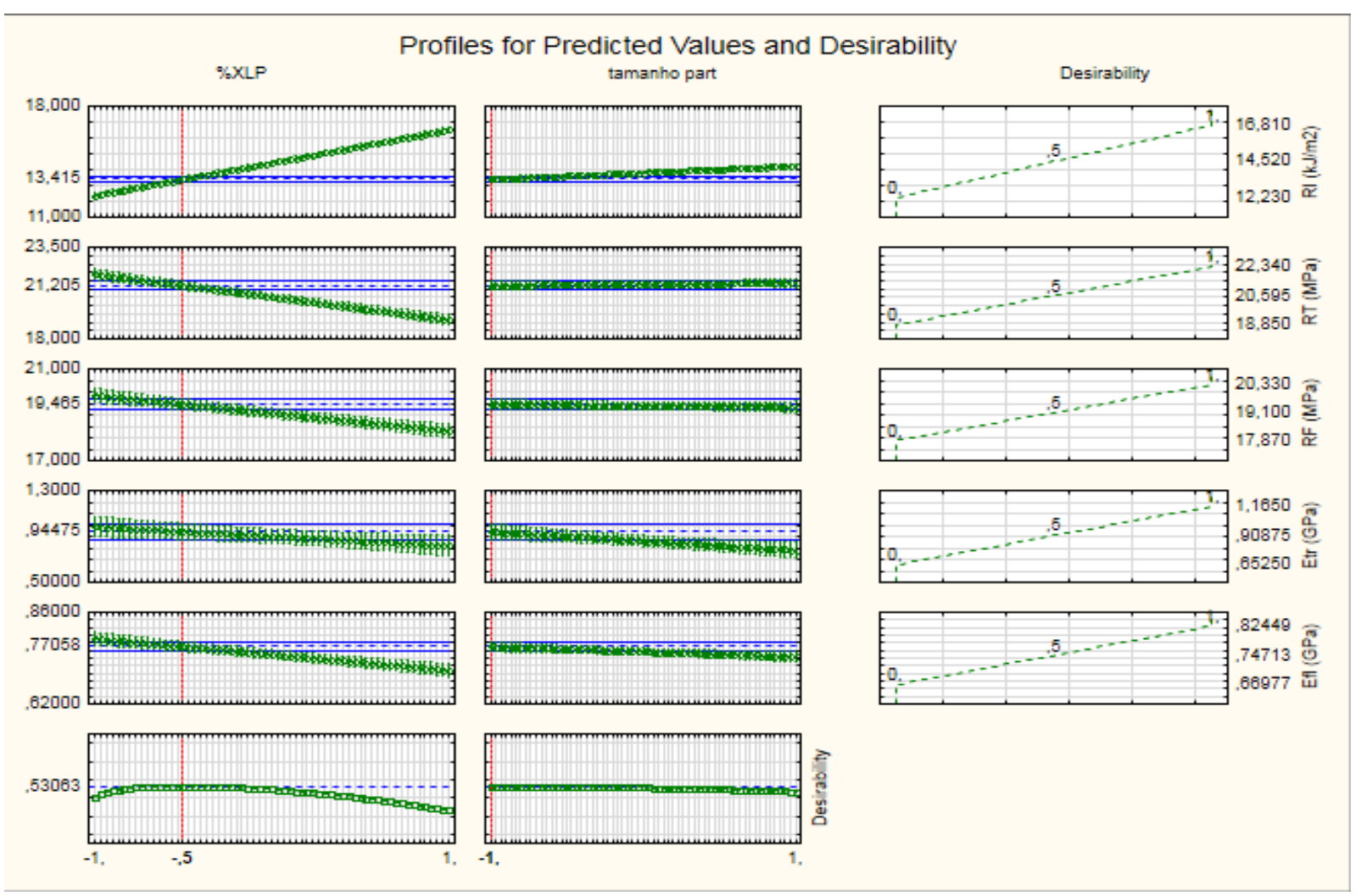

Fonte: Autor

\subsection{ENSAIO DE DEFLEXÃO POR TEMPERATURA (HDT)}

Os resultados obtidos, referentes ao ensaio de deflexão térmica, são apresentados na tabela 13 e figura 39 . 
Foram ensaiados 3 corpos de prova cujos resultados são apresentados através da média e desvio padrão.

Tabela 13 - Resultados do ensaio de HDT

\begin{tabular}{l|c|c}
\hline \multicolumn{3}{c}{ Ensaios de HDT } \\
\hline Compostos & Media $\left({ }^{\circ} \mathrm{C}\right)$ & Desv. Pad \\
\hline Controle & 47,93 & 0,61 \\
\hline XLPE 1\%-100 & 47,60 & 0,62 \\
\hline XLPE 1\%-900 & 47,97 & 0,90 \\
\hline XLPE 5\%-500 & 46,77 & 1,44 \\
\hline XLPE 9\%-100 & 45,60 & 0,66 \\
\hline XLPE 9\%-900 & 43,80 & 0,78 \\
\hline
\end{tabular}

Fonte: Autor

Figura 39 - Resultado do ensaio de HDT

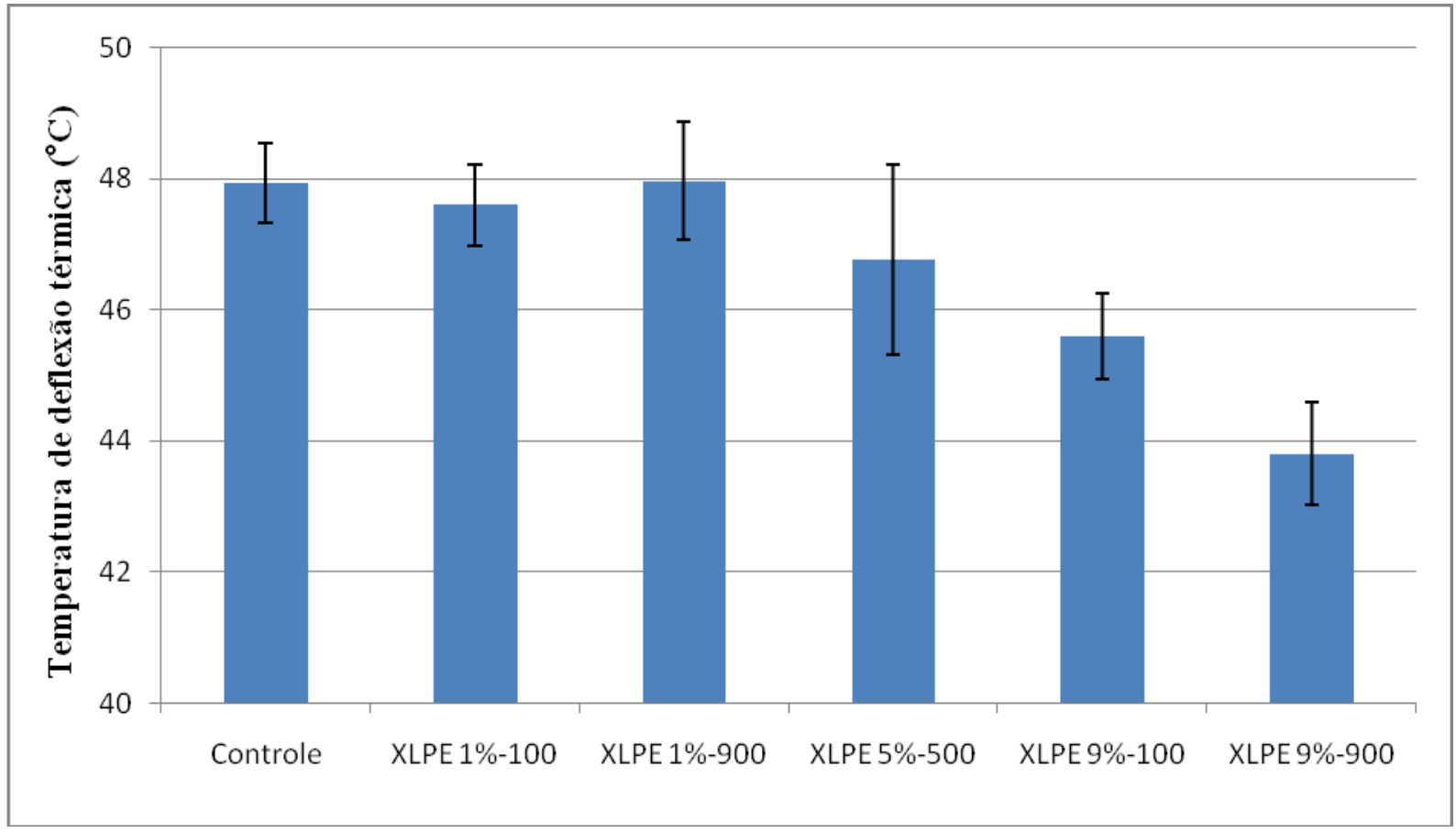

Fonte: Autor

A tabela 14 mostra os coeficientes das equações ajustadas: $\mathrm{a}_{0}+\mathrm{a}_{1} \mathrm{x}_{1}+\mathrm{a}_{2} \mathrm{x}_{2}+\mathrm{a}_{3} \mathrm{X}_{1} \mathrm{x}_{2}$, onde $\mathrm{x}_{1}$ e $\mathrm{x}_{2}$ são as variáveis codificadas referentes aos teores de XLPE e tamanho médio de partícula respectivamente. Através da figura 40 onde mostra o gráfico de Pareto da propriedade HDT, é possível ter uma visão estatística mais apurada possibilitando analisar a contribuição de cada variável na propriedade de HDT e sua significância. 
Tabela 14 - Coeficiente das equações polinomiais dos ajustes de segunda ordem da HDT

\begin{tabular}{c|c|c|c|c|c}
\hline & \multicolumn{4}{|c|}{ Termos lineares } & $\mathrm{R}^{2}$ ajustado \\
\hline & $\mathrm{a}_{0}$ & $\mathrm{a}_{1}$ & $\mathrm{a}_{2}$ & $\mathrm{a}_{3}$ & \\
\hline HDT $\left({ }^{\circ} \mathrm{C}\right)$ & $\mathbf{4 6 , 3 4 6 7}$ & $\mathbf{- 3 , 0 8 3 3 3}$ & $-0,71667$ & $-1,08333$ & 0,7241 \\
\hline
\end{tabular}

Fonte: Autor

Observa-se que a única variável significativa é o teor de XLPE, sendo que seu aumento leva a uma queda no HDT. Isto deve-se ao fato do XLPE que é proveniente da aplicação de fios e cabos, possuir flexibilidade superior ao HDPE puro que é comprovado no ensaio de flexão que a adição de XLPE em HDPE apresenta aumento na flexão, isto faz com que ao aumentar o teor de XLPE, a tendência é reduzir a temperatura de deflexão térmica do composto. A maior queda ocorreu para a formulação 9\% - 900 .

Figura 40 - Pareto HDT efeito significativo no teor de XLPE

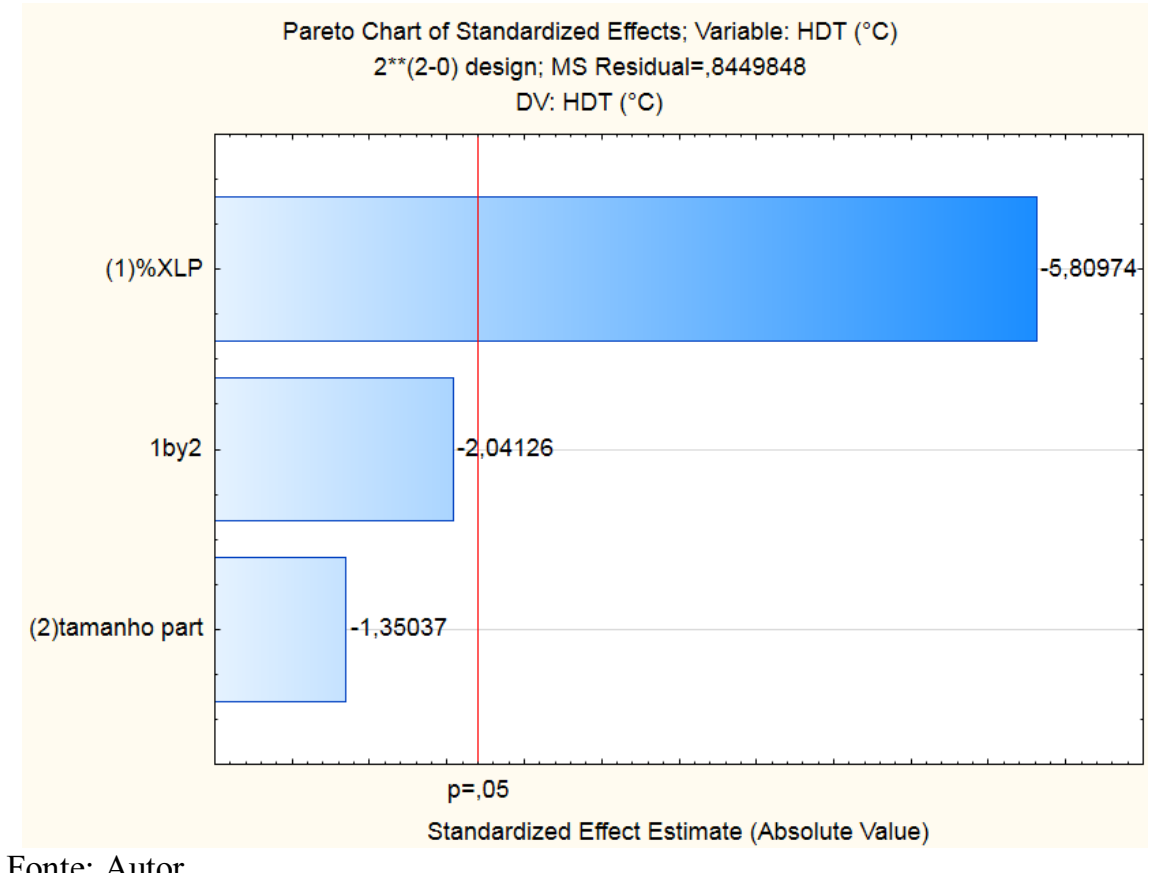

Fonte: Autor

\subsection{VALIDAÇÃO DO MODELO}

Para verificar a necessidade ou não de expandir o modelo do planejamento experimental, ou seja, para verificação de curvatura, foi realizada uma comparação do intercepto do modelo do planejamento estatístico com os resultados obtidos do ponto central, 
ou seja, a composição contendo $5 \%$ de XLPE com tamanho de partícula 500. Esta comparação é mostrada na tabela 15 .

Tabela 15 - Comparação do intercepto do modelo do planejamento estatístico com os resultados do ponto central

\begin{tabular}{l|c|c}
\hline & $\mathrm{a}_{0}$ & Resultados para ponto central (5\%-500) \\
\hline Resistência ao impacto $\left(\mathrm{kJ} / \mathrm{m}^{2}\right)$ & 14,74 & $14,6 \pm 0,2$ \\
\hline Resistência à tração $(\mathrm{MPa})$ & 20,65 & $20,5 \pm 0,5$ \\
\hline Módulo elástico de tração $(\mathrm{MPa})$ & 0,858 & $0,901 \pm 0,095$ \\
\hline Deformação na ruptura $(\%)$ & 97,05 & $94 \pm 5$ \\
\hline Resistência à flexão $(\mathrm{MPa})$ & 18,99 & $18,9 \pm 0,1$ \\
\hline Módulo elástico de flexão $(\mathrm{GPa})$ & 0,738 & $0,791 \pm 0,016$ \\
\hline HDT $\left({ }^{\circ} \mathrm{C}\right)$ & 46,3 & $46,8 \pm 1,4$ \\
\hline
\end{tabular}

Fonte: Autor

Comparação dos resultados do ponto central (com o intercepto do modelo $\left(\mathrm{a}_{0}\right)$ para cada propriedade estudada, mostram grande similaridade. Sendo assim, é verdadeira a hipótese que há uma relação linear entre cada variável independente e a propriedade para estes intervalos estudados, ou seja, não existe curvatura, portanto não houve necessidade de expandir o planejamento.

\subsection{ANÁLISE POR MICROSCOPIA ELETRÔNICA DE VARREDURA (MEV)}

As análises morfológicas foram realizadas nos corpos de prova fraturados provenientes do ensaio de impacto onde foi analisada a superfície da fratura.

Através dos resultados obtidos por MEV, é possível verificar uma forte interação entre o XLPE e o HDPE, pois são quimicamente iguais. Por ser quimicamente igual, a incorporação do XLPE em HDPE proporciona ótima interação e uma forte adesão entre o XLPE e a matriz de HDPE com isto, não houve a necessidade da utilização de um.

Em teores de 1\% e tamanho de partícula de 100, não é possível visualizar o XLPE na matriz de HDPE, a visibilidade do XLPE se dá em tamanho de partícula de 900 para concentração de 1\%. Para as demais concentrações, é possível ver nitidamente as partículas de XLPE e sua interação na matriz conforme figura 41. 
Figura 41 - Fotomicrografia de MEV da superfície fraturada dos compostos:

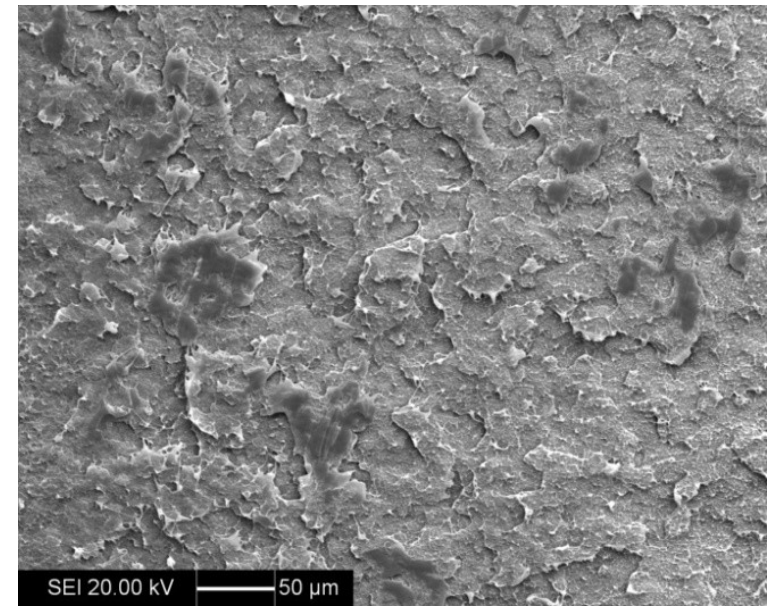

A) Controle 250x

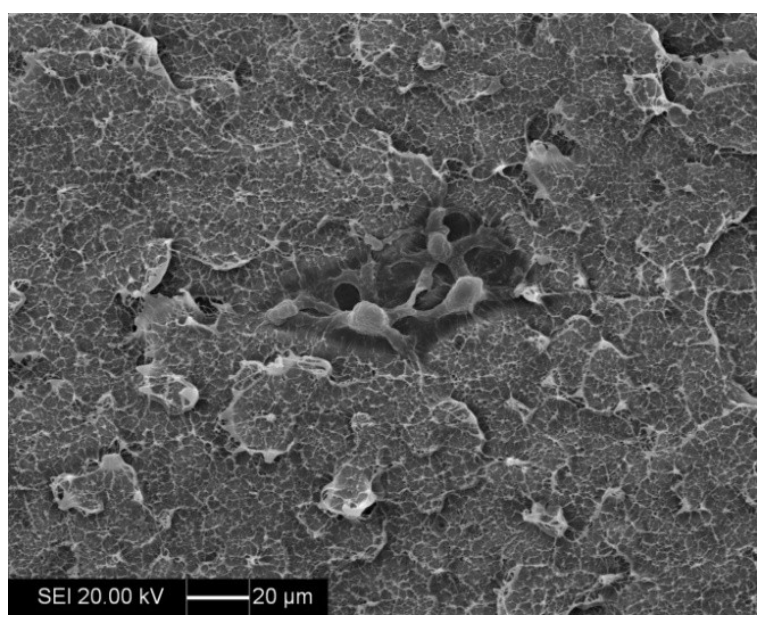

C) XLPE 1\%-900 500x

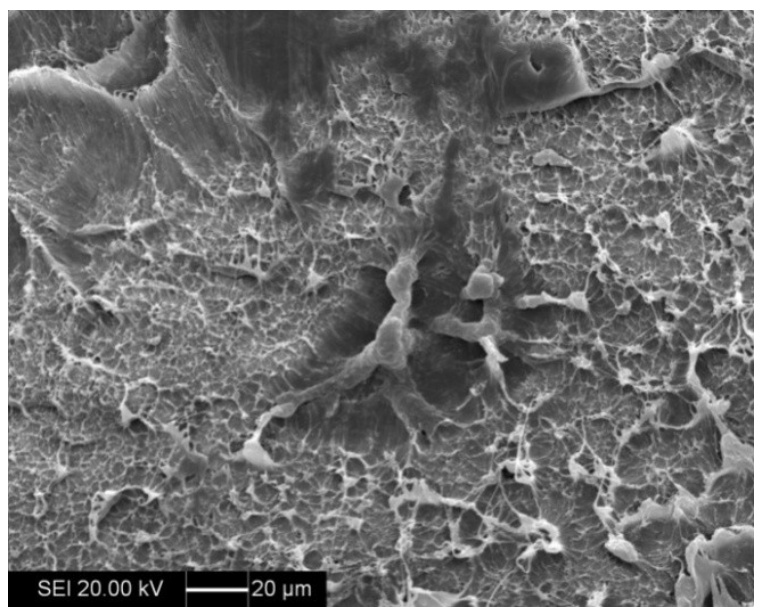

E) XLPE 9\%-100 500x

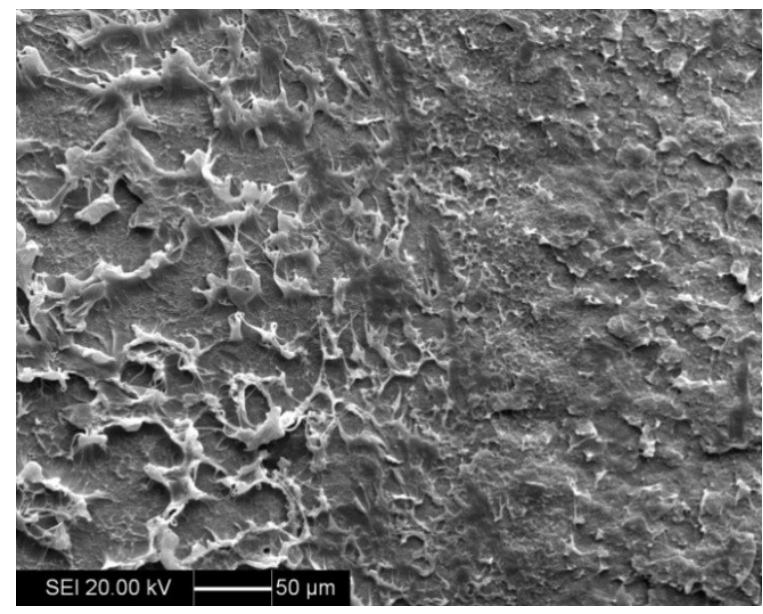

B) XLPE1\%-100 250x

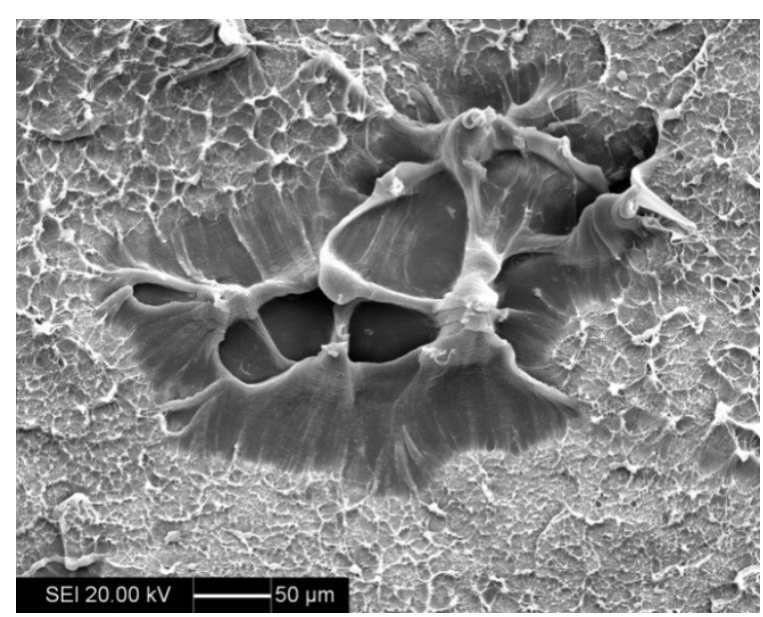

D) XLPE5\%-500 250x

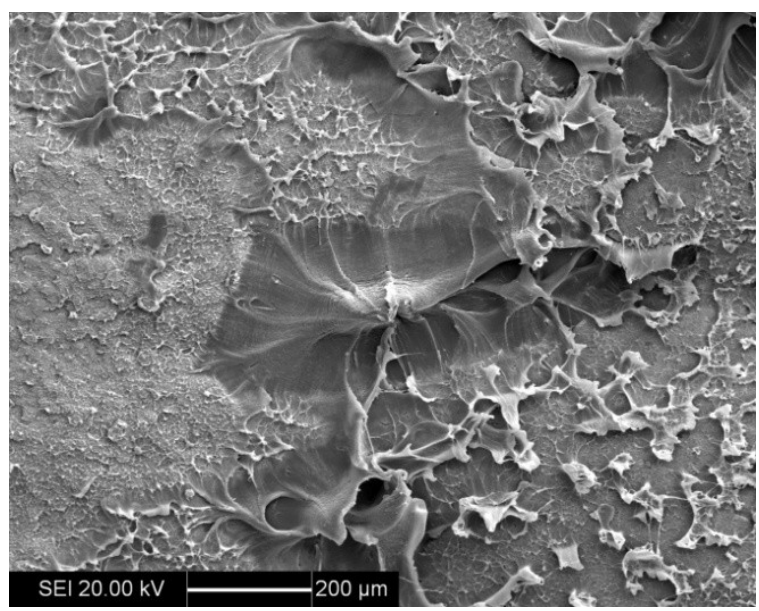

F) XLPE9\%-900 100x

Fonte: Autor 


\section{CONCLUSÕES}

Resíduos de XLPE, provenientes de fios e cabos elétricos, com tamanho médiode 74, 509 e 842 micrometros foram incorporados com êxito em HDPE, por meio de extrusão com dupla rosca corrotacional, usando-se concentrados de XLPE em HDPE produzidos pelo processo de calandragem. Foi utilizado um planejamento fatorial 2 por $2 \mathrm{com}$ ponto central, no qual o teor de XLPE variou de 1 e 9\% em massa. A comparação dos resultados do ponto central (5\% de XLPE e tamanho médio de partícula $509 \mu \mathrm{m})$ com o intercepto do modelo $\left(a_{0}\right)$ para cada propriedade estudada, mostram grande similaridade. Sendo assim, é verdadeira a hipótese que há uma relação linear entre cada variável independente e a propriedade, ou seja, não houve necessidade de expandir o planejamento.

O aumento na concentração de XLPE aumentou a resistência ao impacto e diminuiu as resistências à tração e à flexão, o módulo elástico de flexão e o HDT. O efeito no modulo elástico em tração e na deformação na ruptura não foi significativo para o intervalo de confiança adotada de 95\%. O aumento do tamanho médio de partícula de XLPE influenciou positivamente a resistência ao impacto do HDPE, e reduziu a deformação na ruptura e o módulo elástico de flexão. O efeito nas resistências à tração e à flexão e no módulo de tração não foi significativo para o intervalo de confiança de $95 \%$ adotado. A interação entre as duas variáveis diminuiu a resistência ao impacto e aumentou o módulo elástico em tração, e não foi significativo para as outras propriedades estudadas.

Através do MEV é possível observar uma forte interação da matriz HDPE com o resíduo de XLPE por serem quimicamente semelhantes, esta forte interação corrobora e evidencia o aumento da resistência ao impacto.

Diante dos resultados obtidos, o uso de resíduo de XLPE proveniente de fios e cabos, proporciona um resultado positivo na propriedade impacto, ou seja, para aplicações que necessita o aumento da resistência ao impacto, é tecnicamente viável o uso de resíduo de XLPE micronizado em matriz de HDPE. 


\subsection{SUGESTÕES PARA TRABALHOS FUTUROS}

O trabalho permite sugerir os seguintes trabalhos futuros:

a) Realizar ensaio de DSC para análise de uma possível variação nas temperaturas de transição e grau de cristalinidade;

b) Estudar o comportamento reológico dos compostos visando analisar possíveis problemas que pode ocorrer nos processos de transformação com a adição de XLPE;

c) Verificar se há diferença na flamabilidade dos compostos em função da adição de XLPE;

d) Produzir composto de XLPE em HDPE utilizado os resultados da otimização, ou seja, teor de 3\% de XLPE e tamanho médio de $74 \mu \mathrm{m}$. 


\section{REFERÊNCIAS}

AMERICAN SOCIETY FOR TESTING AND MATERIALS. D638-14: standard test method for tensile properties of plastics. West Conshohocken, PA, 2014.

D790-17: standard test methods for flexural properties of unreinforced and reinforced plastics and electrical insulating materials. West Conshohocken, PA, 2017.

D6110-10: standard test method for determining the charpy impact resistance of notched specimens of plastics. West Conshohocken, PA, 2010.

D648-16: standard test method for deflection temperature of plastics under flexural load in the edgewise position. West Conshohocken, PA, 2016.

BOSS, A. et al. New technology for recycling of plastics from cable waste. In:

INTERNATIONAL CONFERENCE ON INSULATED POWER CABLES, 8., 2011, Versailles. Proceeding...Versailles,: Jicable, 2011.

BOSS, A.; HAGSTRÖM, B. Recycling of XLPE insulations. In: NORDIC INSULATION SYMPOSIUM, 2009, Gothemburg. Anais... Gothemburg,2009.

CANEVAROLO JR., S. V. Ciências dos polímeros: um texto básico para tecnólogos e engenheiros. 2. ed. São Paulo: Artliber, 2006.

CUCCHIARA, M. G.; BONSE, B. C. Propriedades de PEAD contendo XLPE proveniente de revestimento de fios e cabos elétricos. 2015. Iniciação Científica (Dept. de Engenharia de Materiais) - Centro Universitário da FEI, São Bernardo do Campo, 2015.

CUSTÓDIO, G. J. S. Tenacificação de poli(ftalamida) (PPA) através de nanocompósitos com carbonato de cálcio e de blendas com copolímero estireno/etileno-butileno/estireno (SEBS). 2010. 83 f. Dissertação (Mestrado em Ciência e Engenharia de Materiais) - UFSCar, São Carlos, 2010.

FONSECA, L. F. V.; BONSE, B. C. Incorporação de polietileno reticulado (XLPE) provenientes de revestimentos de fios e cabos elétricos em matriz de polietileno de baixa densidade. 2015. 26f. Iniciação Científica (Dept. de Engenharia de Materiais) - Centro Universitário da FEI, São Bernardo do Campo, 2015.

GORNI, A. A. Introdução aos plásticos. Revista plástico industrial. 2003. Disponível em:< http://www.gorni.eng.br/intropol.html> Acesso em: 01 jul. 2017.

GULMINE, J. V. Processos de envelhecimento e correlações estrutura propriedades do XLPE. 2004. 90 f. Tese (Doutorado em Engenharia) - Universidade Federal do Paraná. Curitiba, 2004.

HARPER, C. A. Handbook of plastics technologies: the complete guide to properties and performance. 2nd ed. New York: McGraw-Hill Education, 2006. 
KALYON, D. M.; HALLOUCH, M.; FARES, N. Recycling of thermosets as fillers. In: ANNUAL TECHNICAL CONFERENCE, 42., 1984, New Orleans. Papers... New Orleans: Society of Plastics Engineers, 1984. p. 640-642.

MANO, E. B.; MENDES, L. C. Introdução a polímeros. 2.ed. rev. e ampl. São Paulo: Edgard Blücher, 2004.

MEDINA, V. H. Reciclagem de materiais: tendências tecnológicas de um novo setor. In: CENTRO DE TECNOLOGIA MINERAL. Tendências tecnológicas Brasil 2015: geociências e tecnologia mineral. Rio de Janeiro: CETEM/MCT, 2007. p. 273 - 302.

NEXANS BRASIL. Soluções personalizadas de fios e cabos. 2008. Disponível em: $<$ http://www.nexans.com.br/SouthAmerica/2008/Comparing_pt_5.pdf $>$. Acesso em: 29 jun. 2017.

OGANDO, J. Crosslinked PE can be recycled. The Free Library, 1992. Disponível em: $<$ https://www.thefreelibrary.com/Crosslinked PE can be recycled.-a012429915>. Acesso em: 8 mar. 2017.

OHKI, Y. XLPE recycling technology in Japan. IEEE Electr. Insul. Mag., v. 25, p. 48-49, Mar-Apr/2009.

OLIVEIRA, A. D. Dispersão seletiva de argila montmorilonita em blendas poliméricas de PA6/ABS. 2009. 103f. Dissertação (Mestrado em Ciência e Engenharia de Materiais) UFSCar, São Carlos, 2009.

PEACOCK, J. A. Handbook of polyethylene: structures, properties and applications. New York: Marcel Dekker, 2000.

PICKERING S. Recycling and disposal of thermoset composites, 2013. Disponível em: < https://www.fose1.plymouth.ac.uk/sme/acmc/cpd/Pickering_LCA2013.pdf > . Acesso em: 01 out. 2015.

QUDAIH, R.; JANAJREH, I.; VUKUSIC, S. E. Recycling of cross-linked polyethylene cable waste via particulate infusion. In: GLOBAL CONFERENCE ON SUSTAINABLEMANUFACTURING, 8., 2011, Masdar. Proceedings... Masdar: Springer, 2011. p 233-239.

YOUNG, R. J; LOVELL, P. A. An introduction to polymers, 2nd ed. London: Chapman \& Hall, 1991.

RABELLO, M. Aditivação de polímeros. São Paulo: Artliber, 2000.

SAECHTLING, H. International plastics handbook for the technologist, engineer and user.3rd ed. Munich: Hansen, 1995.

Senna: o brasileiro, o herói, o campeão. Direção de Asif Kapadia. Roteiro de Manish Pandey. [s.l.]: Technicolor Sa, 2010. (106 min.), online, son., color. 
SILVIA, J. C; et al. Reciclagem energética: Uma solução inovadora para o plástico não reciclável. e-xacta, Belo Horizonte, v.4, n.2, ed. especial, p. 87-96, 2011.

SIRISINHA, K.; CHUAYTHONG, P. Reprocessable silane-crosslinked polyethylene: property and utilization as toughness enhancer for high-density polyethylene. Journal of Materials Science, v. 49, n. 14, p. 5182-5189, jul. 2014.

SPINACÉ, M. A. DA S., DE PAOLI M. A. A tecnologia da reciclagem de polímeros. Química Nova, v. 28, n. 1, p. 65-72, 2005.

STEPTO, R. F. T. Crosslinked polymers, edited by Dickie, Ray A, Labana, S. S. \& Baver, R. S. (ACS, Washington), 1988.

TAMBOLI, S. M.; MHASKE, S. T.; KALE, D. D. Crosslinked polyethylene. Indian Journal of Chemical Technology. Mumbai, v.11, p. 853-864, Nov. 2004.

TOKUDA S. et al. Thermoplasticizing technology for the recycling of cross-linked Polyethylene. Furukawa Review, n. 23, p. 88-93, 2003.

USA WIRE \& CABLE, INC. Wire knowledge, 2014. Disponível em <http://www.usawirecable.com/pdfs/wire\%20knowledge.pdf $>$.Acesso em: 18 jan. 2017. 
APÊNDICE A - CURVAS ENSAIO DE TRAÇÃO 
Figura 42 - Curva ensaio de tração HDPE controle $(50 \mathrm{~mm} / \mathrm{min}$.)

\section{TRAÇÃO EM TERMOPLASTICOS}

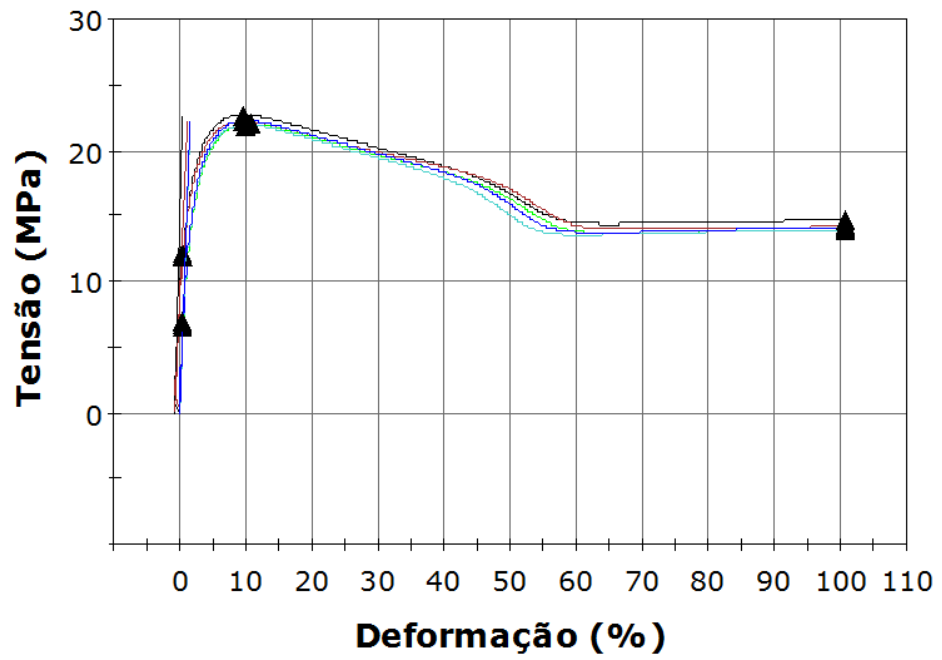

Fonte: Autor

Figura 43 - Curva ensaio de tração HDPE controle $(500 \mathrm{~mm} / \mathrm{min}$.)

\section{TRAÇÃO EM TERMOPLASTICOS}

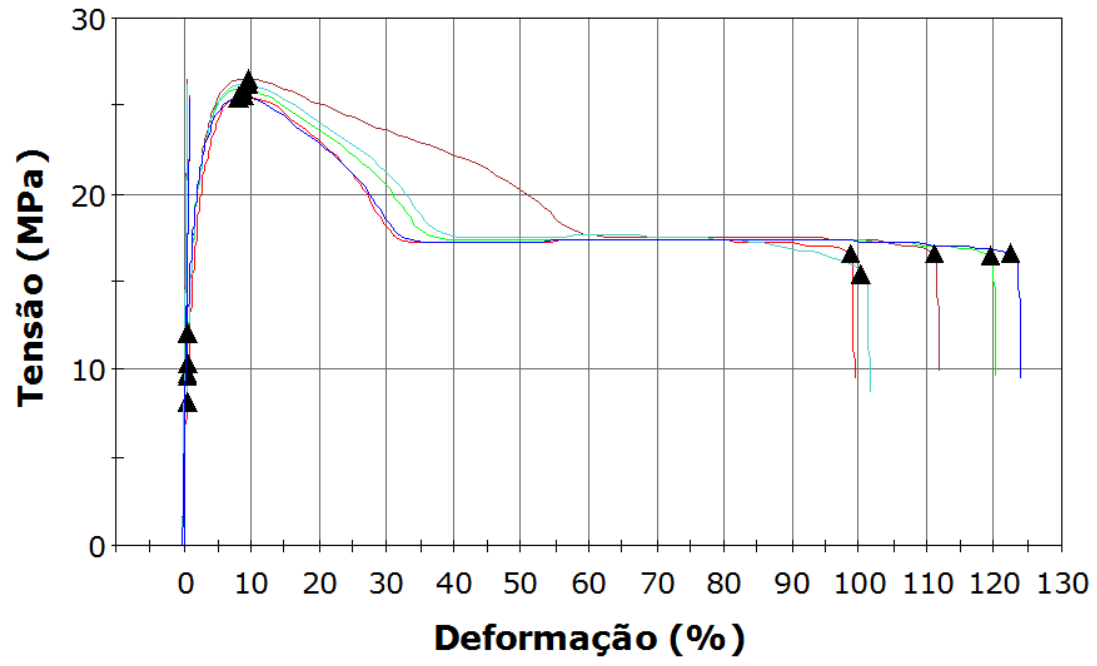

Fonte: Autor 
Figura 44 - Curva ensaio de tração XLPE 1\%-100 (50mm/min.)

\section{TRACÃO EM TERMOPLASTICOS}
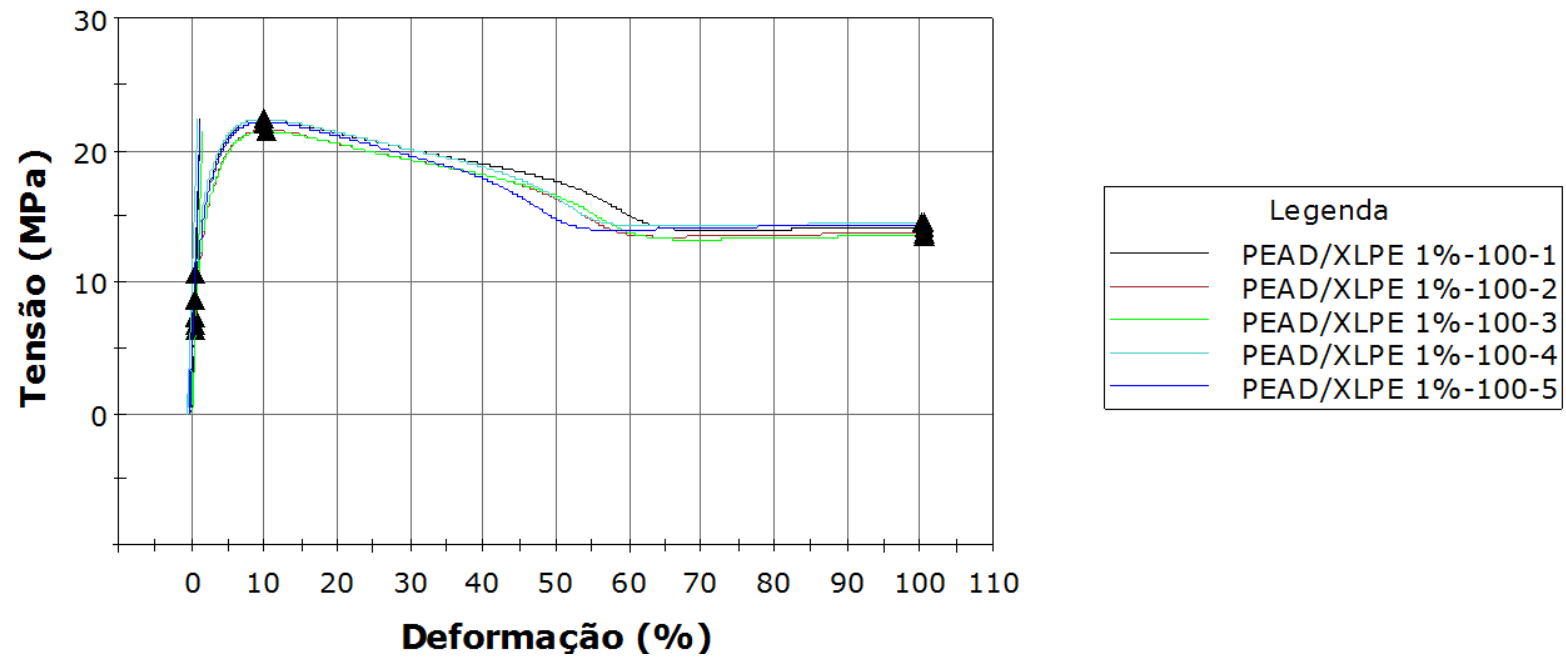

Fonte: Autor

Figura 45 - Curva ensaio de tração XLPE 1\%-100 (500mm/min.)

\section{TRAÇÃO EM TERMOPLASTICOS}

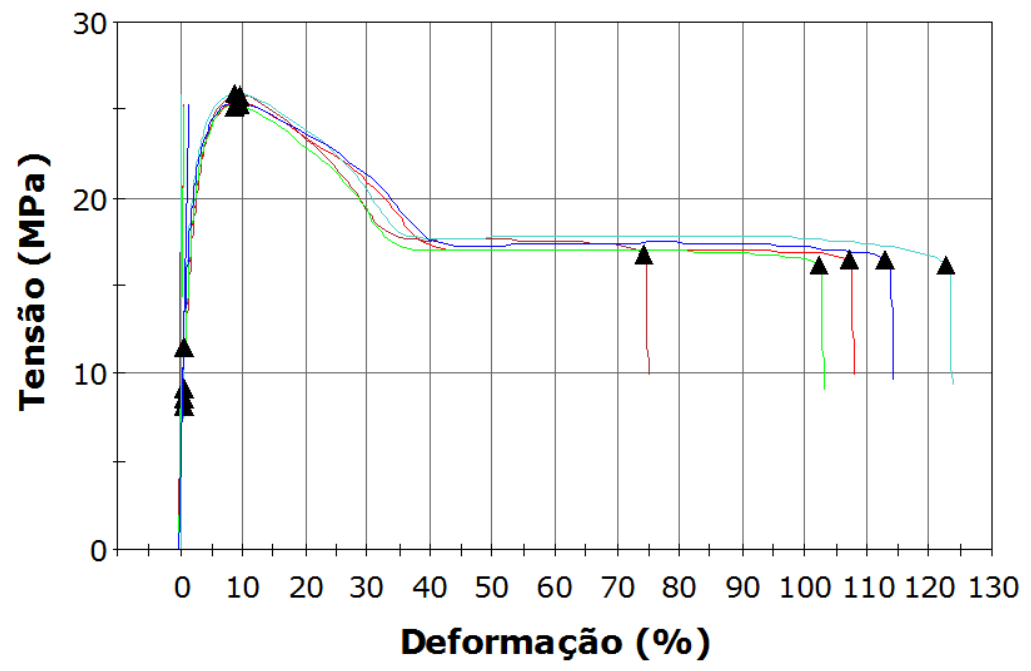

Fonte: Autor 
Figura 46 - Curva ensaio de tração XLPE 1\%-900 (50mm/min.)

\section{TRAÇÃO EM TERMOPLASTICOS}

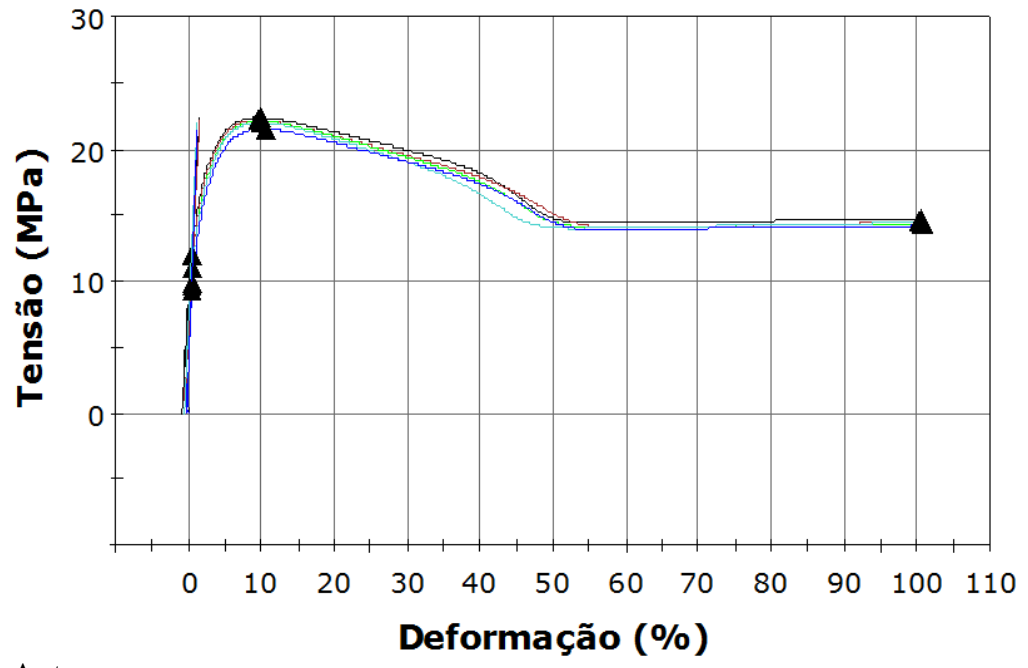

Fonte: Autor

\section{Deformação (\%)}

Figura 47 - Curva ensaio de tração XLPE 1\%-900 (500mm/min.)

\section{TRAÇÃO EM TERMOPLASTICOS}

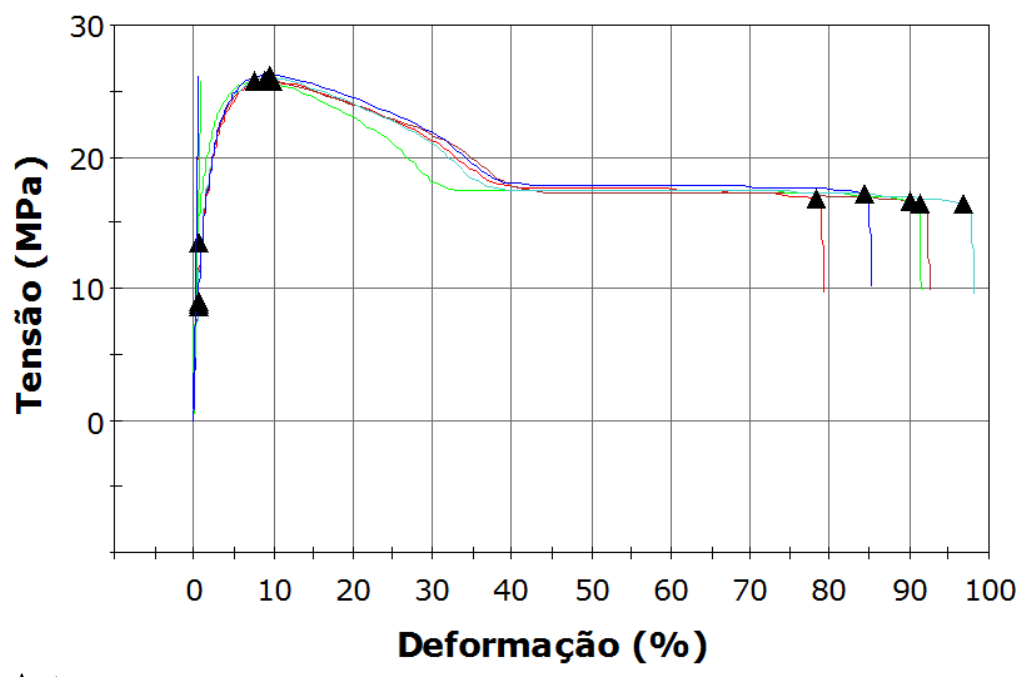

Fonte: Autor 
Figura 48 - Curva ensaio de tração XLPE 5\%-500 (50mm/min.)

\section{TRAÇÃO EM TERMOPLASTICOS}

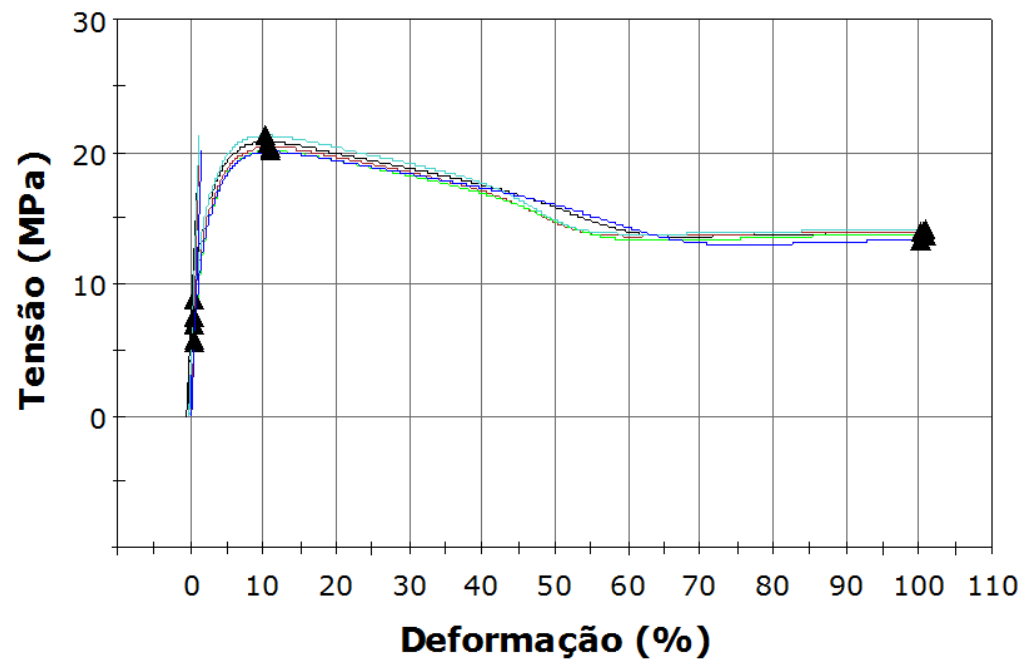

Fonte: Autor

Figura 49 - Curva ensaio de tração XLPE 5\%-500 (500mm/min.)

\section{TRAÇÃO EM TERMOPLASTICOS}

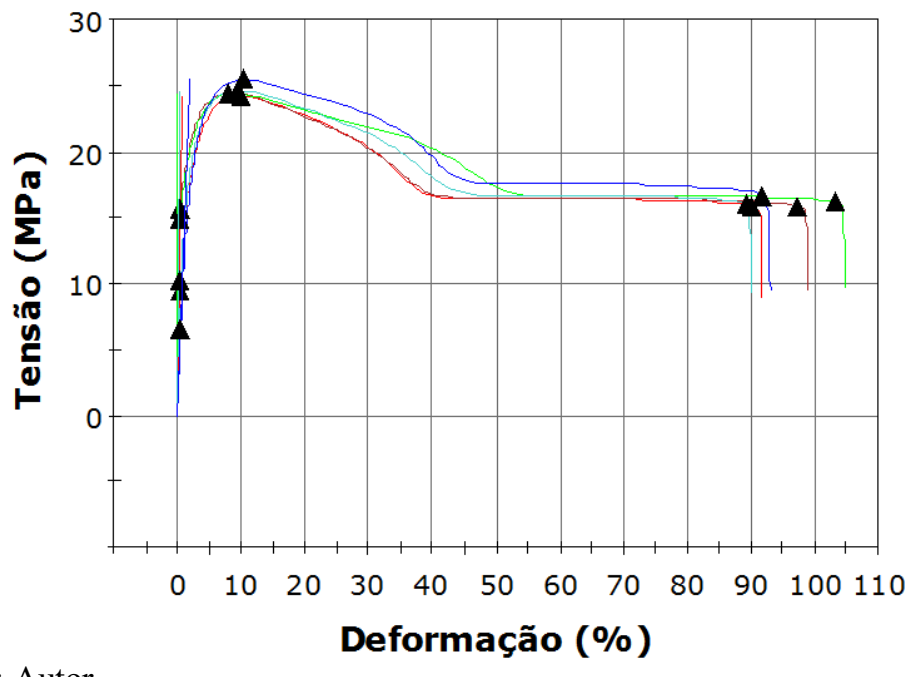

Fonte: Autor 
Figura 50 - Curva ensaio de tração XLPE 9\%-100 (50mm/min.)

\section{TRAÇÃO EM TERMOPLASTICOS}

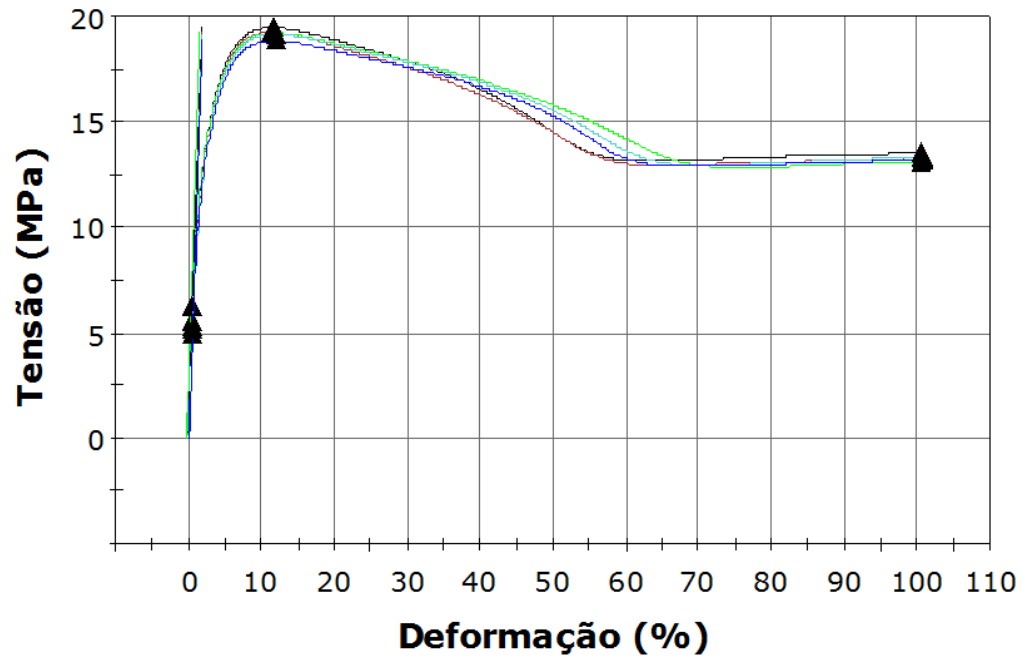

Fonte: Autor

Figura 51 - Curva ensaio de tração XLPE 9\%-100 (500mm/min.)

\section{TRAÇÃO EM TERMOPLASTICOS}

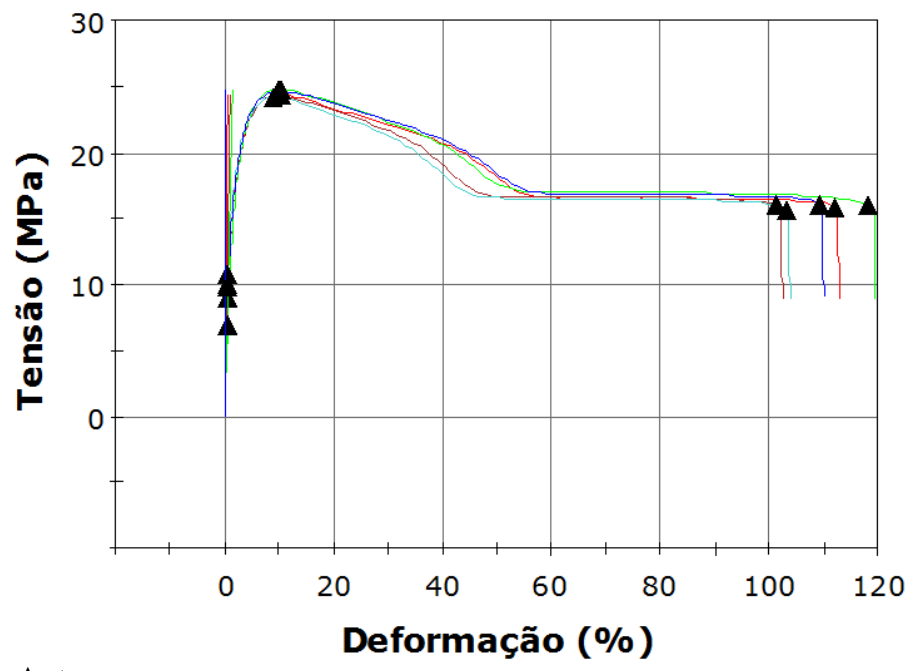

Fonte: Autor 
Figura 52 - Curva ensaio de tração XLPE 5\%-900 (50mm/min.)

\section{TRAÇÃO EM TERMOPLASTICOS}

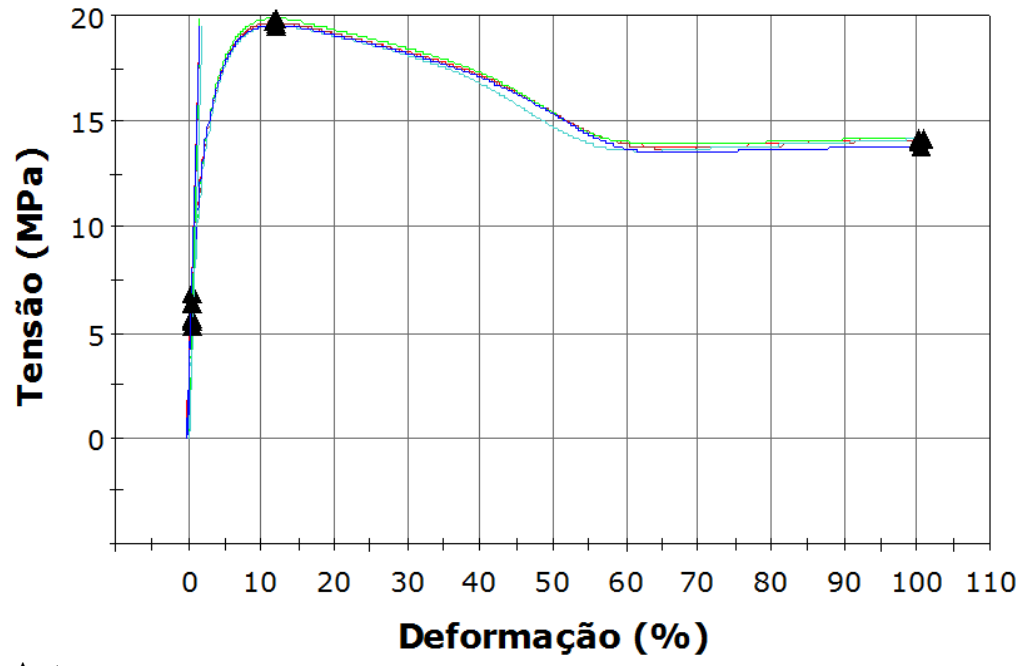

Fonte: Autor

\section{Deformação (\%)}

Figura 53 - Curva ensaio de tração XLPE 9\%-900 (500mm/min.)

\section{TRAÇÃO EM TERMOPLASTICOS}

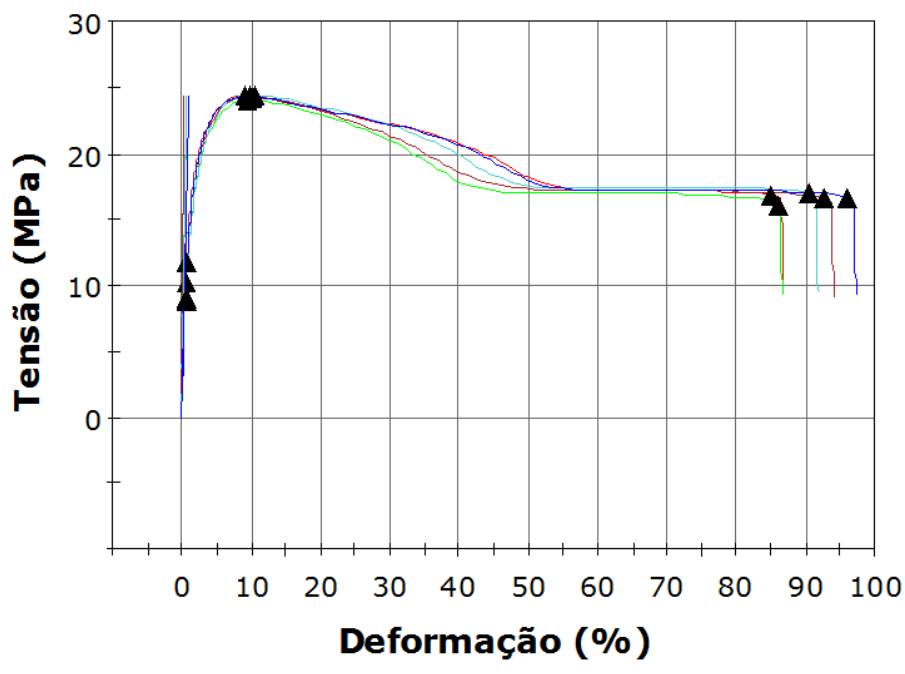

Fonte: Autor 
APÊNDICE B - CURVAS ENSAIO DE FLEXÃO 
Figura 54 - Curva ensaio de flexão HDPE controle

Provete 1 a 5
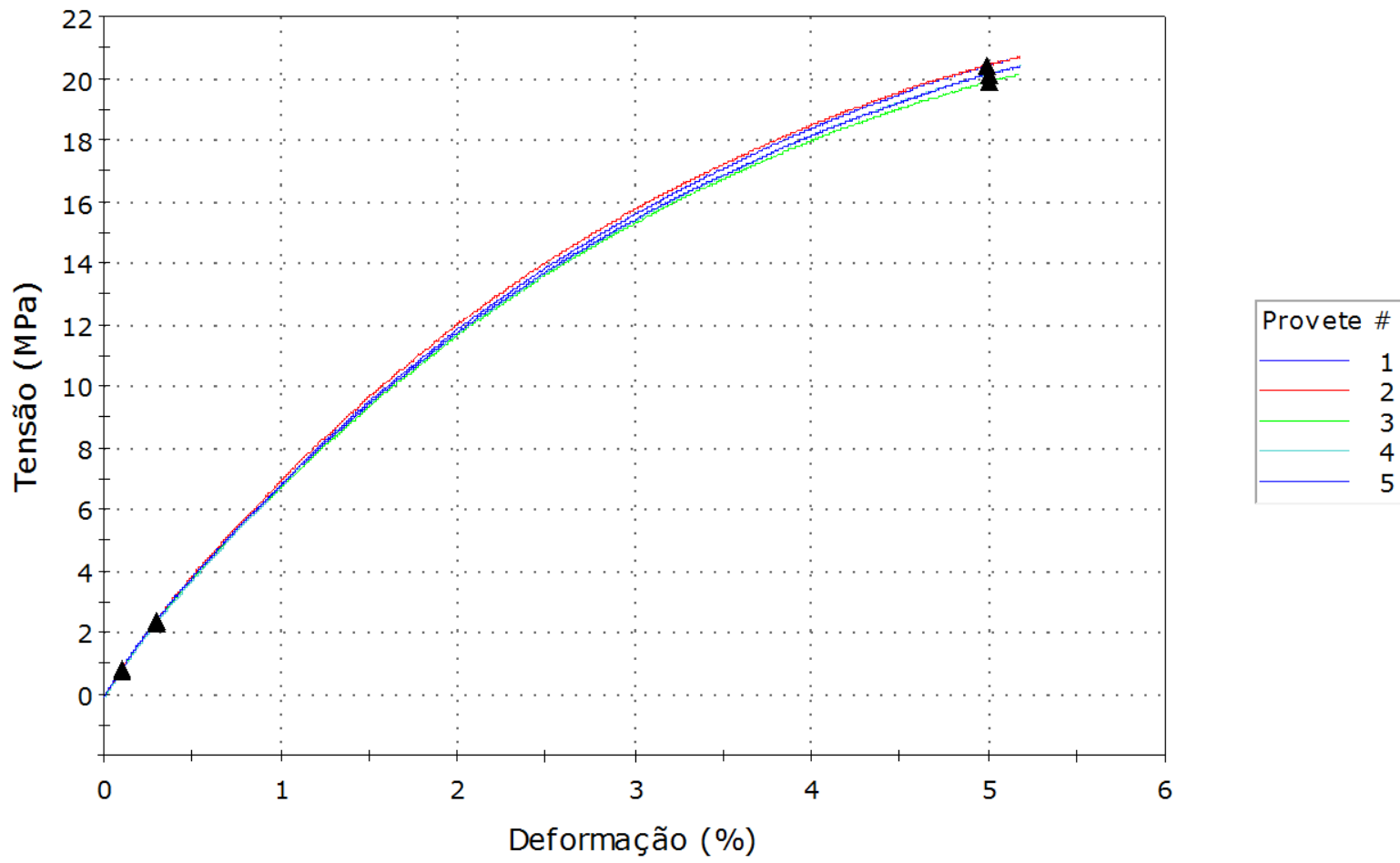

Fonte: Autor

Figura 55 - Curva ensaio de flexão XLPE 1\%-100

Provete 1 a 5
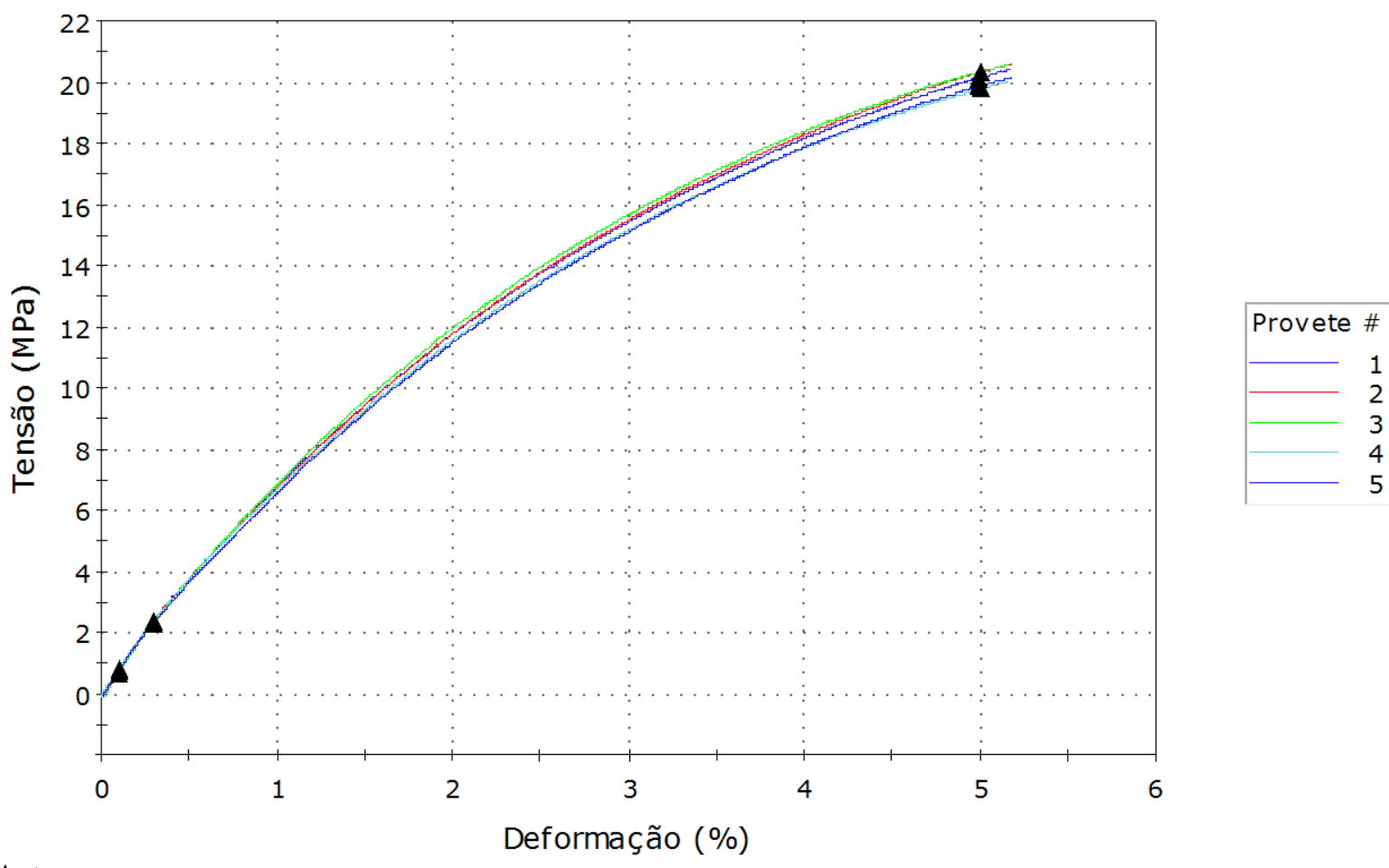

Fonte: Autor 
Figura 56 - Curva ensaio de flexão XLPE 1\%-900

Provete 1 a 5

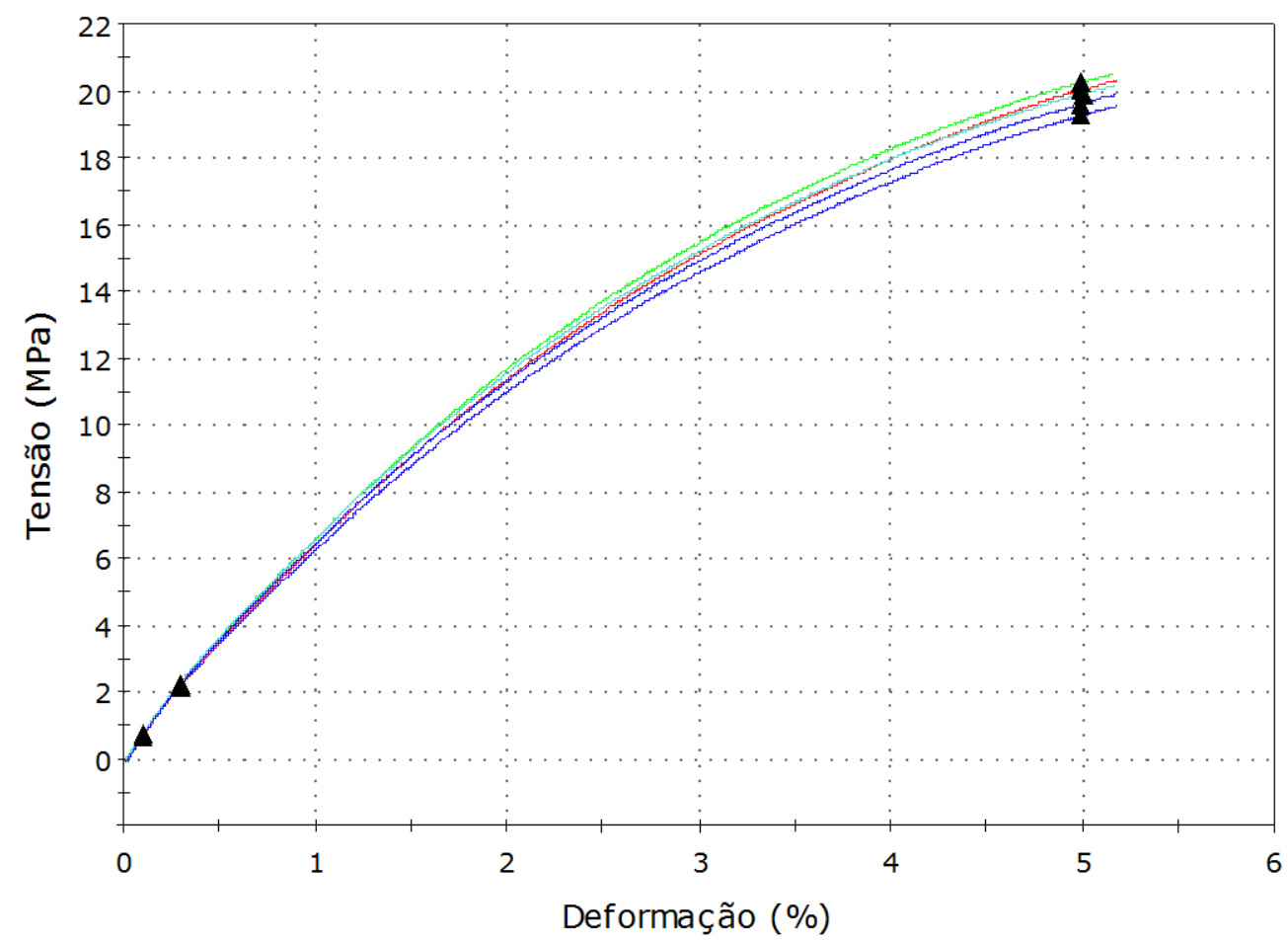

Fonte: Autor

Figura 57 - Curva ensaio de flexão XLPE 5\%-500

Provete 1 a 5

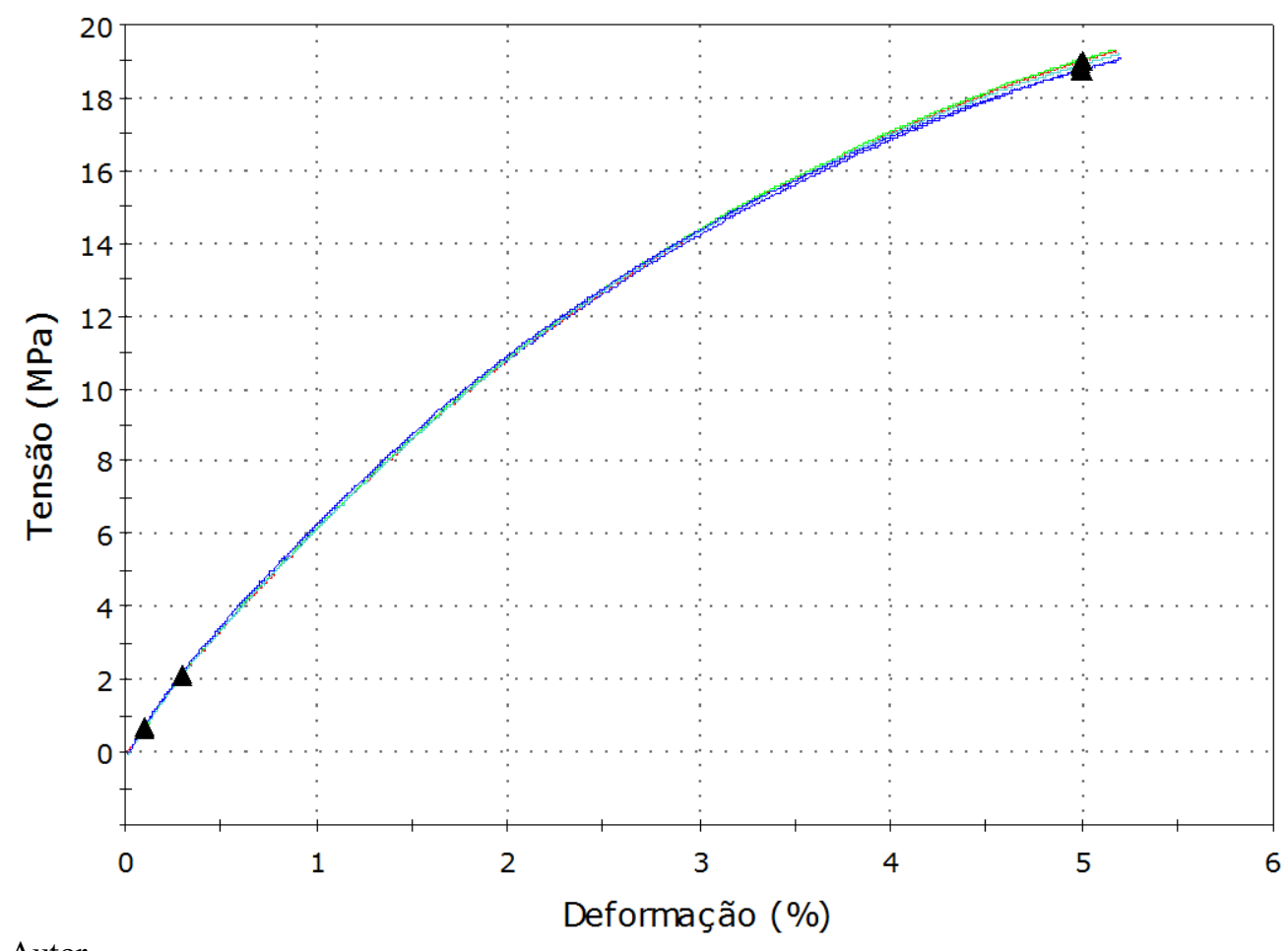


Figura 58 - Curva ensaio de flexão XLPE 9\%-100

Provete 1 a 5

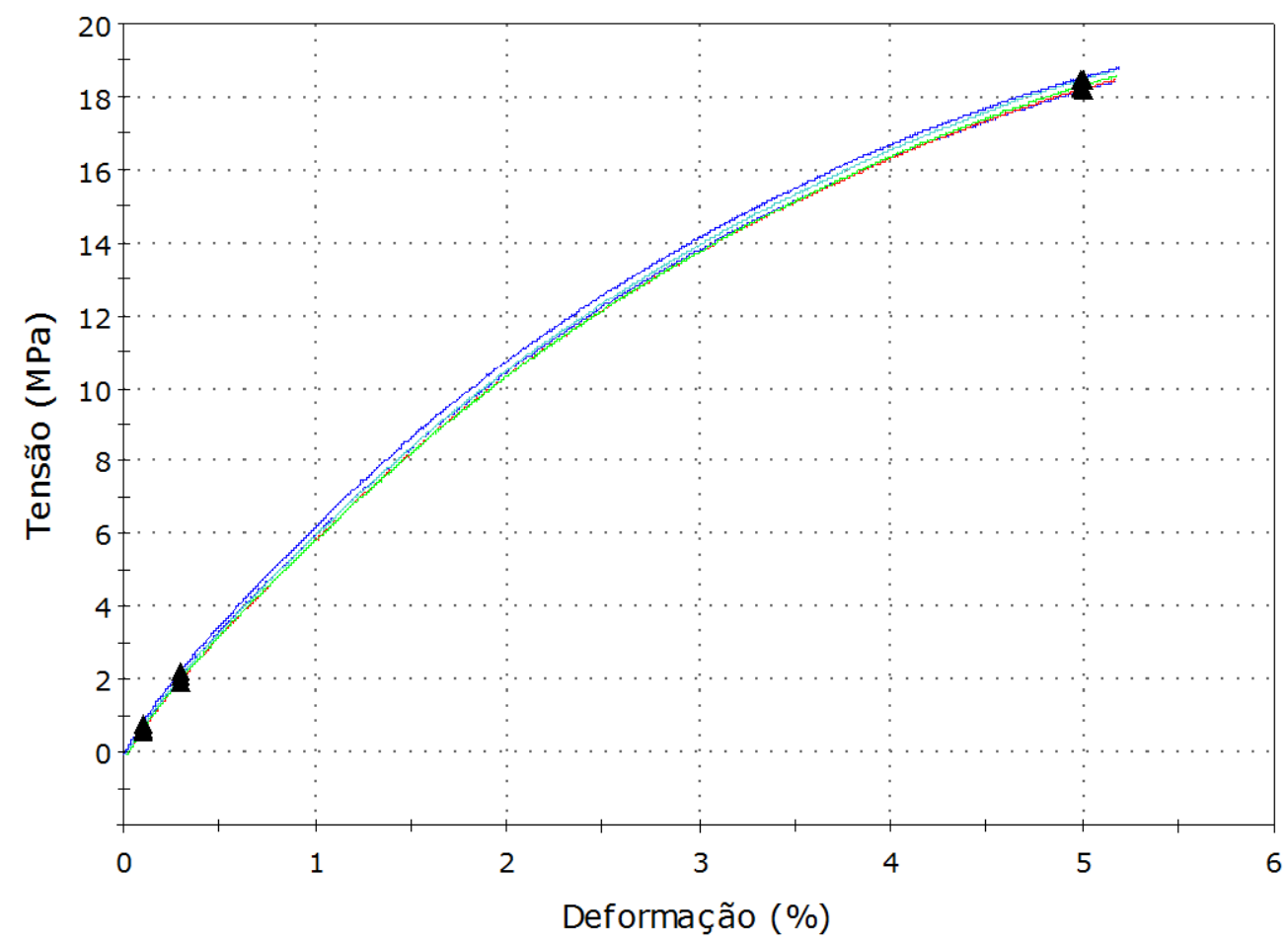

Fonte: Autor

Figura 59 - Curva ensaio de flexão XLPE 9\%-900

Provete 1 a 5

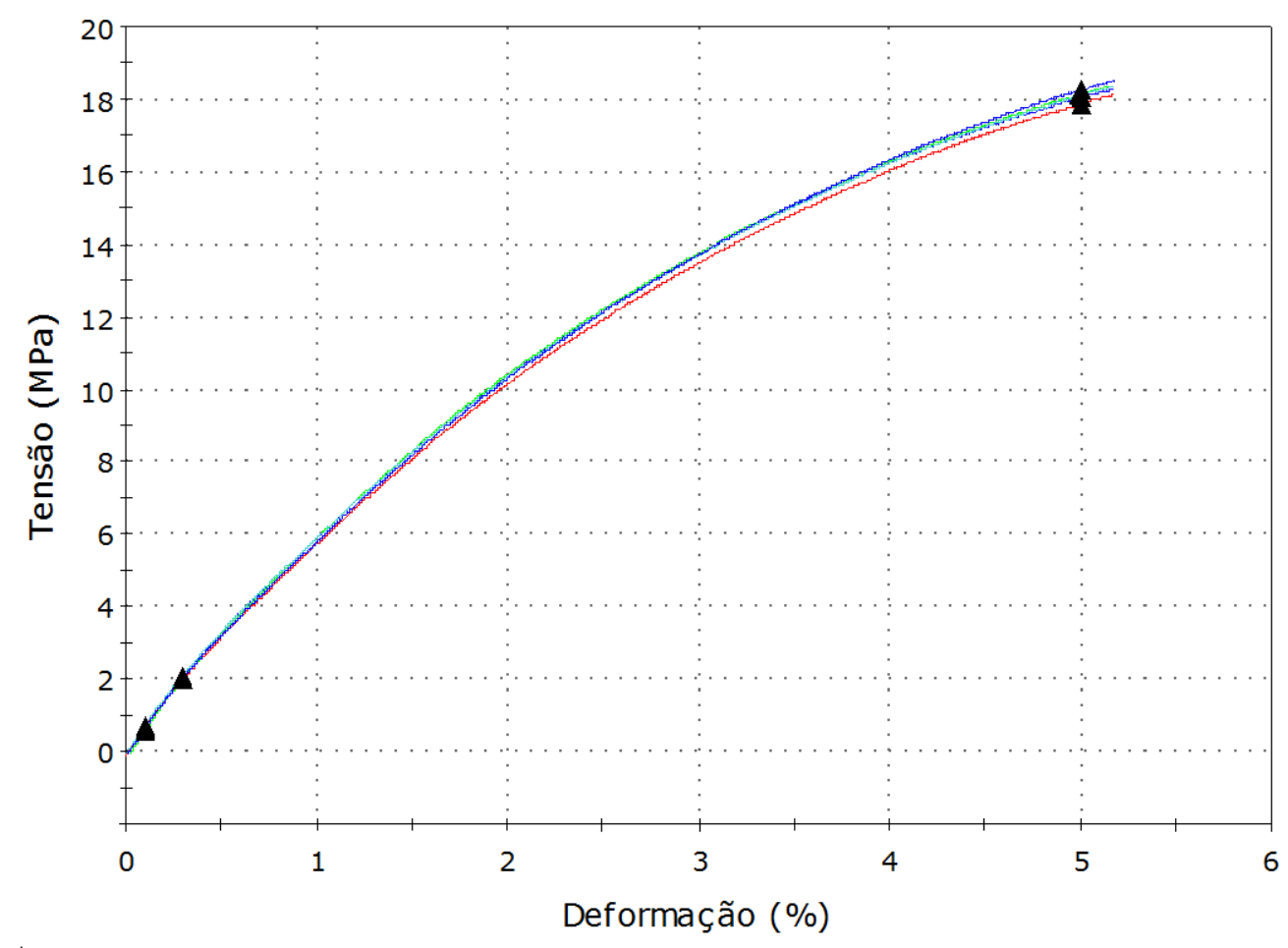


APÊNDICE C - PUBLICAÇÕES 


\section{PUBLICAÇÕES}

RODRIGO SOUSA FREITAS and BALTUS CORNELIUS BONSE - Cross-Linked Polyethylene (XLPE) as Filler in High-Density Polyethylene: Effect of Content and Particle Size. Proceedings of the PPS Europe Africa Conference -Dresden, Germany, 2017, June 26-29.

RODRIGO S. FREITAS, BALTUS C. BONSE - Resíduo de Polietileno Reticulado em Polietileno de Alta Densidade: Tamanho de Partícula a Baixos Teores. Anais do $14^{\circ}$ Congresso Brasileiro de Polímeros - Águas de Lindóia, SP - 22 a 26 de outubro de 2017. 